$1 \% / 899960$

SAND92-1767 - UC-706

Unlimited Release

Printed August 1992

\title{
Preliminary Lightning Tests: Optical Fiber Penetration of an Exclusion Region Barrier
}

Michael A. Dinallo, Richard J. Fisher

Prepared by

Sandia National Laboratories

Albuquerque, New Mexico 87185 and Livermore, California 94550

for the United States Department of Energy

under Contract DE-AC04-76DP00789 


\section{DISCLAIMER}

This report was prepared as an account of work sponsored by an agency of the United States Government. Neither the United States Government nor any agency Thereof, nor any of their employees, makes any warranty, express or implied, or assumes any legal liability or responsibility for the accuracy, completeness, or usefulness of any information, apparatus, product, or process disclosed, or represents that its use would not infringe privately owned rights. Reference herein to any specific commercial product, process, or service by trade name, trademark, manufacturer, or otherwise does not necessarily constitute or imply its endorsement, recommendation, or favoring by the United States Government or any agency thereof. The views and opinions of authors expressed herein do not necessarily state or reflect those of the United States Government or any agency thereof. 


\section{DISCLAIMER}

Portions of this document may be illegible in electronic image products. Images are produced from the best available original document. 


\title{
PRELIMINARY LIGHTNING TESTS: OPTICAL FIBER PENETRATION OF AN EXCLUSION REGION BARRIER
}

DE92 019804

\author{
Michael A. Dinallo \\ Quatro Corporation \\ Albuquerque, New Mexico 87110 \\ Richard J. Fisher \\ Division 2753 \\ Sandia National Laboratories \\ Albuquerque, New Mexico 87185
}

\begin{abstract}
As part of the Direct Optical Initiation (DOI) program, an assessment of the possibility of introducing lightning energy into an exclusion region via an Optical Barrier Feedthrough (OBF) is being carried out. One postulated penetration mechanism is the tracking of current past the OBF on the surface of the dielectric optical fiber itself. During September and October of 1991, a series of tests was conducted on a closed metallic cylindrical test object representing the electrical exclusion region of a weapon. Median-level (30-kA) and severe (200-kA) simulated lightning return strokes, singly, doubly, and in combination with a moderate continuing current, were attached directly to the exterior portion of a fiber optic cable, which penetrated through a hole of controlled size into the interior of the exclusion region. The thickness of the barrier surrounding the hole was $0.06 \mathrm{in}$. Attempts were made to measure any conducted current flowing on the fiber at distances of 1 and 4 inches from the interior surface of the stainless steel top of the cylinder. Test parameter variations included diameter of the penetration hole ( 475 and 500 microns), length of the exterior portion of the cable and whether or not its jacket was present, and the applied test currents.

It is concluded that no signal above measurement noise was recorded on any of the data shots that made up the test series. Measurement resolution was of the order of several amperes. Based on the highest recorded response of $8.5 \mathrm{~A}$, corresponding to a $200-\mathrm{kA}$ input, the OBF can be characterized by a direct-strike lightning attenuation factor of approximately $5 \times 10^{-5}$ or better. Based on the more typically observed noise level of a few amps, the attenuation is commensurately greater.
\end{abstract}


This page left intentionally blank 


\section{CONTENTS}

$\begin{array}{lll}\text { Section } & \text { Page }\end{array}$

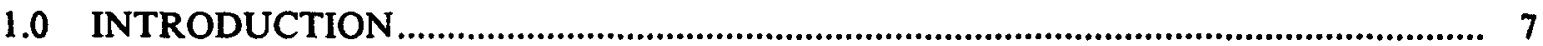

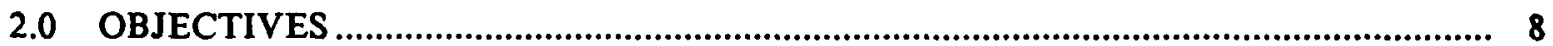

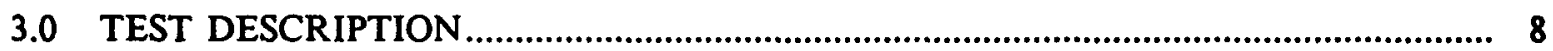

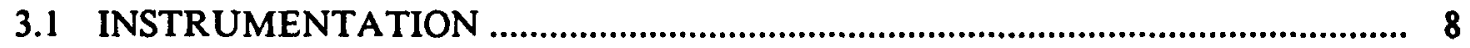

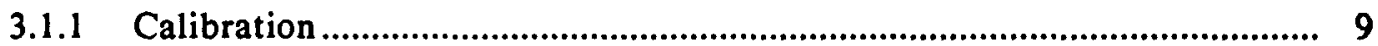

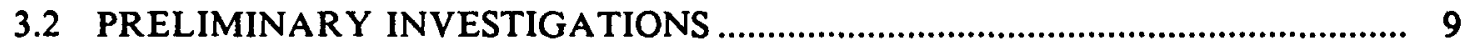

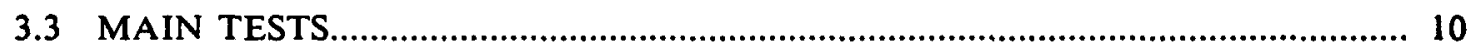

4.0 DATA SUMMARY AND DISCUSSION .................................................... 11

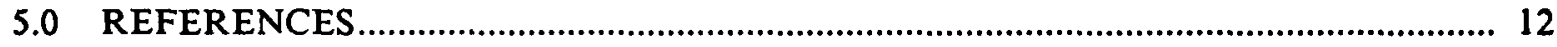

APPENDIX A - INSTRUMENTATION AND SENSOR CALIBRATION ........................... A-1

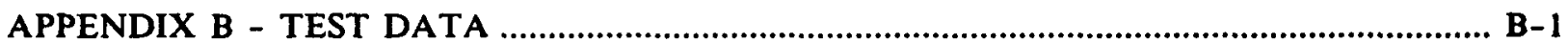




\section{ILLUSTRATIONS}

Figure

1 Basic Test Configuration for DOI Barrier Feedthrough Penetration

Lightning Tests. 16

2 Detailed Features of DOI Barrier Penetration Lightning Test Configuration.. 17

Cross-Section of DOI Fiber Optic Cable 18

Standard SLS Data Acquisition Instrumentation Channel.. 18

5 FM Fiber Optic Transmission Channel for Low Frequency Signals Associated with Continuing Currents................................................................... 19

6 End-to-End Instrumentation Calibration Arrangement ............................................. 19

7 Standard SLS Output Recording Instrumentation ................................................ 20

8 Preliminary Test Object Attached to SLS Electrode................................................. 20

9 a) Applied Simulated Return-Stroke, and b) Recorded Response on Sensor CVT TOP on Shot 1898

10 Noise Shot 1899 Response with CVTs Bypassed by the Fiber Optic,

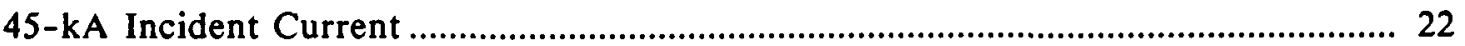

11 Mockup Cylindrical "Exclusion Region" Test Object ............................................ 22

12 Mockup Exclusion Region in Place and Ready for Testing...................................... 23

13 Noise Responses Recorded on Shot 2050 with Barrier Aperture Completely Plugged

14 Noise Response Recorded on Shot 1929 in Which the Barrier Aperture Was Sealed by Copper Tape Internal to the Test Cylinder

\section{TABLES}

Table

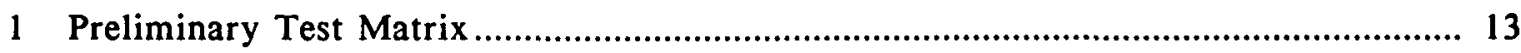

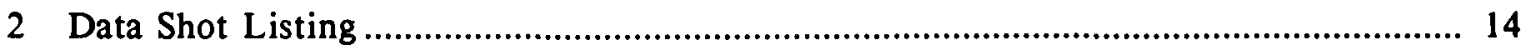

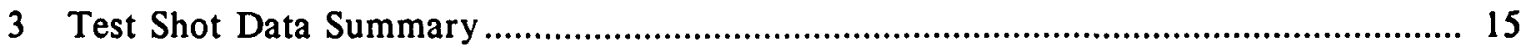




\section{PRELIMINARY LIGHTNING TESTS: \\ OPTICAL FIBER PENETRATION OF AN EXCLUSION REGION BARRIER}

\subsection{INTRODUCTION}

As one facet of the Direct Optical Initiation (DOI) development program, an assessment is being conducted to quantify the lightning energy that can penetrate a metallic exclusion region barrier via a fiber optic cable (FOC) and its optical barrier feedthrough (OBF).

An Optical Barrier Feedthrough Working Group (OBFWG) has attempted to systematically identify and evaluate all credible scenarios and mechanisms by which energy can be introduced into an exclusion region by the attachment of a direct-strike lightning current to the FOC or its feedthrough. As a result of these activities, three areas have been identified for testing. The first, addressed in this report, is the measurement of current flowing on the optical fiber inside the exclusion region due to the direct attachment of lightning to the portion of the FOC exterior to the barrier. Such measurements were carried out on facsimile hardware, designed to represent worst-case geometry and to bias all test conditions in favor of the introduction of lightning energy into the exclusion region. Later tests are planned on actual prototype feedthrough hardware. Finally, although the optical energy detected and transmitted to the initiator end of the cable due to a lightning strike near or directly onto the FOC can be readily shown analytically to be many orders of magnitude below what is necessary to launch a DOI flyer, a test to verify this directly is also being planned for the future.

This interim report documents the test hardware, procedures, and data acquired during the measurements of current flowing on the surface of the optical fiber interior to the barrier due to direct attachment of simulated flash currents to the exterior portion of the fiber. The applied currents included nominal 30 and 200-kA simulated return strokes, either singly, as a double-stroke flash, or in combination with a continuing current. The mechanism of interest during this investigation was current tracking along the surface of the dielectric fiber.

The tests were conducted by personnel of Division 2753-1 in the Sandia Lightning Simulator (SLS) Facility, located in Building 888, in accordance with the test plan of Reference 1. The test plan was developed by Division 2753-1 with input from the OBFWG (Section 10.0 of Ref. 1) and was approved by the chairmen of the working group, K.D. Meeks, 5166 and L.A. Andrews, 2551. The tests were conducted in several phases during September and October of 1991.

It is concluded that no detectable current above associated measurement noise was recorded on the interior portion of the optical fiber. 


\subsection{OBJECTIVES}

The specific objective of the present test was to determine experimentally the upper bound on possible current flow (if any) induced on the portion of an optical fiber interior to a mockup "exclusion region" due to dielectric surface tracking of simulated lightning currents attached directly to the exterior portion of the fiber.

\subsection{TEST DESCRIPTION}

Figure 1 shows the basic test configuration, and Figure 2 is an enlarged view showing the key test variables. Figure 3 shows a cross-sectional view of the construction of the FOC. The baseline FOC configuration used in these tests was one in which the portion of the cable exterior to the test cylinder consisted of the entire layup shown in Figure 3, and the portion internal to the barrier consisted of the fused silica core, the cladding, and adjacent polyimide buffer. This latter combination, of nominal $470-\mu$ diameter, will be referred to as the basic fiber. One of the variations tested was the effect of removing the kevlar strength member layer and polyurethane jacket from the exterior portion of the cable.

The original matrix of anticipated test variations is given in Table 1. This table was intended to reflect all significant combinations of variables that might result in measurable current on the interior portion of the fiber, and, if necessary, to provide a measure of its sensitivity to penetration design parameters. Since no detectable responses in excess of measurement noise were recorded, the actual set of variations covered was limited to a subset of Table 1 and is given in Section 4, wherein the data are summarized and discussed.

\subsection{INSTRUMENTATION}

Figure 2 indicates that the primary sensors consisted of the two current viewing transformers (CVTs) positioned around the optical fibers inside the test cylinder. These were chosen to be Pearson Model 2879s, selected on the basis of their sensitivity and appropriate specified current-time saturation product. Two sensors were installed at distances of 1 and 4 inches from the barrier to provide an indication of the distribution of current along the interior length of the fiber. In addition, in order to record long duration responses driven by the continuing current component of the applied test current, a $0.6-\Omega$ current viewing resistor (CVR) was added in series with the fiber during the tests in which continuing current was applied.

The standard facility instrumentation used in recording the responses is diagrammed in Figure 4. Since the operating bandwidth of the NanoFast fiber optic links is $200 \mathrm{MHz}$, the overall measurement bandwidth is effectively set by the choice of sampling interval on the Tektronix 7612D digitizers. For those records meant to resolve the rise times of test signals, a sampling interval of $100 \mathrm{~ns}$ or less was employed. Longer duration records were sampled at correspondingly slower rates. 
A variation of Figure 4 was implemented for the recording of the CVR response. Due to the long duration of the continuing current, a bandwidth extending to d.c. on the low end is required to accurately record any detected signal driven by continuing current. Since the nominal low frequency cutoff of the NanoFast fiber optic links is $160 \mathrm{~Hz}$, these units are not suitable for continuing current applications. For that reason, an auxiliary channel, as shown in Figure 5 was used. The key feature of this channel is the Dymec FOL, which operates in the FM mode. As employed in these tests, it had an effective 3-dB bandwidth of d.c. to just under $1 \mathrm{MHz}$, which is more than adequate for continuing current signals.

\subsubsection{Calibration}

All individual components of the instrumentation channels were either verified to have valid Sandia Calibration Laboratory (SCL) certification stickers or were calibrated at the SLS facility using signal sources with valid SCL status. Furthermore, each assembled recording channel was individually subjected to end-to-end calibration(s) by injecting known signals through the sensors and recording the results over the entire channel through to hard copy output. This procedure was employed several times throughout the testing period using either a calibrated Velonix Model 587 high current pulse generator (Figure 6) or, in the case of the Dymec FM channel, a $1-\mathrm{kHz}$ repetitive square wave from a calibrated Tektronix Model PG 506 Precision Calibration Generator. Calibration data are presented and discussed in Appendix A.

The applied currents from the SLS during these tests were recorded using the standard facility instrumentation shown in Figure 7. The coaxial CVRs used in these measurements are all under valid SCL certification, and the remainder of the instrumentation channels are periodically calibrated in situ by the SLS operations staff.

The calibration of all instrumentation channels employed during these tests was therefore verified to within $\pm 5 \%$.

\subsection{PRELIMINARY INVESTIGATIONS}

A number of preliminary test shots were conducted on previously available cylindrical hardware. The purposes of these tests were to evaluate methods for attaching the SLS output to the end of the optical fiber, to get a quick indication of the magnitude of current that might be injected onto a fiber penetrating a relatively large $635-\mu$ diameter hole (needed for the final selection of the CVTs), and to work out the practical details of installing and operating the sensing instrumentation inside the cylindrical test object. Also, the particular cylinder employed contained a longitudinal slot along one side that would allow photography of the internal fiber during testing in the event that significant currents could be detected. Figure 8 is a photograph of this preliminary test configuration.

After an initial set of shots it was evident, by visual inspection, that arcing was occurring from the SLS output electrode to the barrier, independently of the presence of the FOC. In an attempt to determine the length of cable most conducive to the channeling of the applied current onto the FOC, a sequence of shots using various lengths of cable was performed. At 
16 inches, internal breakdown occurred within the SLS. The most consistent evidence of arc termination at the aperture was observed at a FOC length of 4 inches. During subsequent shots taken under these conditions with simulated nominal 30-kA peak return-stroke currents, typical response amplitudes of a few amperes were recorded on the interior portion of the cable. An example is shown in Figure 9, along with the associated applied test current. A noise shot, shown in Figure 10, was then performed, during which the FOC inside the cylinder was routed to bypass all of the sensors. A comparison of the noise with the data shots suggested that nothing but measurement noise had been detected in any of the shots to that point, possibly due to the presence of the large photography slot in the cylinder that was being used. At that point, it was decided to proceed to the testing of the cylinder and barrier that had been fabricated specifically for these tests, and which did not include a photography slot.

\subsection{MAIN TESTS}

The mockup exclusion region and barrier used for the remainder of the tests were provided by Division 2551 and are shown in Figure 11. The cylinder body was made of aluminum, but, in order to minimize erosion during multiple test shots, the top of the cylinder, representing an exclusion region barrier surface, was made of stainless steel. Two separate barrier pieces were provided with hole sizes of 475 and $500-\mu$ diameters, respectively, locally surrounded by a barrier thickness of 0.06 inches. A third barrier piece with no hole in it (i.e., the existing hole was completely plugged by solder) was used to characterize measurement noise. Figure 12 shows this hardware mounted on the instrumentation cylinder with a length of FOC attached and ready for a test shot from the SLS.

Following end-to-end instrumentation calibration checks, carried out as described in Section 3.1.1, a series of seven shots was conducted with the $475-\mu$ diameter penetration, an external FOC length of 4 in, and 30-kA peak test currents. On occasion, the external portion of the FOC withstood two or more shots, but it generally broke during the first exposure. In some cases, the jacket of the fiber was frayed, split, or completely blown off. In other instances it remained intact. In those cases when the jacket was blown off, the remaining basic fiber was reconnected to the SLS, and a second shot was performed on the same fiber. No change in the measured response was ever noted that could be attributed to the presence or absence of the jacket on the exterior portion or to the multiple exposure of the same optical fiber. The measured data, including the results of noise shots, and associated physical observations are summarized in Section 4.

The next series of shots was intended to combine conditions that should bound the observed response. These included use of the 500- $\mu$ diameter penetration, 4 -in exterior cable length, and 200-kA peak test current. Four test shots, plus two noise shots, were conducted. The results are summarized in Section 4. In all cases, the exterior portion of the FOC was destroyed by the 200-kA current.

The data acquired up to this point had all been taken with single simulated return strokes. Additional shots were then performed, during which the applied test currents consisted of either two return strokes, of 40 and $200-\mathrm{kA}$ peak amplitudes, in that order and with a $60-\mathrm{ms}$ 
interstroke interval, or the same sequence with the addition of continuing current during the interstroke interval. These results are also summarized in Section 4.

The recorded data traces from all of the test shots summarized and discussed in Section 4 are presented in Appendix B.

\subsection{DATA SUMMARY AND DISCUSSION}

Table 2 lists all relevant data shots made during the present tests. Table 3 summarizes the results on a stroke-by-stroke basis. The associated recorded data traces of the shots listed in Table 3 are all to be found in Appendix B.

The range of applied return-stroke current peak amplitudes employed in this series includes the mean, or typical, return-stroke value of $30 \mathrm{kA}$ and the approximate one-percentile value of $200 \mathrm{kA} \mathrm{[2].} \mathrm{That} \mathrm{is,} \mathrm{only} \mathrm{one} \mathrm{percent} \mathrm{of} \mathrm{all} \mathrm{observed} \mathrm{lightning} \mathrm{return} \mathrm{strokes} \mathrm{exceed} \mathrm{a} \mathrm{peak}$ current amplitude of $200 \mathrm{kA}$. The applied continuing current amplitude of $\sim 350 \mathrm{~A}$, falls at approximately the ten-percentile level of its distribution [3]. These tests are, therefore, quite severe in nature.

Critical to the interpretation of the test results is the nature of the noise data that were acquired. There are two types of noise evident, for example, in Figure 13. The first is the high frequency random "hash," due primarily to the fiber optic transmission link, that rides on the overall response waveform. The second component, termed "event noise," is due to the high transient electromagnetic environment in the vicinity of the test object and instrumentation chamber. These fields are related to the very large currents (as high as $200 \mathrm{kA}$ ) and voltages (up to $\sim 1 \mathrm{MV}$ ) associated with the firing of the SLS. With the instrumentation sensitivities set as high as were required for these tests, coupling of a mere fraction of these large fields into the various components of the system results in noise magnitudes and waveforms similar to those displayed in Figure 13.

Noise shots were conducted in various configurations. In each case, the sensors were left installed inside the test cylinder, but other factors were varied. For example, the data of Figure 10 was acquired with a fiber installed in the cylinder but not inserted through the CVTs. Figure 13 corresponds to a shot in which the hole was completely plugged with solder, while Figure 14 resulted from a shot with the $500-\mu$ penetration sealed by copper tape on the inside of the top plate.

Careful examination of all the noise data led to the conclusion that the event noise structure and amplitude varied from shot to shot following the disassembly and reassembly of the test object but was essentially repeatable during sequential shots performed without disturbing the cylinder, such as during shots 2050 through 2052 (Appendix B). It was further concluded that, in general, the measurement floor set by the envelope of observed event noise signals is of the order of a few amps, regardless of attempts to seal up the test structure, and any signals recorded at that level or below during any of the testing should be attributed to noise. 
The results of Table 3 define an absolute upper bound on the current injected past the barrier penetration due to surface tracking on the fiber in the absence of burnthrough of the barrier. (The injection of energy into the exclusion region under conditions in which the barrier is penetrated by burnthrough is not an issue peculiar to the fiber optic feedthrough, and it was not intended to be addressed during these tests.) From Table 3, the worst-case upper bound can be considered to be approximately 8.5 amperes (whether real or noise), as observed during the 200-kA second stroke of Shot 2049, a double-stroke simulation that included continuing current. However, since the noise response for the same applied environment and instrumentation sensitivities (Shots 2050 through 2052 of Appendix B) exhibits virtually the same magnitude, the response bound is, realistically, probably well lower than that. Nevertheless, assuming, for the sake of argument, that the 8.5-A response is real, the upperbound on the attenuation factor of the OBF is $8.5 / 2 \times 10^{5}$, or $\sim 4 \times 10^{-5}$. Based on the more typically observed noise level of less than $5 \mathrm{~A}$, the attenuation factor improves accordingly.

The action integral of a current waveform (sometimes known as its specific energy) is defined as $\int \mathrm{i}^{2} \mathrm{dt}(\mathrm{J} / \Omega)$ and provides a quantitative measure of the energy potentially available from a given current waveform to a resistive load. The approximate action integral of the 8.5-A response is $8 \times 10^{-4} \mathrm{~J} / \Omega$, which, when associated with an assumed $1-\mathrm{m} \Omega$ load, results in a deposited energy of only $8 \times 10^{-7} \mathrm{~J}$. If the assumption is made that this entire energy is somehow delivered to a DOI flyer, its comparison with the launching energy threshold of the flyer provides an ultra-conservative basis for establishing a safety margin of many orders of magnitude for the lightning interaction scenario addressed by the present investigation.

\subsection{REFERENCES}

1. "Lightning Test Plan: Optical Fiber Penetrations of Exclusion Region Barriers, ISSUE A," R.J. Fisher, June 5, 1991.

2. "Recommended Baseline Direct-Strike Lightning Environment for Stockpile-to-Target Sequences," R.J. Fisher and M.A. Uman, SAND89-0192, May 1989.

3. The Lightning Discharge, M.A. Uman, Academic Press, Orlando, FL (1987), p.341. 
TABLE 1

PRELIMINARY TEST MATRIX

\begin{tabular}{|c|c|c|c|c|c|c|c|c|}
\hline $\begin{array}{l}\text { TEST } \\
\text { SHOT }\end{array}$ & $\underset{(k A)}{I_{p}}$ & $\mathrm{CC}$ & $\begin{array}{c}\text { FOC } \\
\text { JACKET }\end{array}$ & $\begin{array}{l}\text { h } \\
\text { (in) }\end{array}$ & $\begin{array}{l}x^{2} \\
\text { (in) }\end{array}$ & $\underset{(\mu)}{d}$ & GROUNDED $^{3}$ & COMMENT \\
\hline $\begin{array}{l}1 \\
2 \\
3 \\
4 \\
5 \\
6 \\
7 \\
\end{array}$ & $\begin{array}{l}30 \\
30 \\
30 \\
30 \\
30 \\
30 \\
30\end{array}$ & $\begin{array}{l}\mathbf{N} \\
\mathbf{N} \\
\mathbf{N} \\
\mathbf{N} \\
\mathbf{N} \\
\mathbf{N} \\
\mathbf{Y}\end{array}$ & $\begin{array}{c}\mathbf{Y} \\
\mathbf{Y} \\
\mathbf{Y} \\
\mathbf{Y} \\
\mathbf{N} \\
\text { W.C. } \\
\text { W.C. }\end{array}$ & $\begin{array}{l}2 \\
4 \\
\text { W.C. } \\
\text { W.C. } \\
\text { W.C. } \\
\text { W.C. } \\
\text { W.C. }\end{array}$ & $\begin{array}{l}0.8,4 \\
0.8,4 \\
0.8,4 \\
0.8,4 \\
0.8,4 \\
0.8,4 \\
0.8,4\end{array}$ & $\begin{array}{l}475 \\
475 \\
475 \\
500 \\
500 \\
500 \\
500\end{array}$ & $\begin{array}{c}\mathbf{Y} \\
\mathbf{Y} \\
\mathbf{N} \\
\text { W.C. } \\
\text { W.C. } \\
\text { W.C. } \\
\text { Y }\end{array}$ & $\begin{array}{l}\text { Effect of } h \\
\text { Effect of termination } \\
\text { Effect of } d \\
\text { Effect of Jacket } \\
\text { Repeat of worst case } \\
\text { Continuing Current }\end{array}$ \\
\hline $\begin{array}{l}8 \\
9\end{array}$ & $\begin{array}{l}200 \\
200\end{array}$ & $\begin{array}{l}\mathbf{N} \\
\mathbf{Y}\end{array}$ & $\begin{array}{l}\text { W.C. } \\
\text { W.C. }\end{array}$ & $\begin{array}{l}\text { W.C. } \\
\text { W.C. }\end{array}$ & $\begin{array}{l}0.8,4 \\
0.8,4\end{array}$ & $\begin{array}{l}\text { W.C. } \\
\text { W.C. }\end{array}$ & $\begin{array}{l}\mathbf{Y} \\
\mathbf{Y}\end{array}$ & $\begin{array}{l}\text { Effect of } I_{p} \\
\text { Continuing Current }\end{array}$ \\
\hline 10 & 200 & $\mathbf{N}$ & W.C. & W.C. & $0.8,4$ & W.C. & $\mathbf{Y}$ & $\begin{array}{l}\text { Non-conductive epoxy } \\
\text { seal }^{5}\end{array}$ \\
\hline 11 & 200 & $\mathbf{N}$ & W.C. & W.C. & $0.8,4$ & W.C. & $\mathbf{Y}$ & Silver epoxy seal \\
\hline
\end{tabular}

NOTES:

1 Refers to FOC jacket and strength material external to the barrier.

2 Unless data suggest a reason to modify, the CVTs will be located at 0.8 and 4 in from top barrier.

3 For all shots in which the FOC is grounded, a CVR will be monitored.

4 W.C. stands for "worst-case."

5 Epoxy seal at the fiber exit from the barrier. 
TABLE 2

DATA SHOT LISTING

\begin{tabular}{|c|c|c|c|c|c|c|c|}
\hline \multirow[b]{2}{*}{$\begin{array}{c}\text { SHOT } \\
\text { ID }\end{array}$} & \multirow{2}{*}{$\begin{array}{l}\text { EXTERN. } \\
\text { LENGTH } \\
\text { (in) }\end{array}$} & \multirow[b]{2}{*}{$\begin{array}{l}\text { DATA } \\
\text { TYPE }\end{array}$} & \multicolumn{2}{|c|}{ HARDWARE } & \multirow[b]{2}{*}{$\begin{array}{l}\text { STROKE } \\
\text { SEQUENCE }\end{array}$} & \multicolumn{2}{|c|}{ FEEDTHROUGH } \\
\hline & & & PRELIM. & MOCKUP & & $E\left(\mathrm{kA}_{\mathrm{A}}{ }^{I_{1}}\right.$ & $\begin{array}{l}\text { DIAMETER } \\
\qquad(\mu)\end{array}$ \\
\hline $\begin{array}{l}1898 \\
1899 \\
1914 \\
1920 \\
1926 \\
\end{array}$ & $\begin{array}{l}4 \\
4 \\
4 \\
4 \\
4\end{array}$ & $\begin{array}{l}\text { Fiber } \\
\text { Noise } \\
\text { Fiber } \\
\text { Fiber } \\
\text { Fiber } \\
\end{array}$ & $\begin{array}{l}\mathrm{X} \\
\mathrm{X}\end{array}$ & $\begin{array}{l}\mathbf{X} \\
\mathbf{X} \\
\mathbf{X} \\
\end{array}$ & $\begin{array}{l}\text { Single } \\
\text { Single } \\
\text { Single } \\
\text { Single } \\
\text { Single }\end{array}$ & $\begin{array}{r}25 \\
45 \\
30 \\
30 \\
200\end{array}$ & $\begin{array}{c}635 \\
635^{1} \\
475 \\
475 \\
500\end{array}$ \\
\hline $\begin{array}{l}1927 \\
1929 \\
1930 \\
2027 \\
2033\end{array}$ & $\begin{array}{c}4 \\
-- \\
-- \\
4 \\
4\end{array}$ & $\begin{array}{l}\text { Fiber } \\
\text { Noise } \\
\text { Noise } \\
\text { Fiber } \\
\text { Fiber }\end{array}$ & & $\begin{array}{l}\mathbf{X} \\
\mathbf{X} \\
\mathbf{X} \\
\mathbf{X} \\
\mathbf{X}\end{array}$ & $\begin{array}{l}\text { Single } \\
\text { Single } \\
\text { Single } \\
\text { Single } \\
\text { Double }\end{array}$ & $\begin{array}{c}200 \\
200 \\
200 \\
200 \\
40 / 200^{2}\end{array}$ & $\begin{array}{c}500 \\
\text { Taped } \\
\text { Taped } \\
500 \\
500\end{array}$ \\
\hline $\begin{array}{l}2049 \\
2050 \\
2051 \\
2052\end{array}$ & $\begin{array}{l}4 \\
-- \\
-- \\
--\end{array}$ & $\begin{array}{l}\text { Fiber } \\
\text { Noise } \\
\text { Noise } \\
\text { Noise }\end{array}$ & & $\begin{array}{l}X \\
X \\
X \\
X\end{array}$ & $\begin{array}{l}\mathrm{Dbl} / \mathrm{CC}^{3} \\
\mathrm{Dbl} / \mathrm{CC} \\
\mathrm{Dbl} / \mathrm{CC} \\
\mathrm{Dbl} / \mathrm{CC}\end{array}$ & $\begin{array}{l}\text { 40/.3/200 } \\
\text { Same } \\
\text { Same } \\
\text { Same }\end{array}$ & $\begin{array}{c}500 \\
\text { Plugged } \\
\text { Plugged } \\
\text { Plugged }\end{array}$ \\
\hline
\end{tabular}

1 Fiber bypassed the CVTs

2 Interstroke interval $=60 \mathrm{~ms}$

3 Continuing current 
TABLE 3

TEST SHOT DATA SUMMARY

$\begin{array}{cccc}\begin{array}{c}\text { SHOT } \\ \text { ID }\end{array} & \begin{array}{c}\mathbf{I}_{p} \\ (\mathbf{k A})\end{array} & \begin{array}{c}\text { SENSOR } \\ \text { TYPE }\end{array} & \begin{array}{c}\text { PEAK } \\ \text { RESPONSE }\end{array} \\ & \text { (A) }\end{array}$

COMMENTS

\begin{tabular}{|c|c|c|c|c|}
\hline $\begin{array}{l}1898 \\
1899 \\
1914 \\
1920 \\
1926\end{array}$ & $\begin{array}{c}25 \\
45 \\
30 \\
30 \\
200\end{array}$ & $\begin{array}{l}\text { CVT } \\
\text { CVT } \\
\text { CVT } \\
\text { CVT } \\
\text { CVT }\end{array}$ & $\begin{array}{l}-5 \\
-5 \\
\pm 1 \\
0.16 \\
-0.3\end{array}$ & $\begin{array}{l}\text { Preliminary hardware } \\
\text { Noise shot with fiber bypassing sensors } \\
\text { Mockup hardware with } \text { BPA }^{1} \text { of } 475 \mu \\
\text { Gain increased by x100 from } 1914 \\
\text { BPA of } 500 \mu\end{array}$ \\
\hline $\begin{array}{l}1927 \\
1929 \\
1930 \\
2027\end{array}$ & $\begin{array}{l}200 \\
200 \\
200 \\
200\end{array}$ & $\begin{array}{l}\text { CVT } \\
\text { CVT } \\
\text { CVT } \\
\text { CVT }\end{array}$ & $\begin{array}{l}-1.0 \\
-1.5 \\
+0.45 \\
-0.55\end{array}$ & $\begin{array}{l}\text { Repeat of } 1926 \\
\text { No fiber, BPA copper-taped } \\
\text { Noise, repeat of } 1929 \\
\text { Repeat of } 1926,27 \text {. BPA of } 500 \mu\end{array}$ \\
\hline 2033 & 40,200 & CVT & $+0.2 /-0.2$ & Within noise amplitudes of noise shots \\
\hline 2049 & $40,200^{2}$ & CVT/CVR & $\begin{array}{l}+0.9 /-0.7 \\
-8.5 /-2.7\end{array}$ & $\begin{array}{l}\text { Note polarity change on CVT from 1st to } \\
\text { 2nd stroke, implying measurement is not } \\
\text { real current. }\end{array}$ \\
\hline 2050 & Same & CVT/CVR & $\begin{array}{c}+1.3 /-0.7 \\
+4 /-1.7\end{array}$ & Noise, aperture plugged \\
\hline 2051 & Same & CVT/CVR & $+6 /-1.7$ & Test object undisturbed, no lst stroke data \\
\hline 2052 & Same & CVT/CVR & $\begin{array}{l}-1.4 /-.5 \\
+4.5 /-1.7\end{array}$ & Test object undisturbed \\
\hline
\end{tabular}

1 Barrier Plate Aperture

2 Plus continuing current of $\sim 350 \mathrm{~A}$ amplitude 


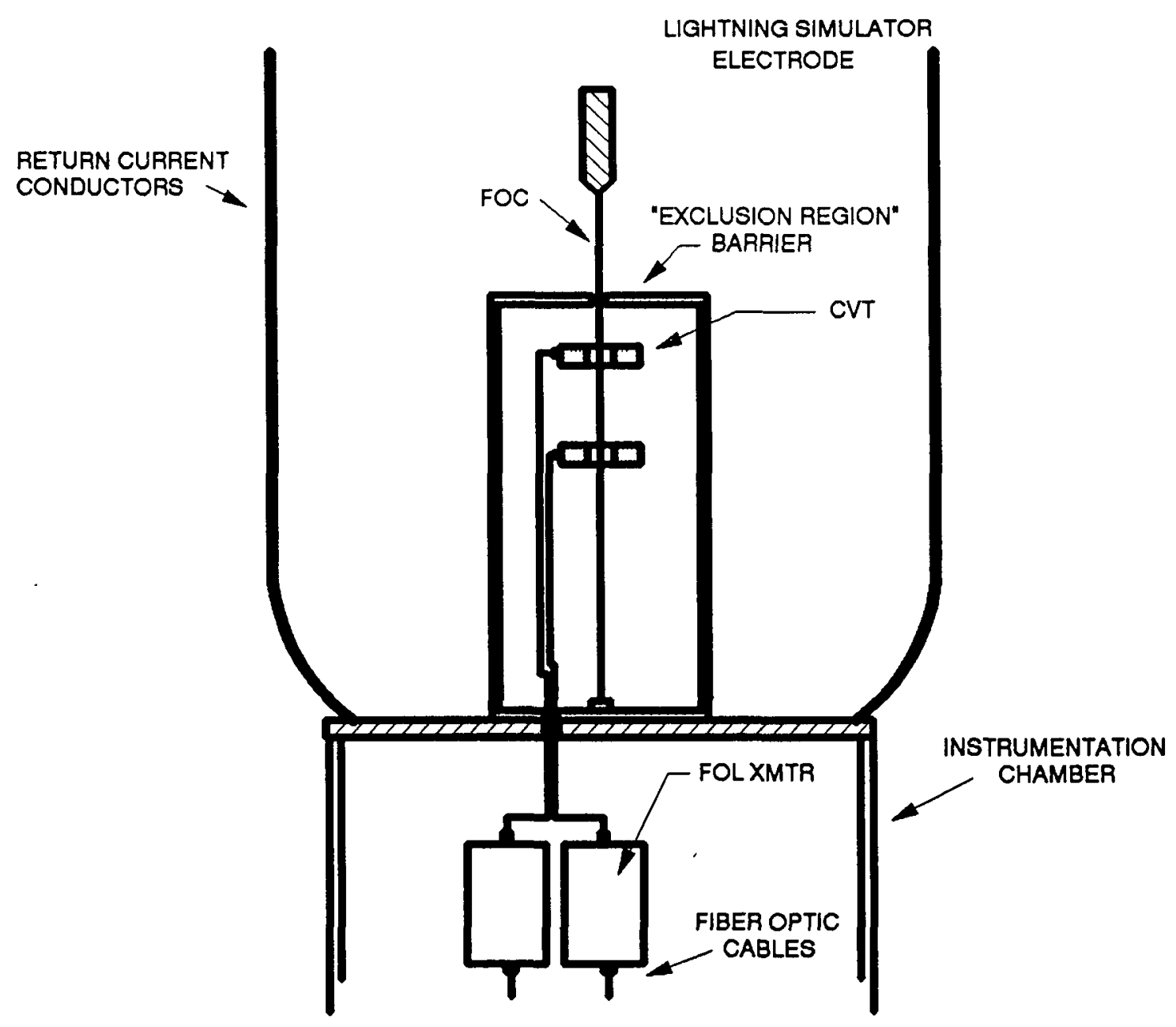

Figure 1. Basic Test Configuration for DOI Barrier Feedthrough Penetration Lightning Tests 


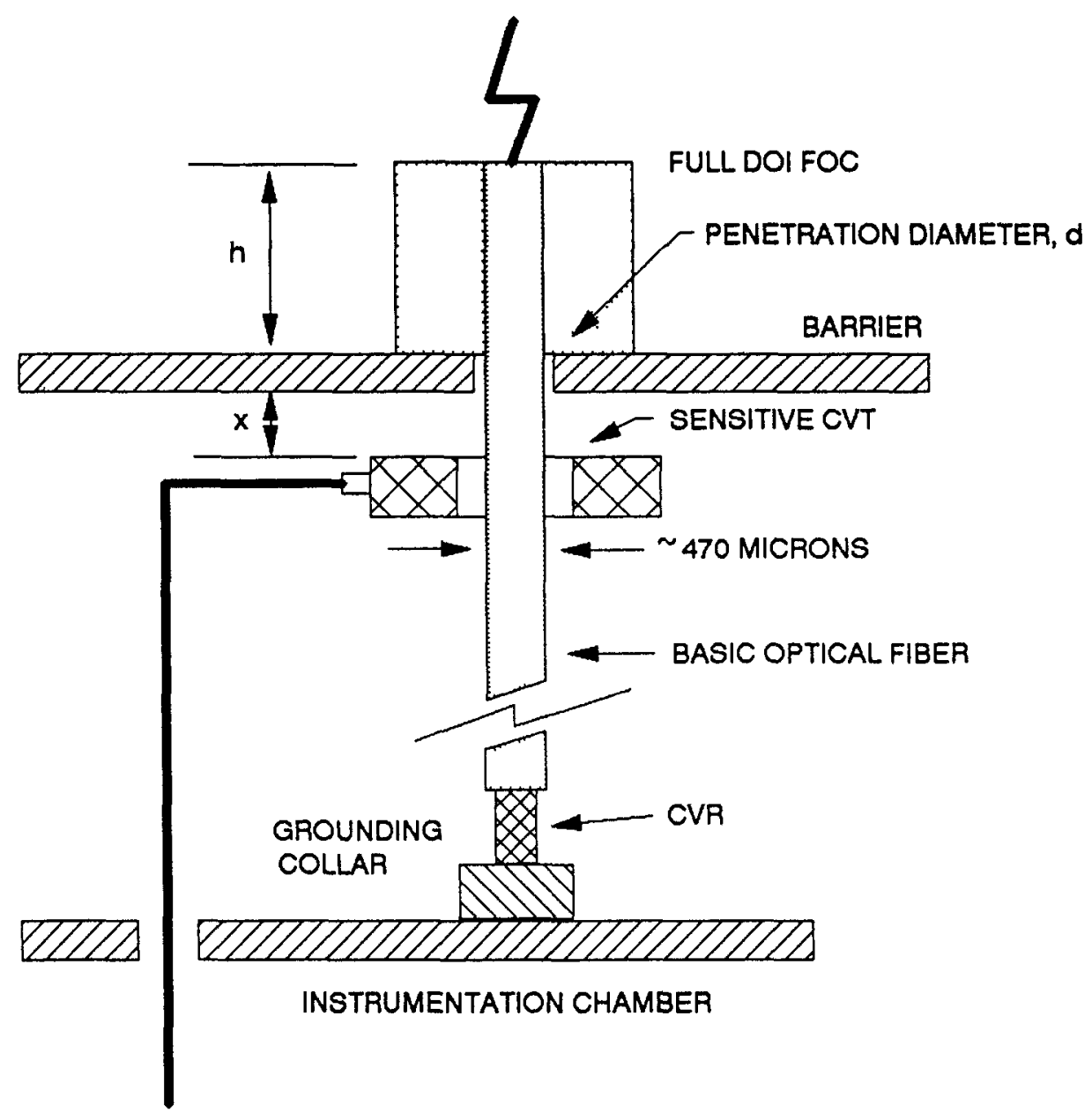

POSSIBLE VARIABLES

1. FOC WITH AND WITHOUT JACKET (EXTERNAL TO BARRIER)

2. LENGTH OF EXTERNAL FIBER, $h$

3. DISTANCE OF PROBE FROM BARRIER, $x$

4. ADDITION OF SILVER EPOXY SEAL AT BARRIER EXIT

5. DIAMETER OF PENETRATION HOLE, $d$

6. FOC GROUNDED OR FLOATED AT BOTTOM

7. TEST CURRENT PEAK AMPLITUDE

$$
\mathrm{l} p=30,200 \mathrm{kA}
$$

8. WITH AND WITHOUT CONTINUING CURRENT

Figure 2. Detailed Features of DOI Barrier Penetration Lightning Test Configuration 


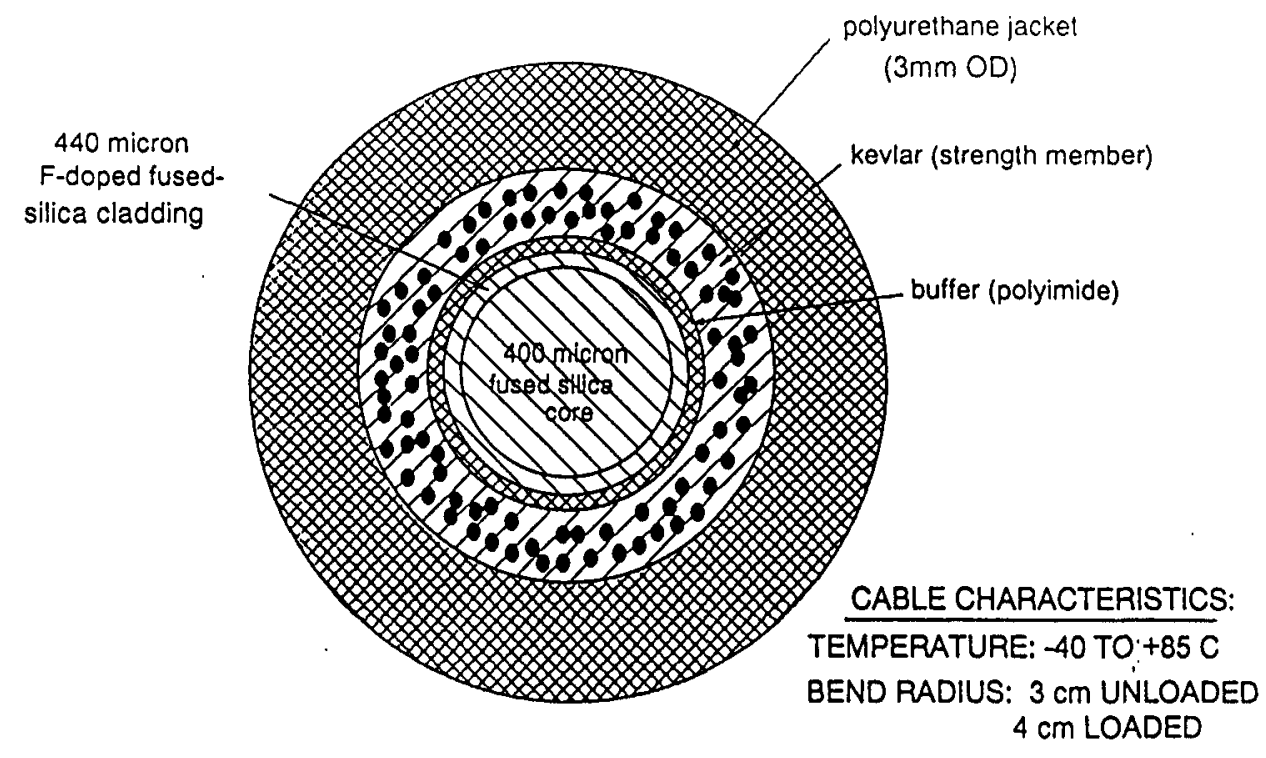

Figure 3. Cross-Section of DOI Fiber Optic Cable

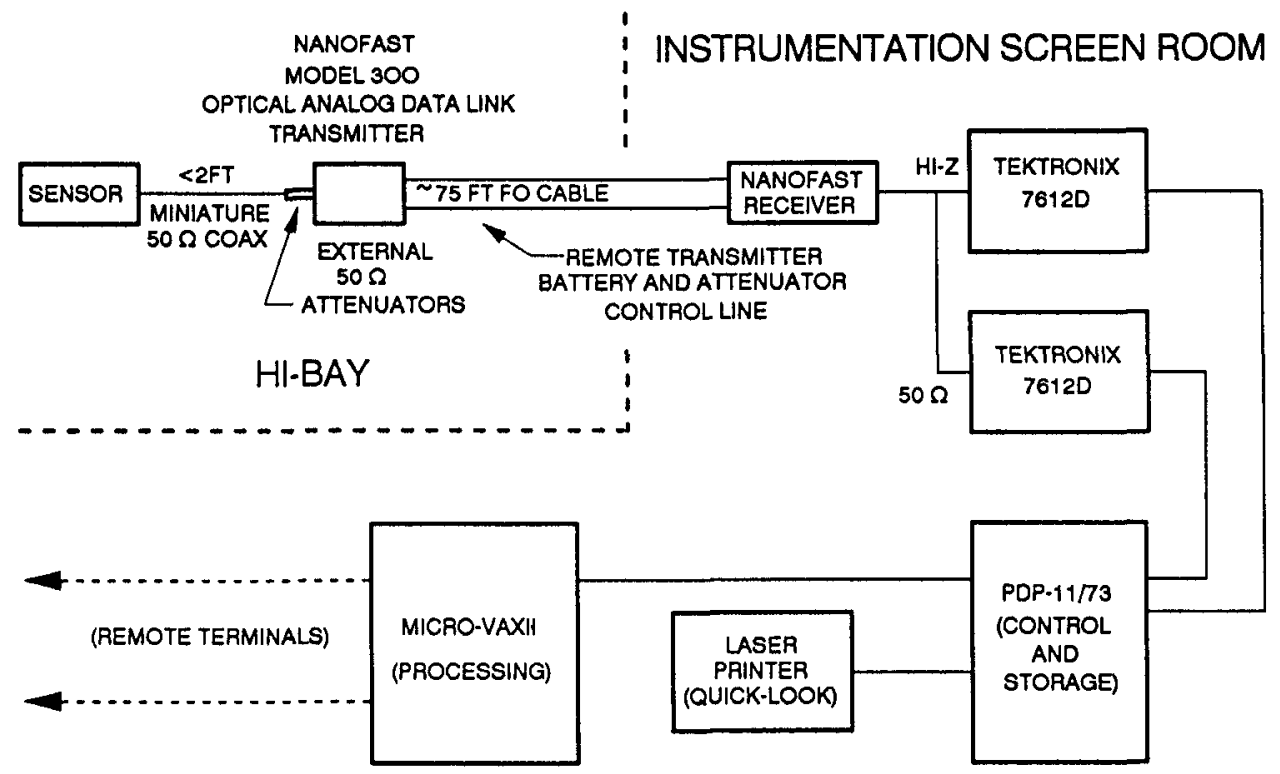

Figure 4. Standard SLS Data Acquisition Instrumentation Channel 


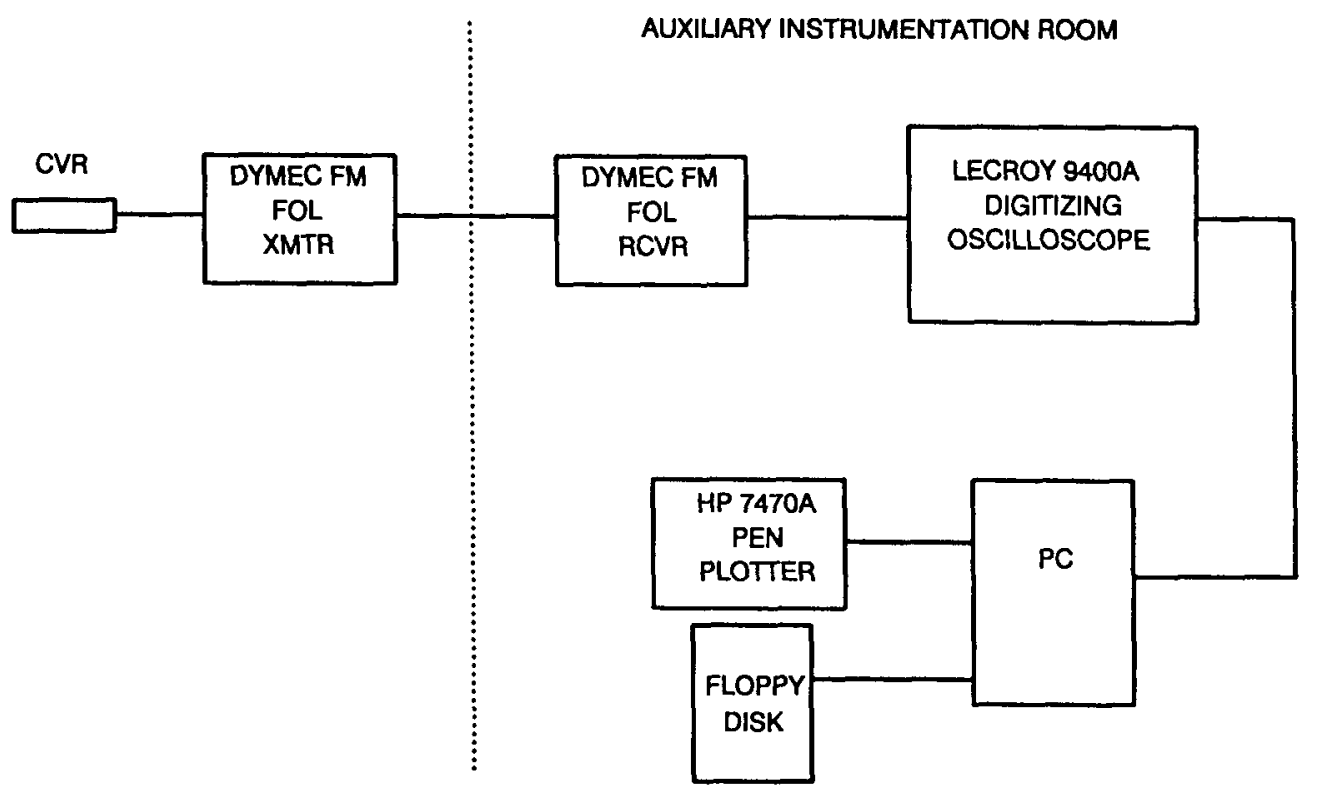

Figure 5. FM Fiber Optic Transmission Channel for Low Frequency Signals Associated with Continuing Currents

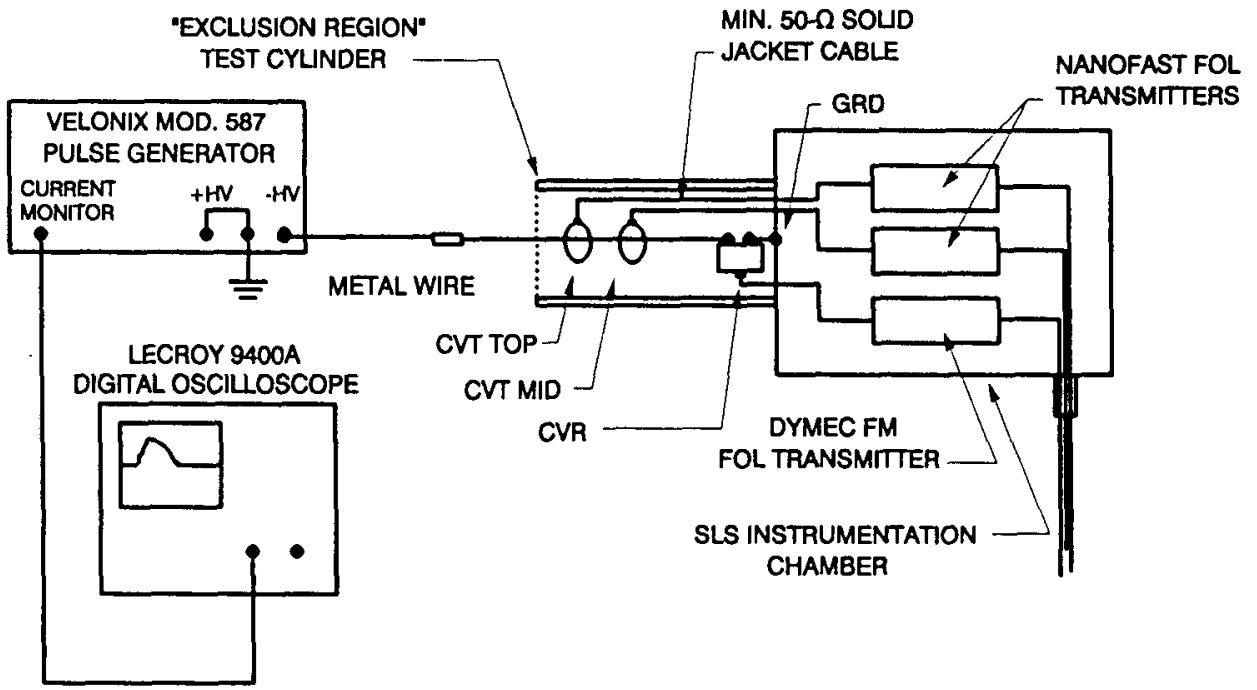

Figure 6. End-to-End Instrumentation Calibration Arrangement 


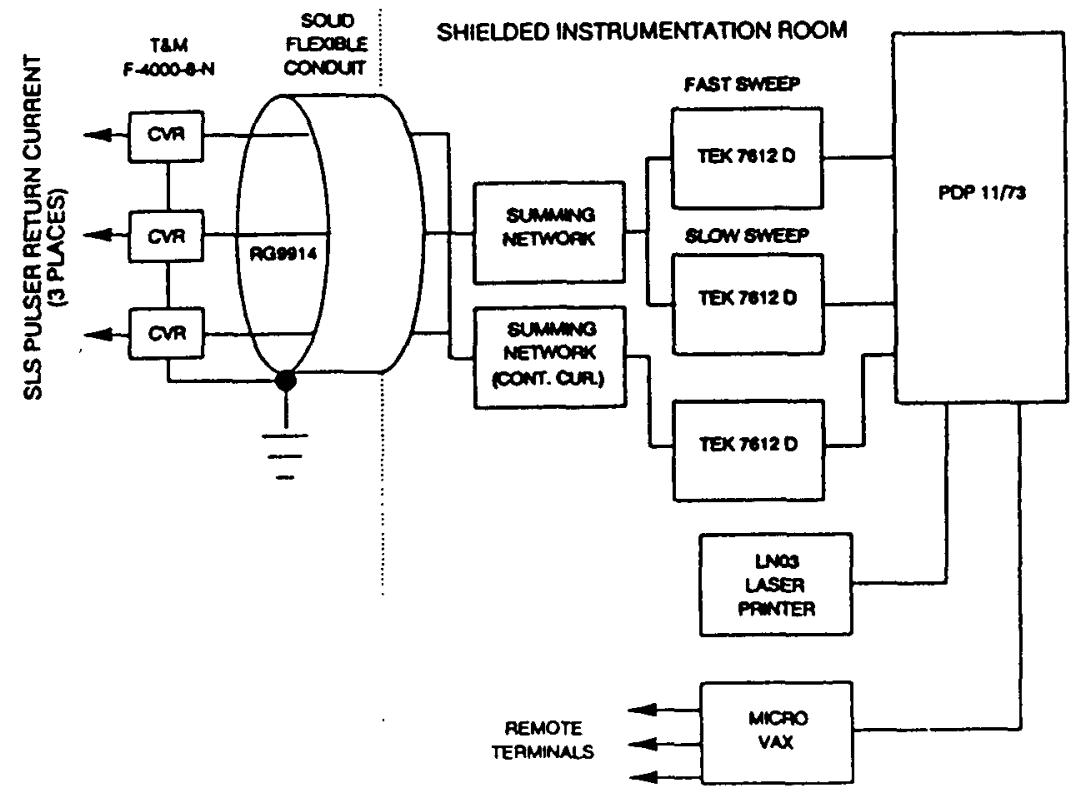

Figure 7. Standard SLS Output Recording Instrumentation

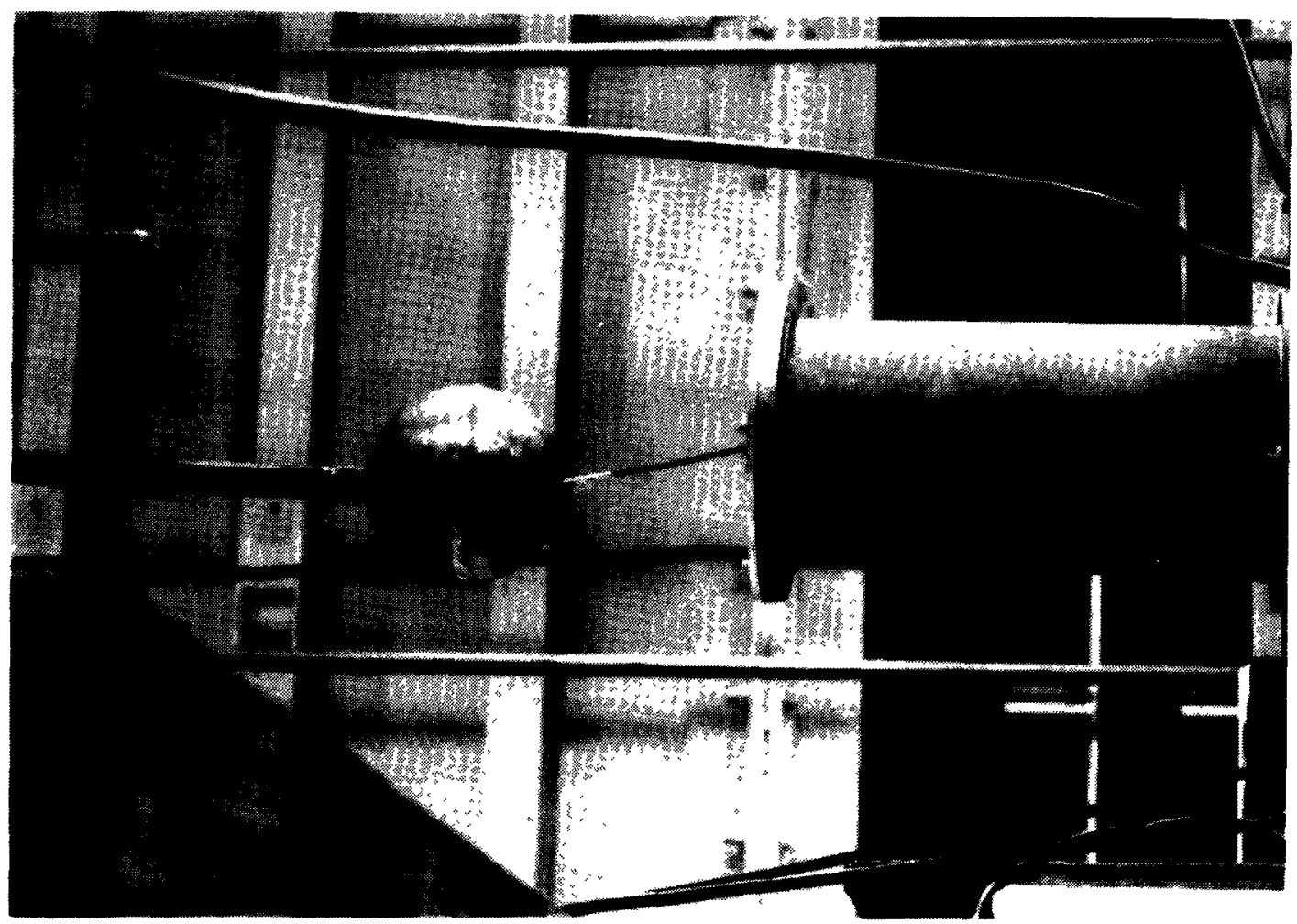

Figure 8. Preliminary Test Object Attached to SLS Electrode 


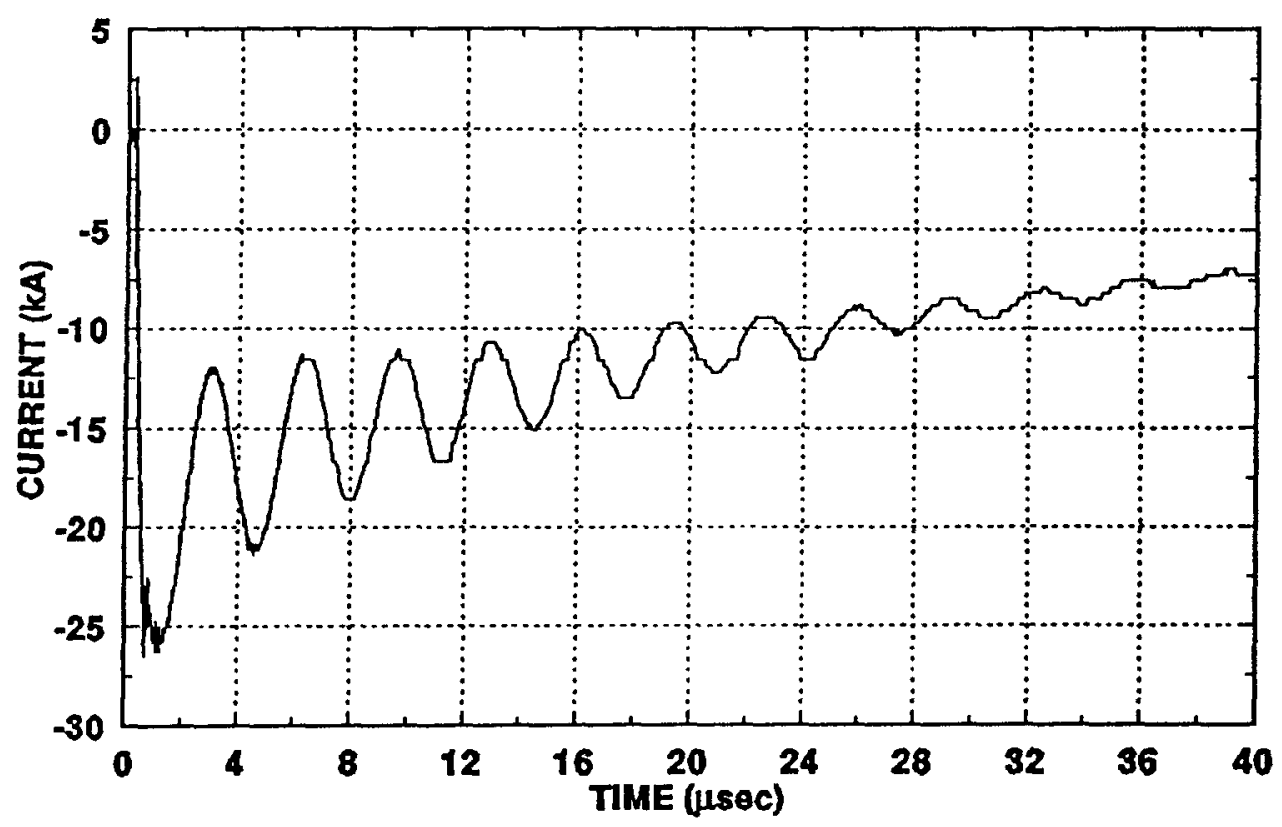

(a)

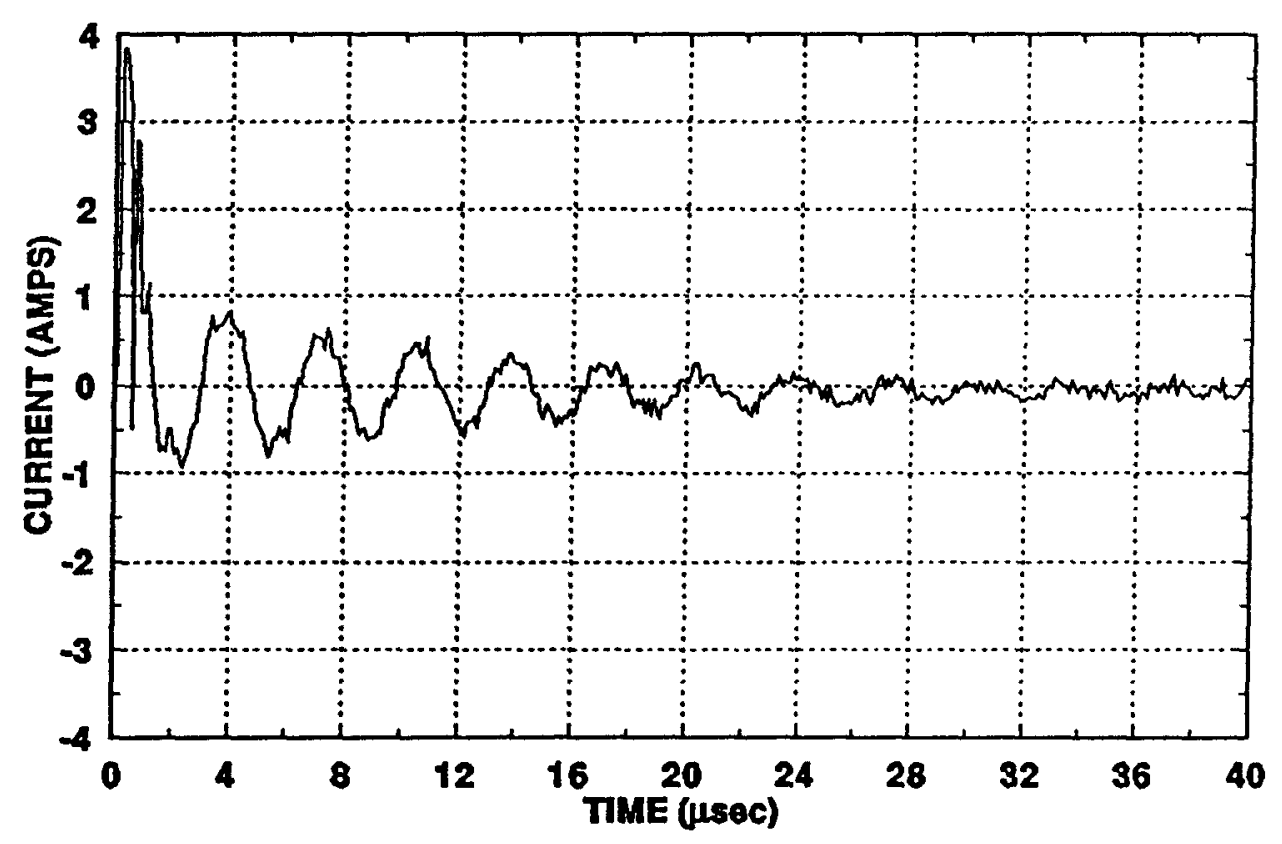

(b)

Figure 9. a) Applied Simulated Return-Stroke, and b) Recorded Response on Sensor CVT TOP on Shot 1898 


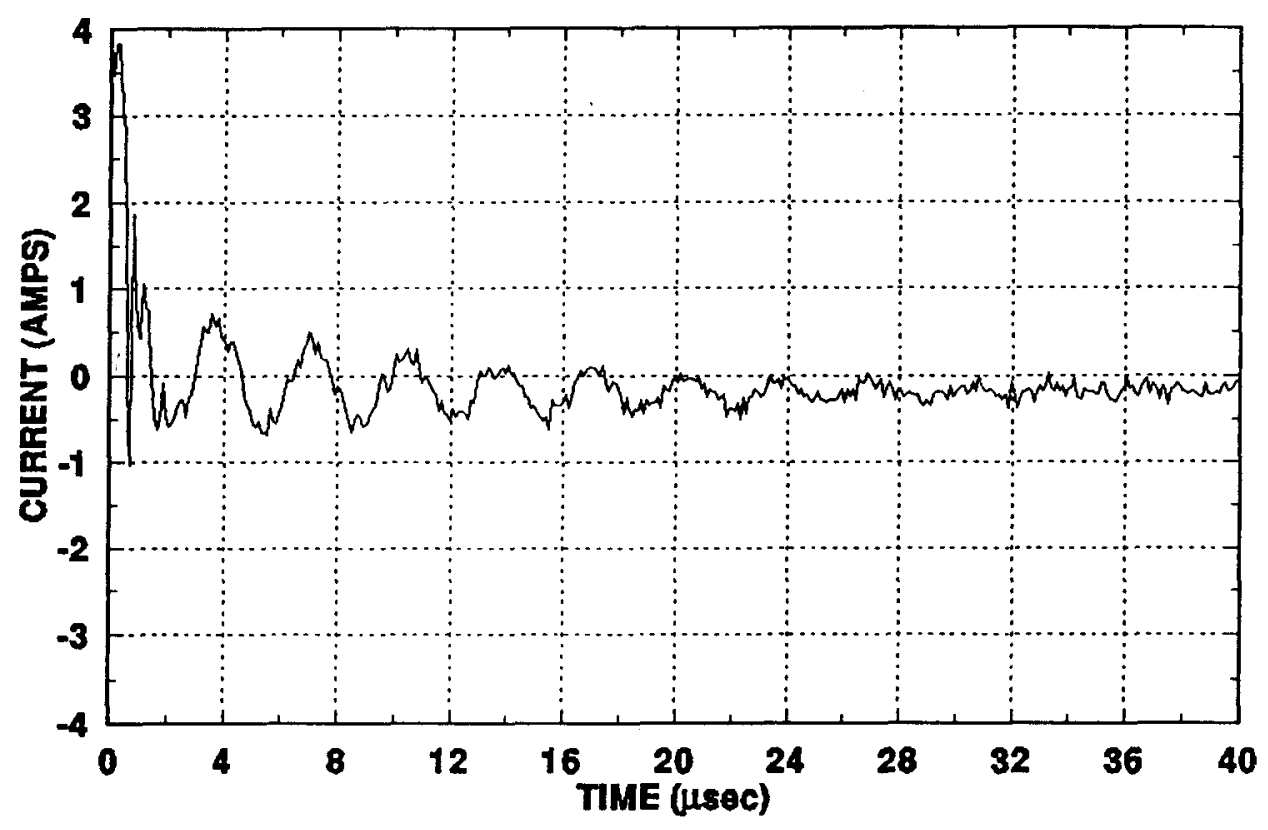

Figure 10. Noise Shot 1899 Response with CVTs Bypassed by the Fiber Optic, 45-kA Incident Current

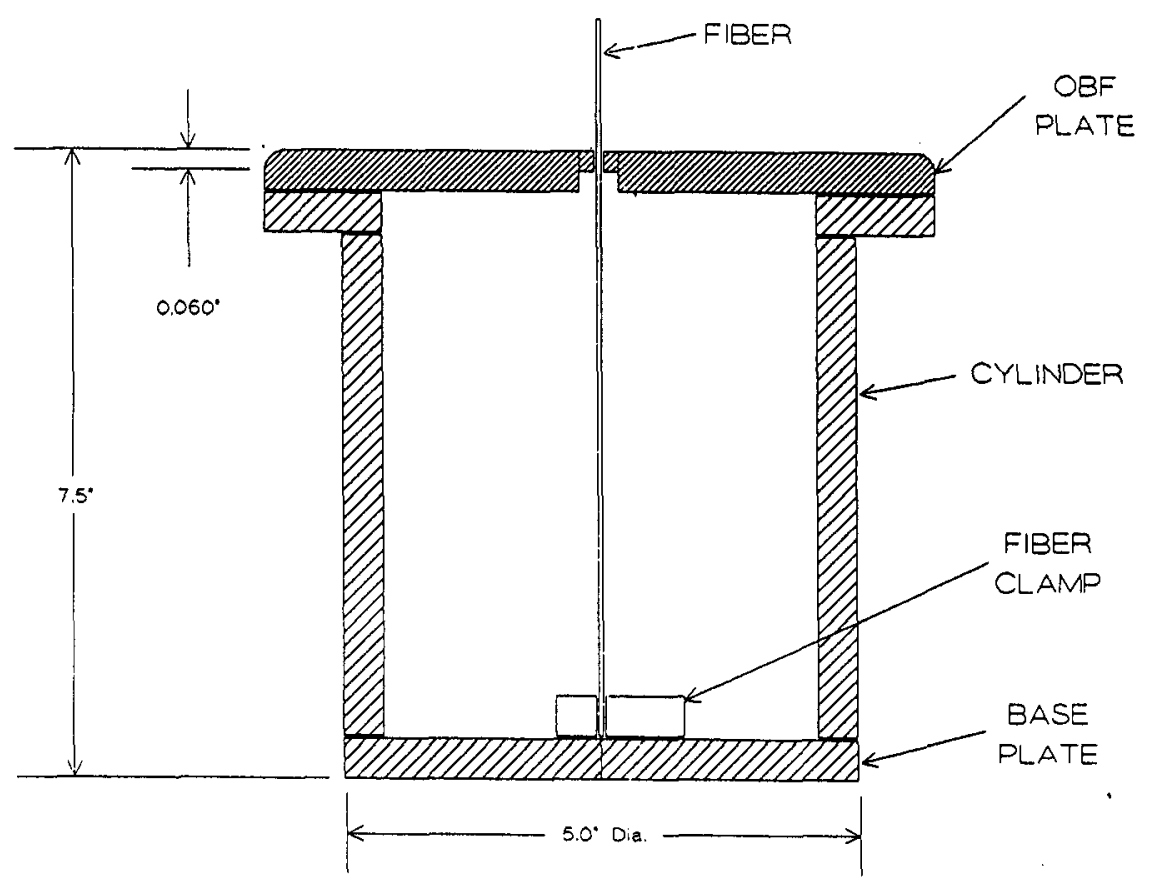

Figure 11. Mockup Cylindrical "Exclusion Region" Test Object 


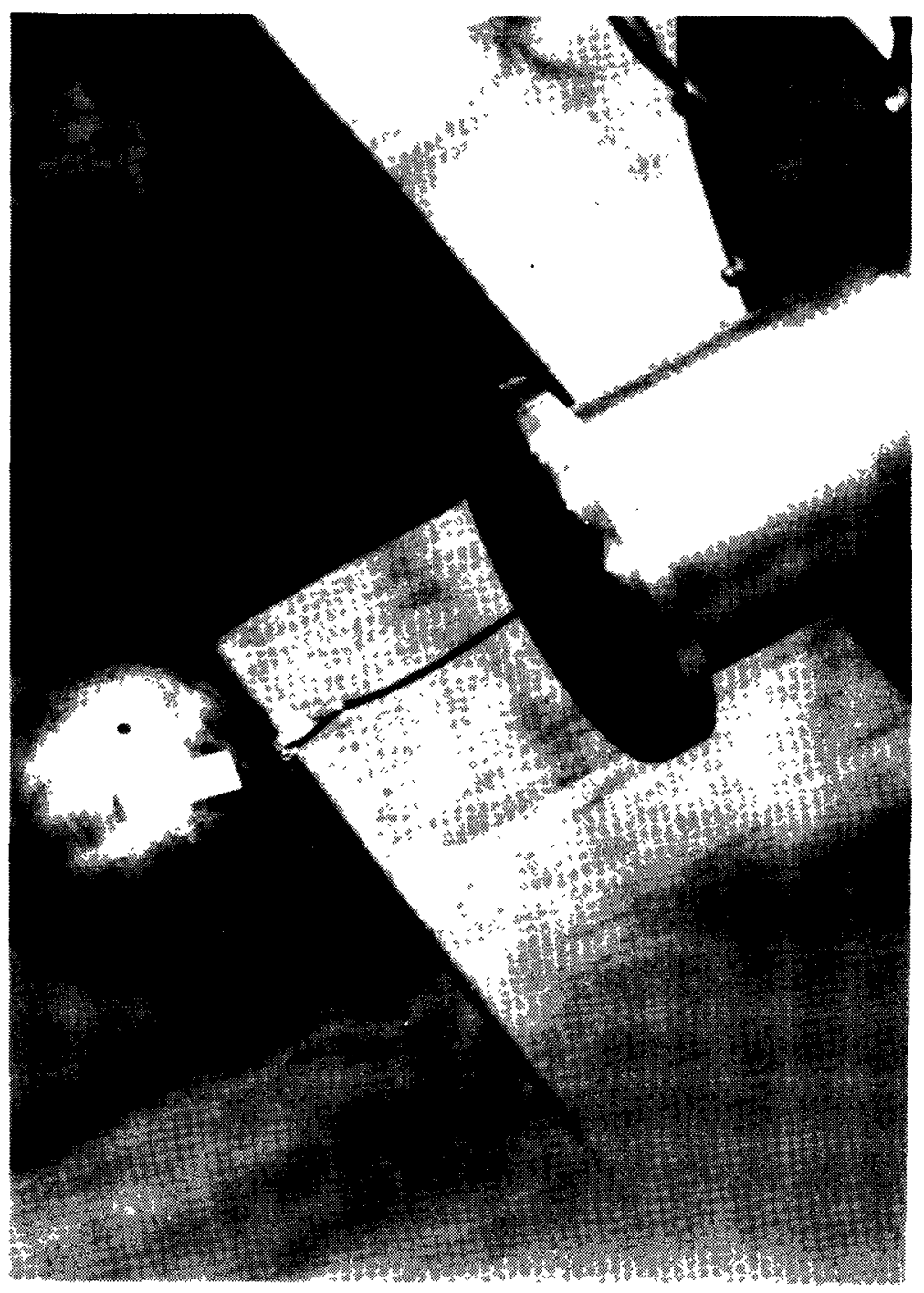

Figure 12. Mockup Exclusion Region in Place and Ready for Testing 


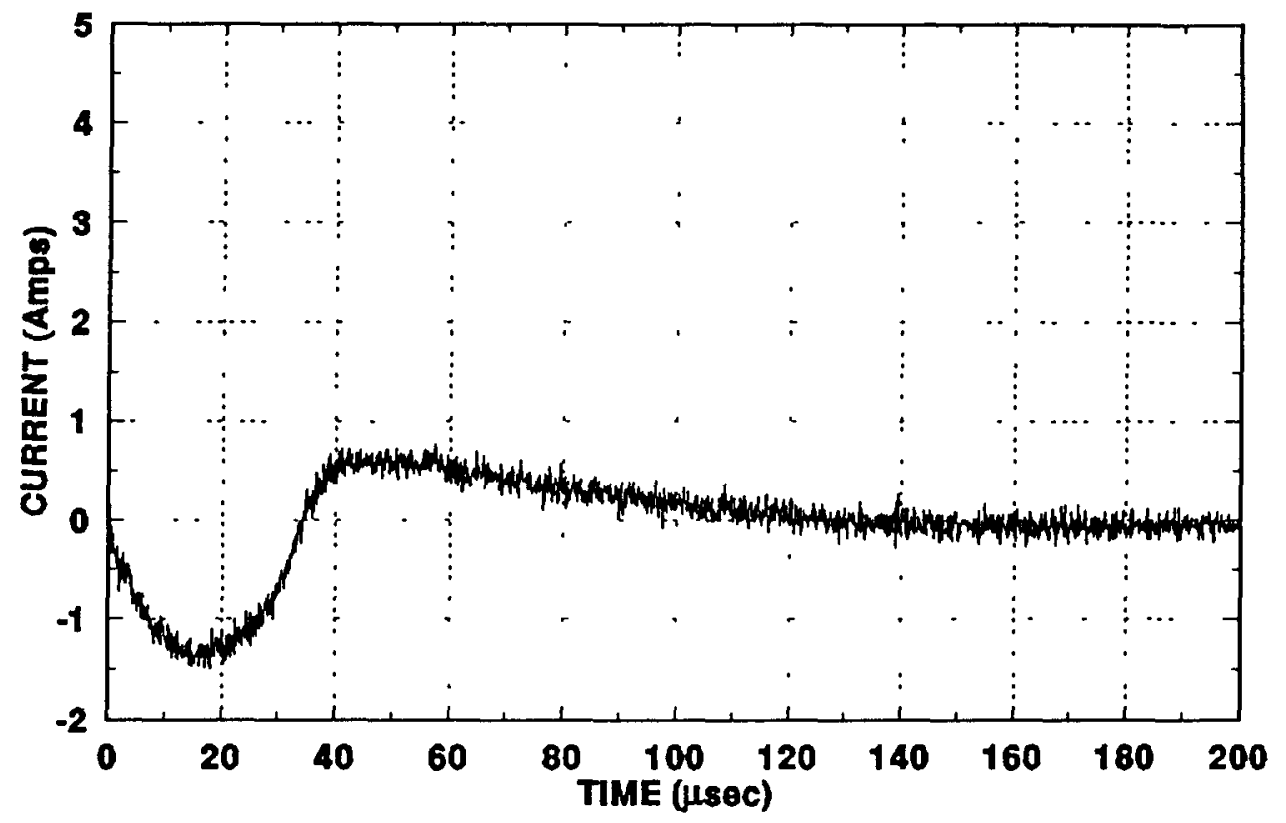

(a)

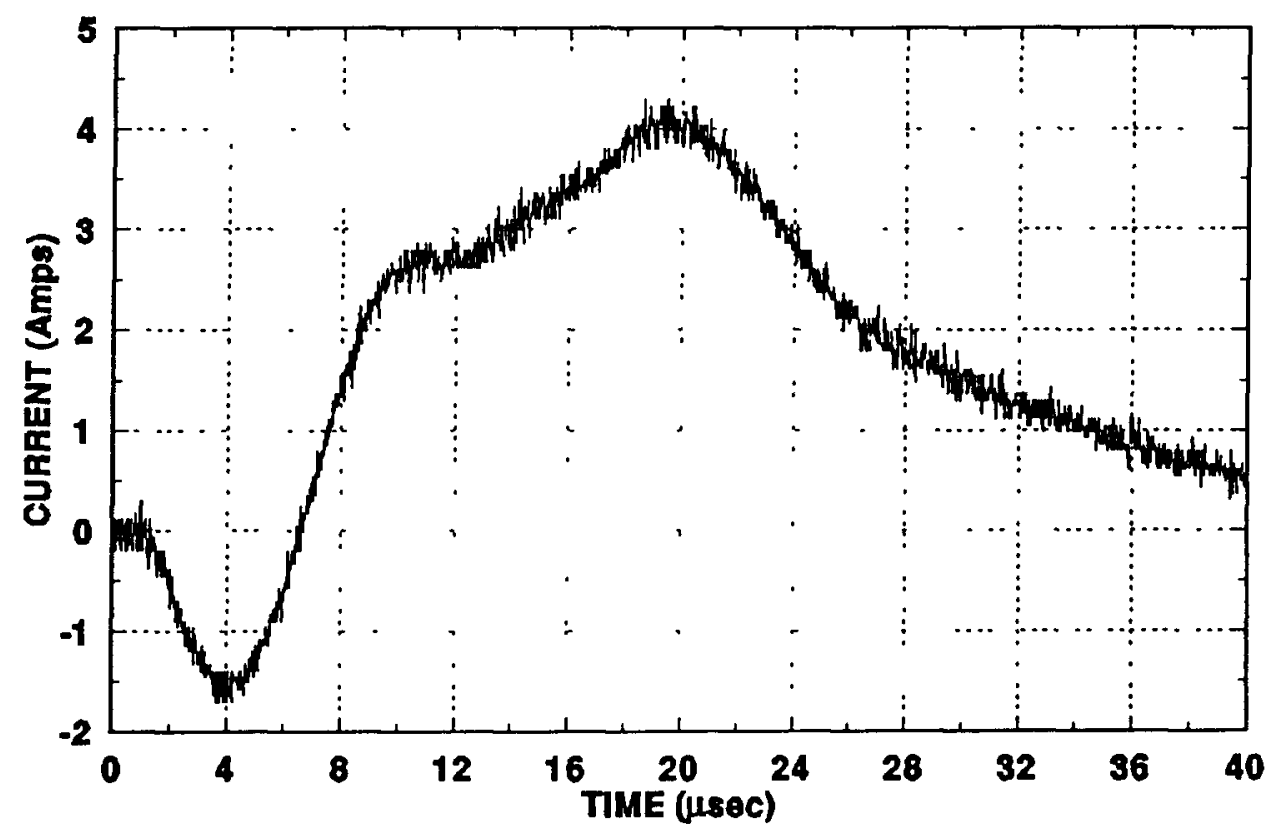

(b)

Figure 13. Noise Responses Recorded on Shot 2050 with Barrier Aperture Completely Plugged. a) First Stroke (40 kA), and b) Second Stroke (200 kA) 


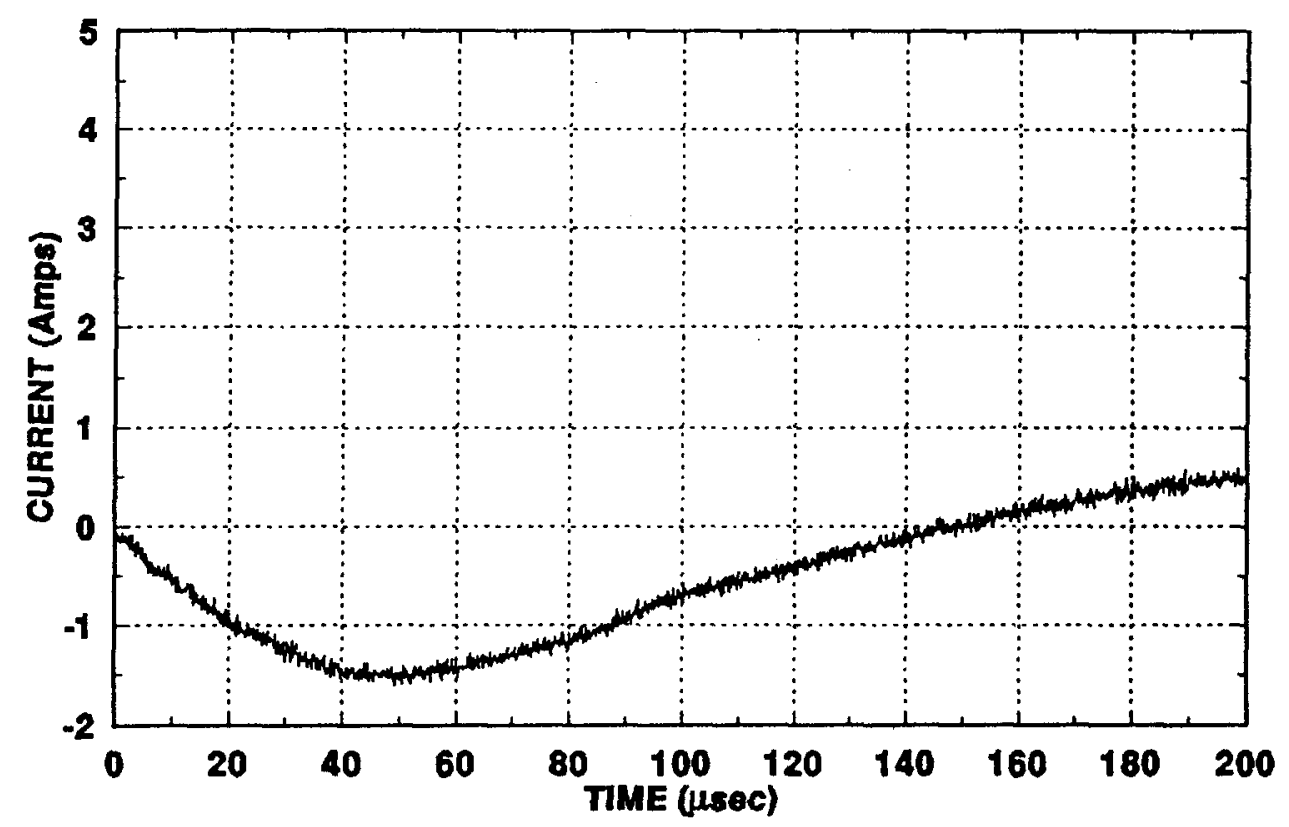

Figure 14. Noise Response Recorded on Shot 1929 in Which the Barrier Aperture Was Sealed by Copper Tape Internal to the Test Cylinder 
This page left intentionally blank 


\section{APPENDIX A \\ INSTRUMENTATION AND SENSOR CALIBRATION}

This appendix provides documentation on how the instrumentation was checked for calibration accuracy during the DOI barrier feedthrough lightning test. Only instrumentation and sensors under valid Sandia Calibration Laboratory certification status were used in this test.

The configuration of the main instrumentation channels used for recording responses internal to the test article due to simulated return-stroke currents is shown in Figure 4 in the report text. The sensors employed for the return-stroke portions of the test were current viewing transformers (CVT). The continuing current portions of the test currents have durations (low frequency content) that require a measurement bandwidth extending to d.c. on the low end. A separate current viewing resistor (CVR) and FM fiber optic link (Figure 5) was therefore used in addition to the CVT channels during test shots involving continuing currents.

The calibration of the CVT channels was verified in three steps. The Pearson Model 2879 CVTs were checked separately. To do this, they were installed around a piece of grounding braid that was connected across the terminals of a Velonix Model 587 pulse generator. A certified Model 110A CVT was also installed and used to provide the measured reference output of the pulser. Figure A-1 shows the recorded reference and the responses of the two CVTs employed during the tests. The signals were each recorded directly on a certified LeCroy Model 9400A digitizing oscilloscope and plotted using an HP7470A $x-y$ plotter. Agreement is to within 8 percent. The same process was repeated for an input current amplitude of $10 \mathrm{~A}$, and the results are shown in Figure $\mathrm{A}-2$.

Next, calibration of the data transmission and recording instrumentation was checked by injecting a known squarewave signal from a Tektronix Model PG 506 precision calibration generator directly into the input of each NanoFast fiber optic transmitter and recording the response obtained through the entire channel (through to hard copy). The results are shown in Figure A-3. Since it was anticipated that the currents flowing on the test fiber would be small, a $1 \mathrm{mV}$ peak-to-peak input amplitude was used, along with the highest available gain (x100) of the NanoFast fiber optic link. Figure A-3 indicates that signals as low as $0.2 \mathrm{mV}$ would be discernible. The peak-to-peak noise amplitude of $0.1 \mathrm{mV}$, when corrected for the system gain factor of 100 , corresponds to the fiber optic's specified receiver noise level of $10 \mathrm{mV}$. The apparent roll-off of the square wave is due to the 3-dB lower frequency response point of the fiber optics, which was measured to be approximately $10 \mathrm{~Hz}$.

The final step in validating the CVT channels was to inject a pulse from the Velonex 587 pulser through the CVT and record the response through the full data channel shown in Figure 4. The result is shown in Figure A-4. Discounting the superimposed fiber optic receiver noise, agreement with the injected input is to within 5 percent.

As mentioned above, a CVR was required for capturing any test responses due to long continuing currents. No commercial sensor was available that would fit physically into the test object, so a nominal $0.6-\Omega$ CVR was fabricated and calibrated. Calibration was performed at discrete frequencies using a certified HP 3523B precision function generator. The calibration results are shown in Table $A-1$.

The Dymec FM fiber optic link used in conjunction with the CVR has a built-in calibration pulse generator, independently calibrated against a certified source, which is used to establish the end-to-end sensitivity of the fiber optic link and its associated LeCroy $9400 \mathrm{~A}$ digitizing oscilloscope. This cal signal was applied periodically during testing and used to define the sensitivity scale of the plotted data. 


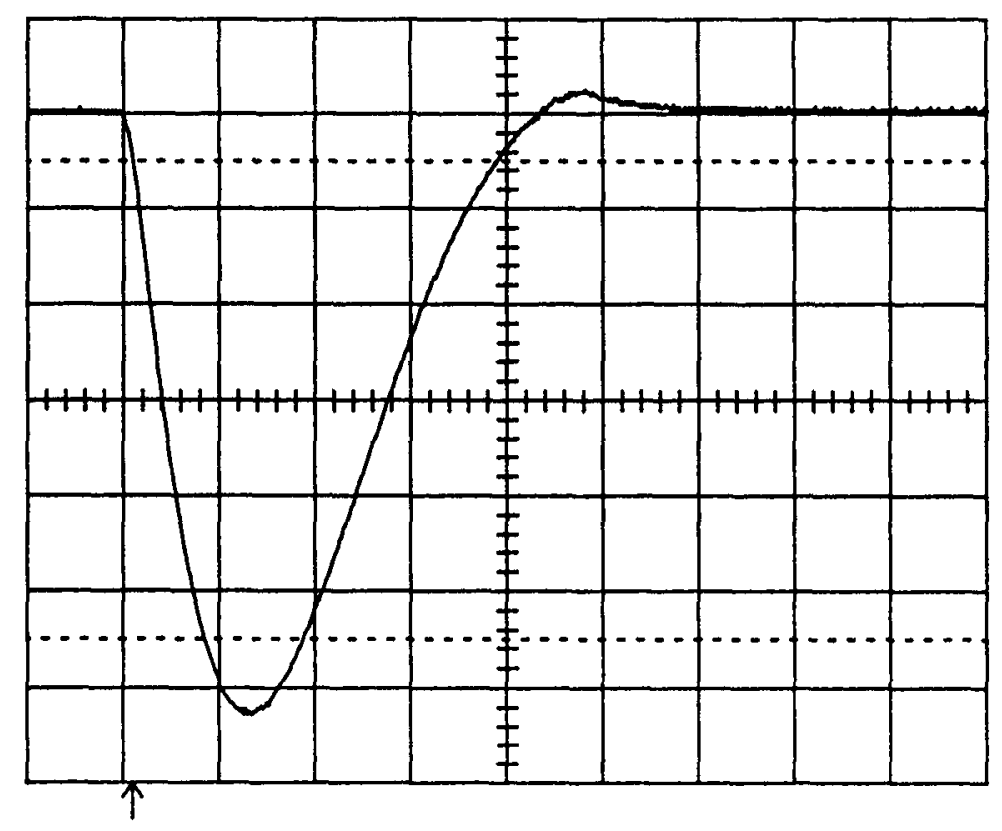

(a) $20 \mathrm{~A} / \mathrm{div}$ and $10 \mu \mathrm{s} / \mathrm{div}$

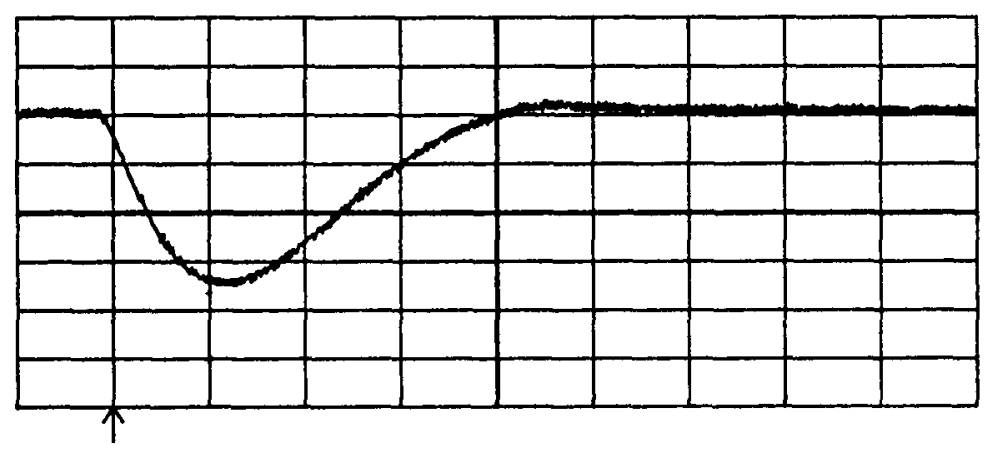

(b) $40 \mathrm{~A} / \mathrm{div}$ and $10 \mu \mathrm{s} / \mathrm{div}$

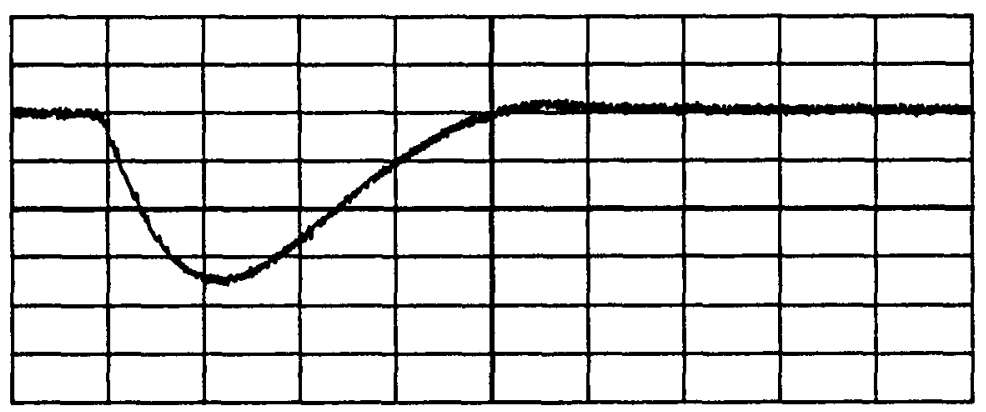

(c) $40 \mathrm{~A} / \mathrm{div}$ and $10 \mu \mathrm{s} / \mathrm{div}$

Figure A-1. CVT Sensor Checks. a) Current Injected from Velonix, b) Top CVT and c) Bottom CVT Response 


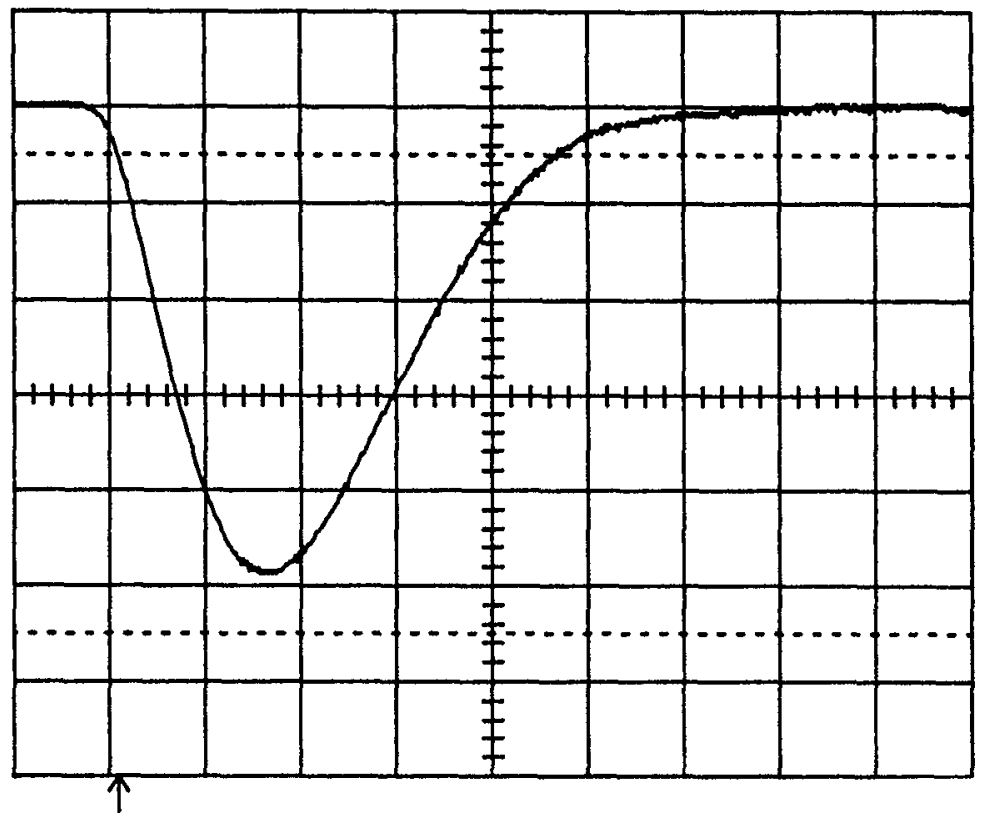

(a) $2 \mathrm{~A} / \mathrm{div}$ and $10 \mu \mathrm{s} / \mathrm{div}$

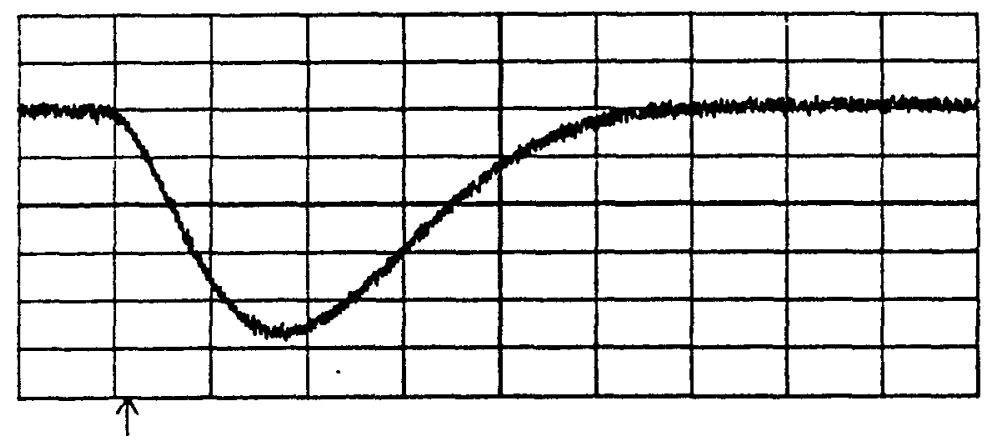

(b) $2 \mathrm{~A} / \mathrm{div}$ and $10 \mu \mathrm{s} / \mathrm{div}$

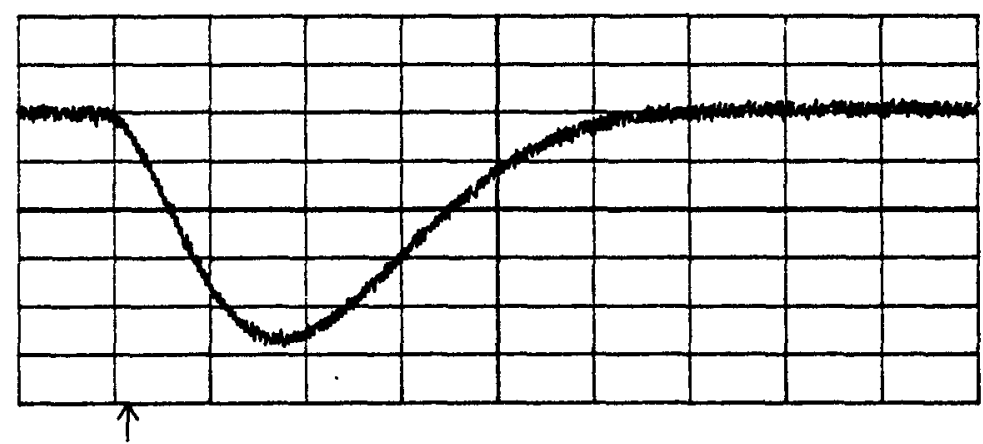

(c) $2 \mathrm{~A} / \mathrm{div}$ and $10 \mathrm{~ms} / \mathrm{div}$

Figure A-2. CVT Sensor Checks at Nominal 1-A Input Level. a) Input Current, b) Top CVT and c) Bottom CVT 


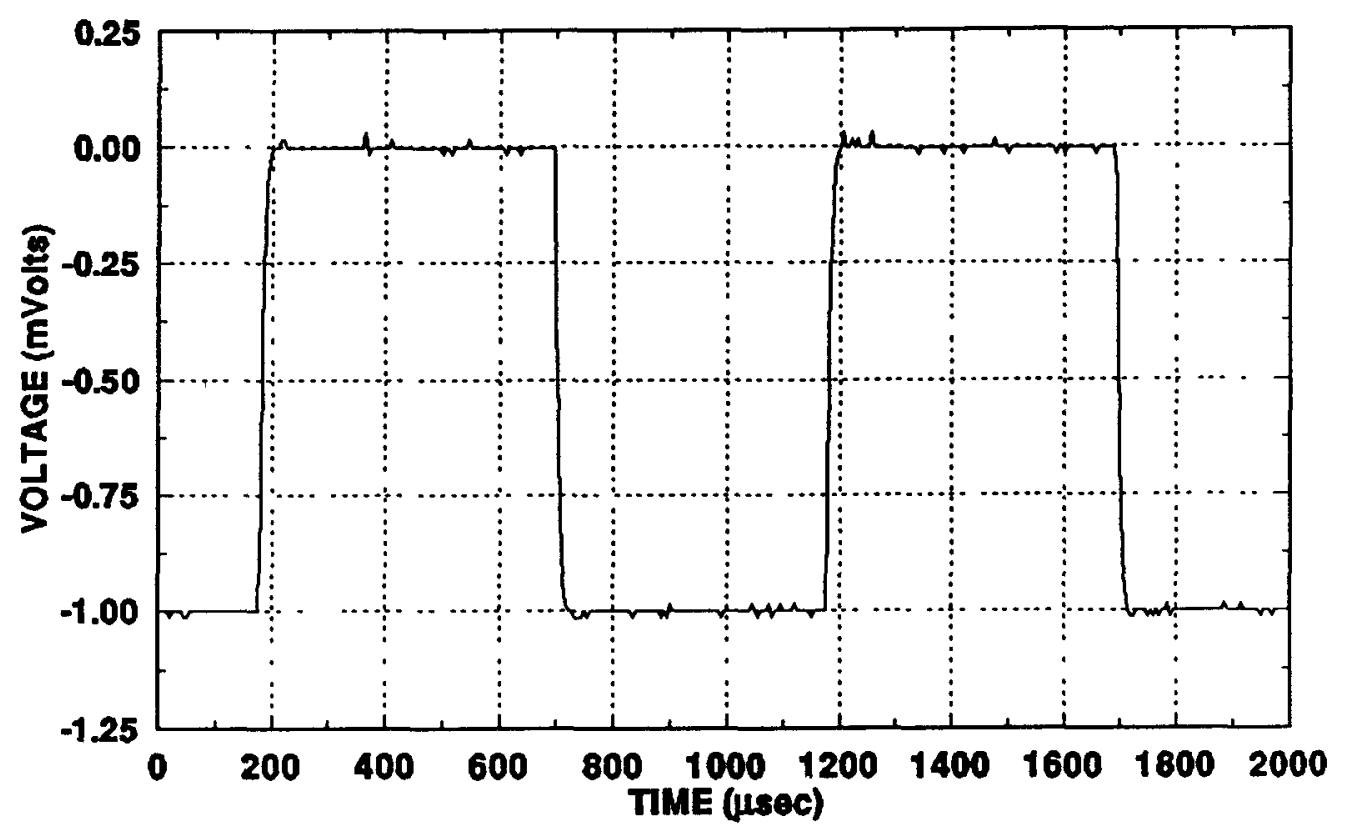

(a)

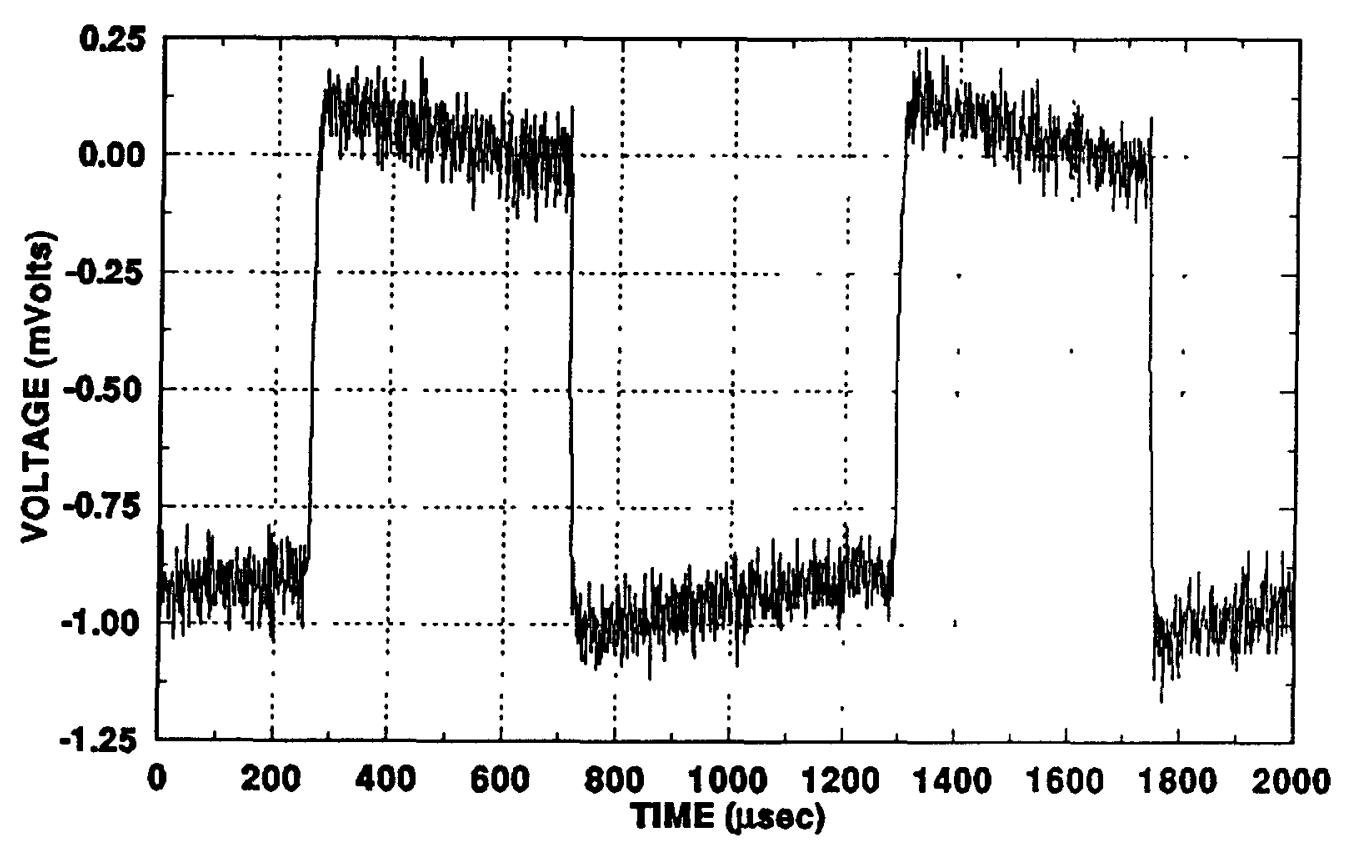

(b)

Figure A-3. (a) 1-kHz Squarewave Calibration Signal Injected into NanoFast FOL, b) Recorded Output 


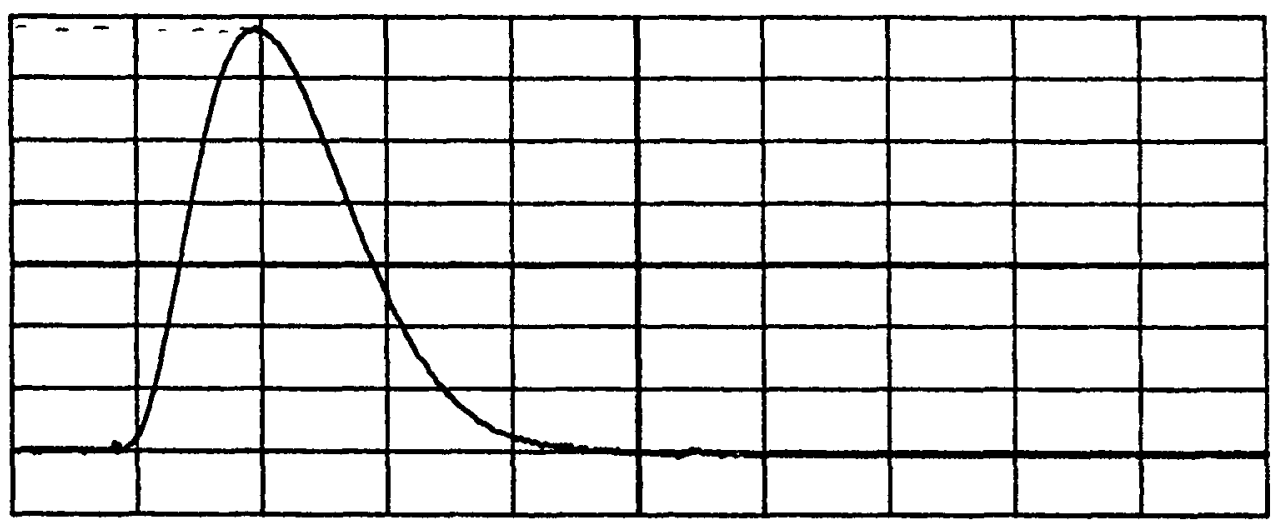

(a) $1 \mathrm{~A} / \mathrm{div}$ and $20 \mu \mathrm{s} / \mathrm{div}$

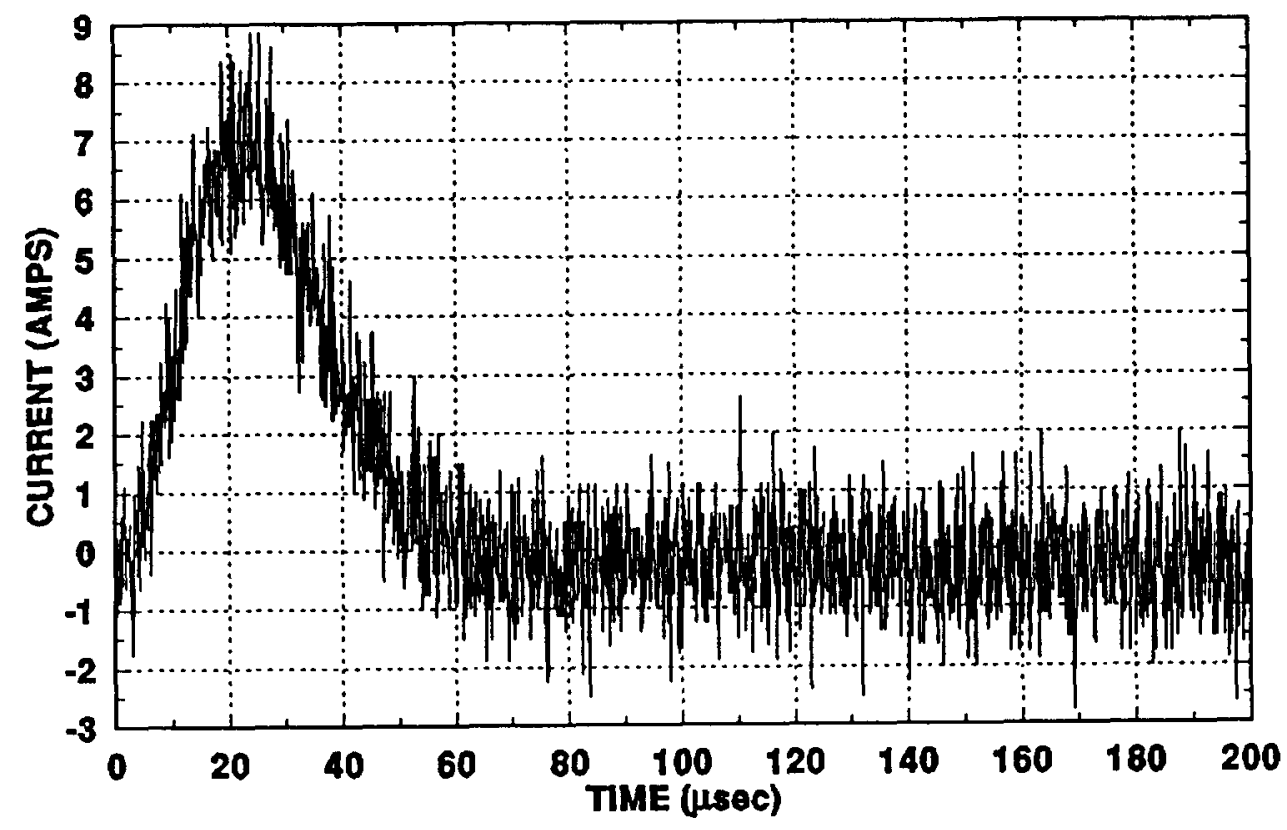

(b)

Figure A-4. End-to-End Check of CVT Recording Channel. A) Input, and b) Recorded Response 
Table A-1

Fabricated CVR ${ }^{1}$ Calibration Results

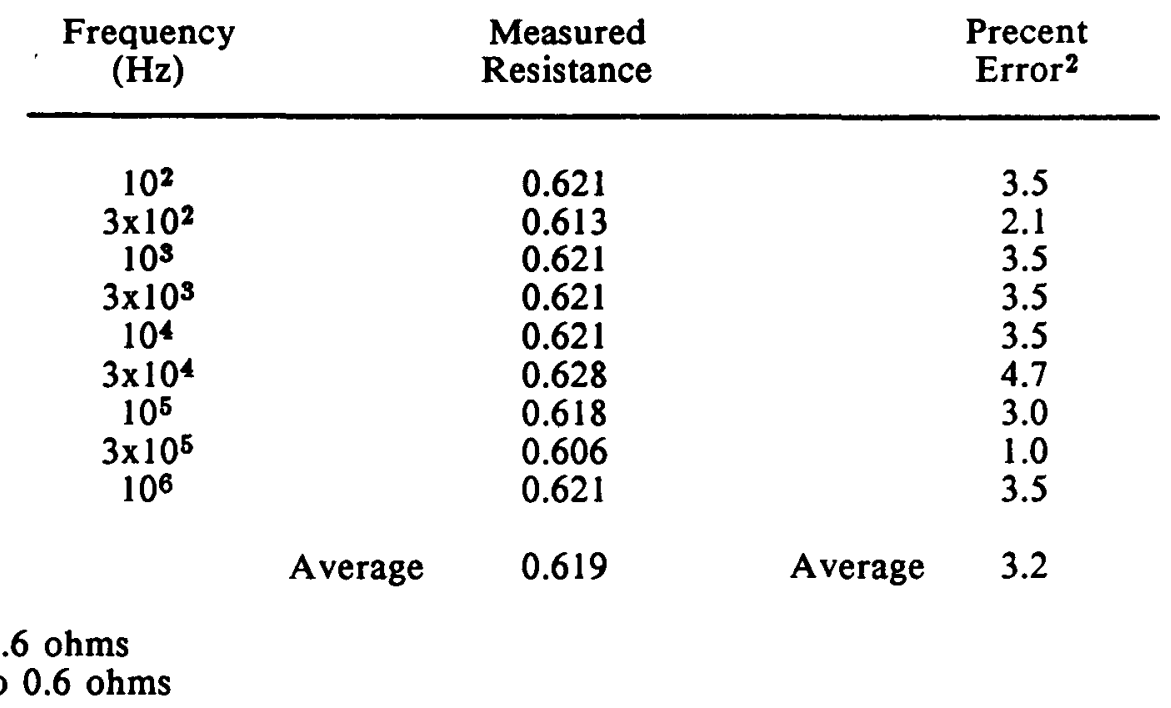




\section{APPENDIX B TEST DATA}

This appendix contains the recorded data traces for each of the test shots summarized in Table 3 of the report, which is reproduced below for easier reference. Organization is by test shot number. Included for each shot are plots of the applied simulated lightning flash currents and the corresponding recorded responses.

TABLE 3

TEST SHOT DATA SUMMARY

\begin{tabular}{|c|c|c|c|c|}
\hline $\begin{array}{c}\text { SHOT } \\
\text { ID }\end{array}$ & $\begin{array}{c}I_{p_{1}} \\
(\mathrm{kA})\end{array}$ & $\begin{array}{c}\text { SENSOR } \\
\text { TYPE }\end{array}$ & $\begin{array}{l}\text { PEAK } \\
\text { RESPONSE } \\
\text { (A) }\end{array}$ & COMMENTS \\
\hline $\begin{array}{l}1898 \\
1899 \\
1914 \\
1920 \\
1926\end{array}$ & $\begin{array}{c}25 \\
45 \\
30 \\
30 \\
200\end{array}$ & $\begin{array}{l}\text { CVT } \\
\text { CVT } \\
\text { CVT } \\
\text { CVT } \\
\text { CVT }\end{array}$ & $\begin{array}{l}-5 \\
-5 \\
\pm 1 \\
0.16 \\
-0.3\end{array}$ & $\begin{array}{l}\text { Preliminary hardware } \\
\text { Noise shot with fiber bypassing sensors } \\
\text { Mockup hardware with } \text { BPA }^{1} \text { of } 475 \mu \\
\text { Gain increased by x100 from } 1914 \\
\text { BPA of } 500 \mu\end{array}$ \\
\hline $\begin{array}{l}1927 \\
1929 \\
1930 \\
2027\end{array}$ & $\begin{array}{l}200 \\
200 \\
200 \\
200\end{array}$ & $\begin{array}{l}\text { CVT } \\
\text { CVT } \\
\text { CVT } \\
\text { CVT }\end{array}$ & $\begin{array}{l}-1.0 \\
-1.5 \\
+0.45 \\
-0.55\end{array}$ & $\begin{array}{l}\text { Repeat of } 1926 \\
\text { No fiber, BPA copper-taped } \\
\text { Noise, repeat of } 1929 \\
\text { Repeat of } 1926,27 \text {. BPA of } 500 \mu\end{array}$ \\
\hline 2033 & 40,200 & CVT & $+0.2 /-0.2$ & $\begin{array}{l}\text { Within noise amplitudes of noise shots } \\
192930\end{array}$ \\
\hline 2049 & $40,200^{2}$ & CVT/CVR & $\begin{array}{l}+0.9 /-0.7 \\
-8.5 /-2.7\end{array}$ & $\begin{array}{l}\text { Note polarity change on CVT from 1st to } \\
\text { 2nd stroke, implying measurement is not } \\
\text { real current. }\end{array}$ \\
\hline 2050 & Same & CVT/CVR & $\begin{array}{c}+1.3 /-0.7 \\
+4 /-1.7\end{array}$ & Noise, aperture plugged \\
\hline 2051 & Same & CVT/CVR & $+6 /-1.7$ & Test object undisturbed, no 1st stroke data \\
\hline 2052 & Same & $\mathrm{CVT} / \mathrm{CVR}$ & $\begin{array}{l}-1.4 /-.5 \\
+4.5 /-1.7\end{array}$ & Test object undisturbed \\
\hline
\end{tabular}

1 Barrier Plate Aperture

2 Plus continuing current of $\sim 350 \mathrm{~A}$ amplitude 


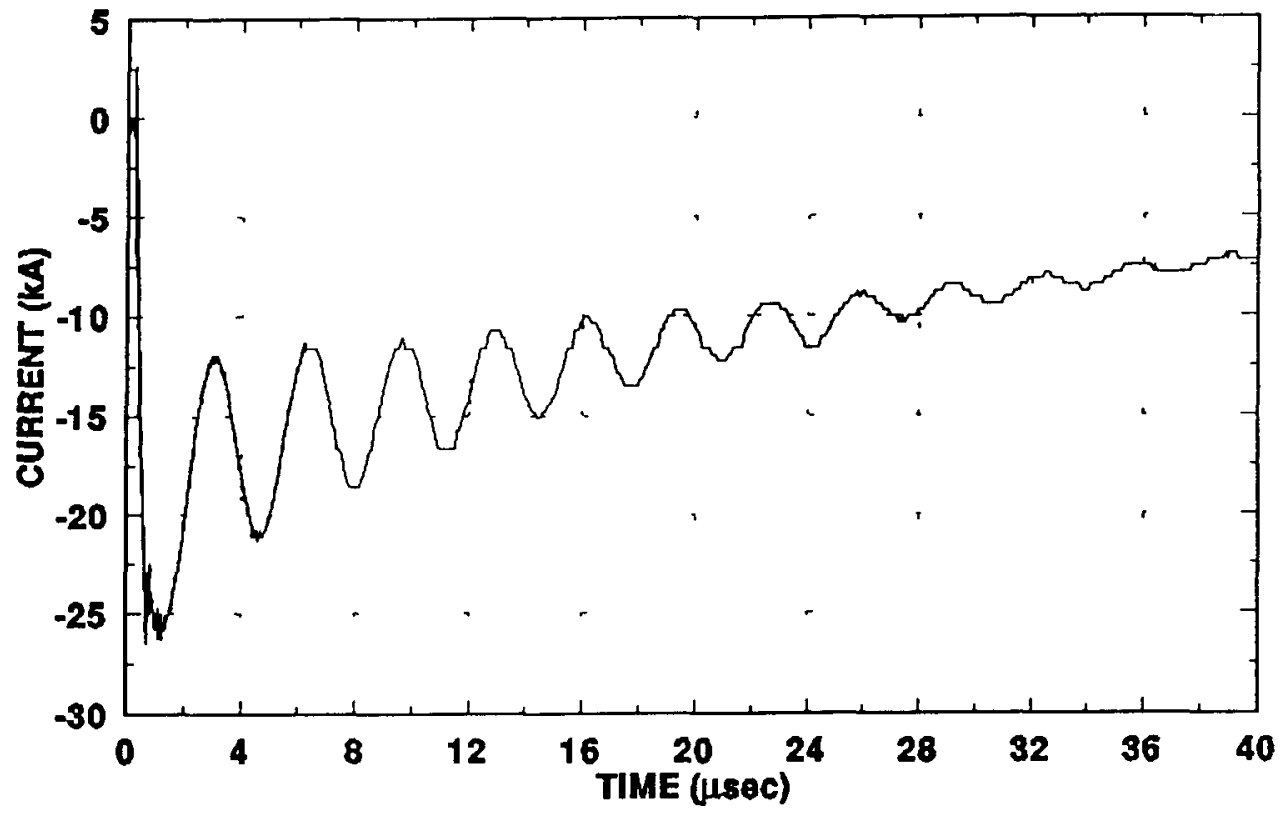

Figure B-1. Applied Test Current, Shot 1898

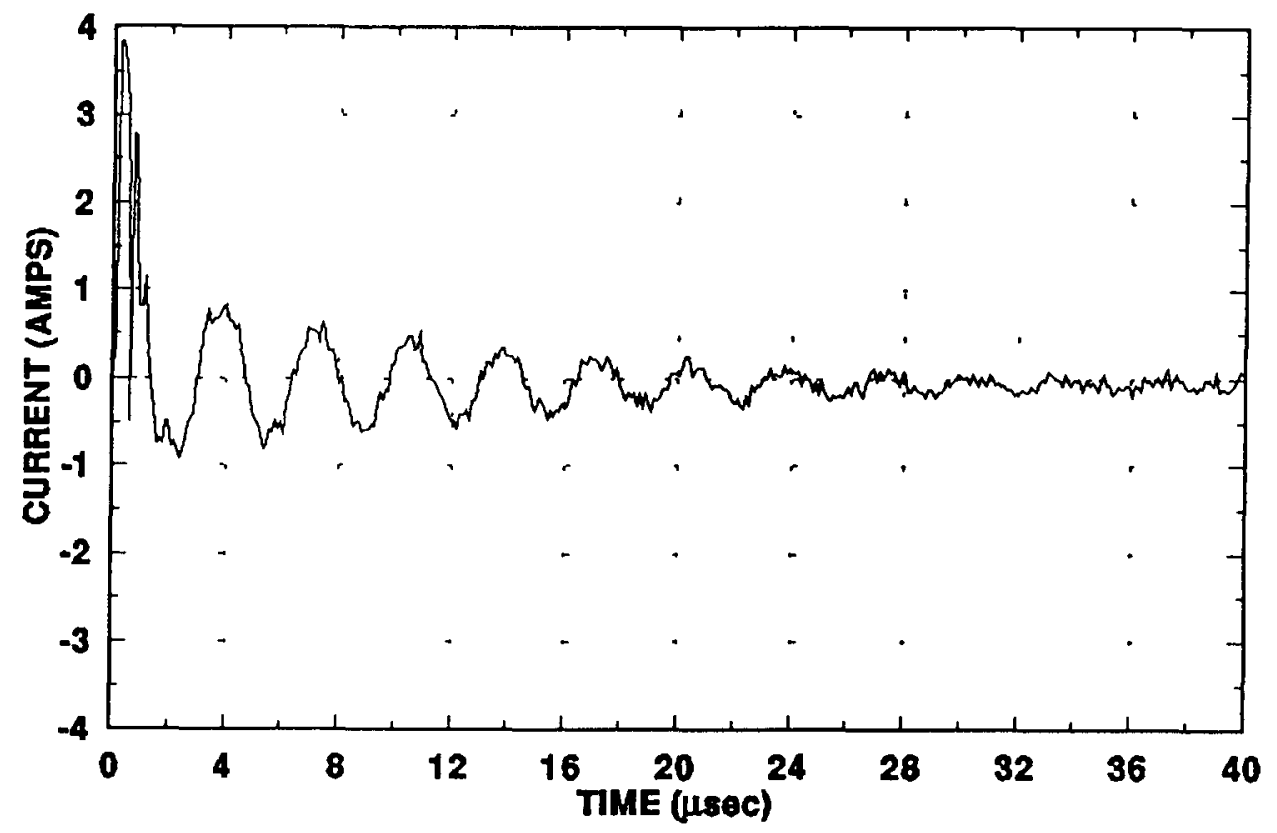

Figure B-2. Response of Upper CVT, Shot 1898 


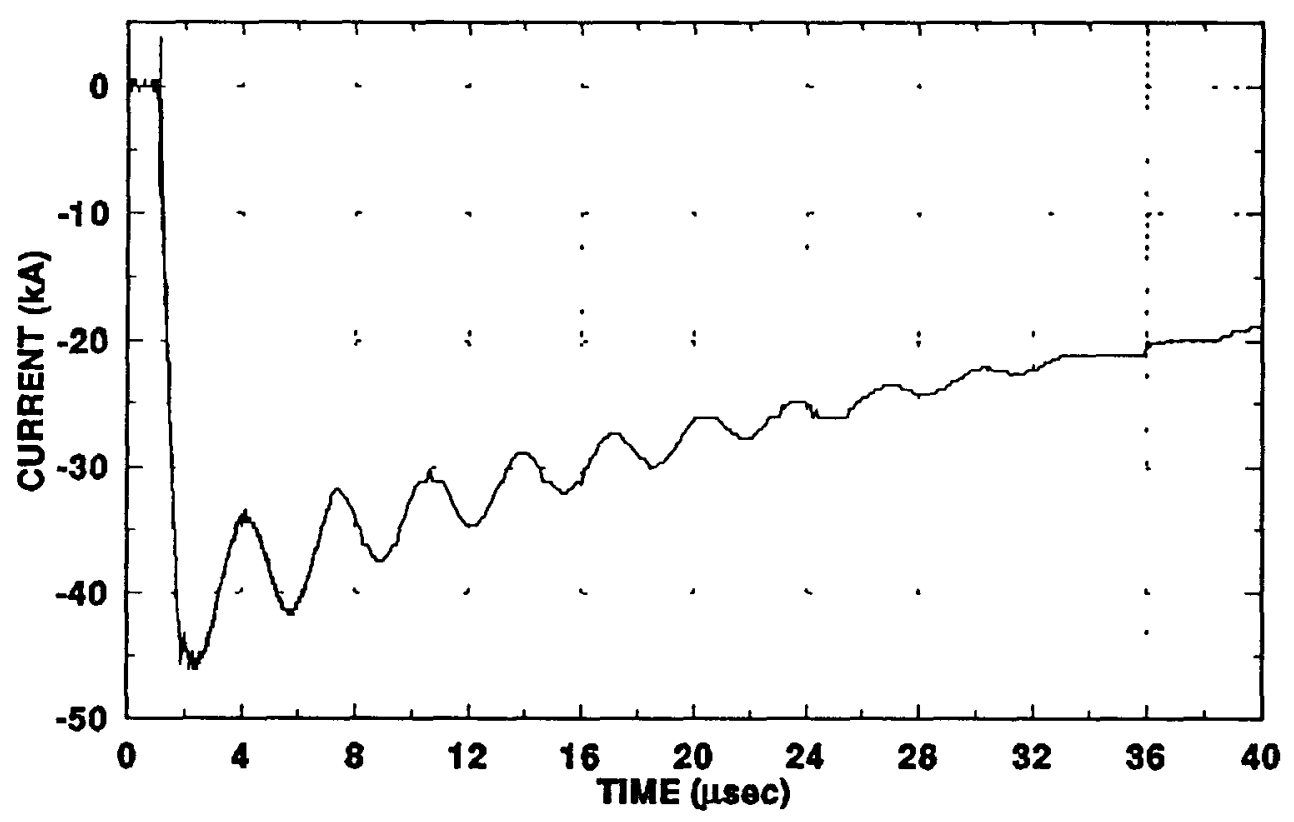

Figure B-3. Applied Test Current, Shot 1899

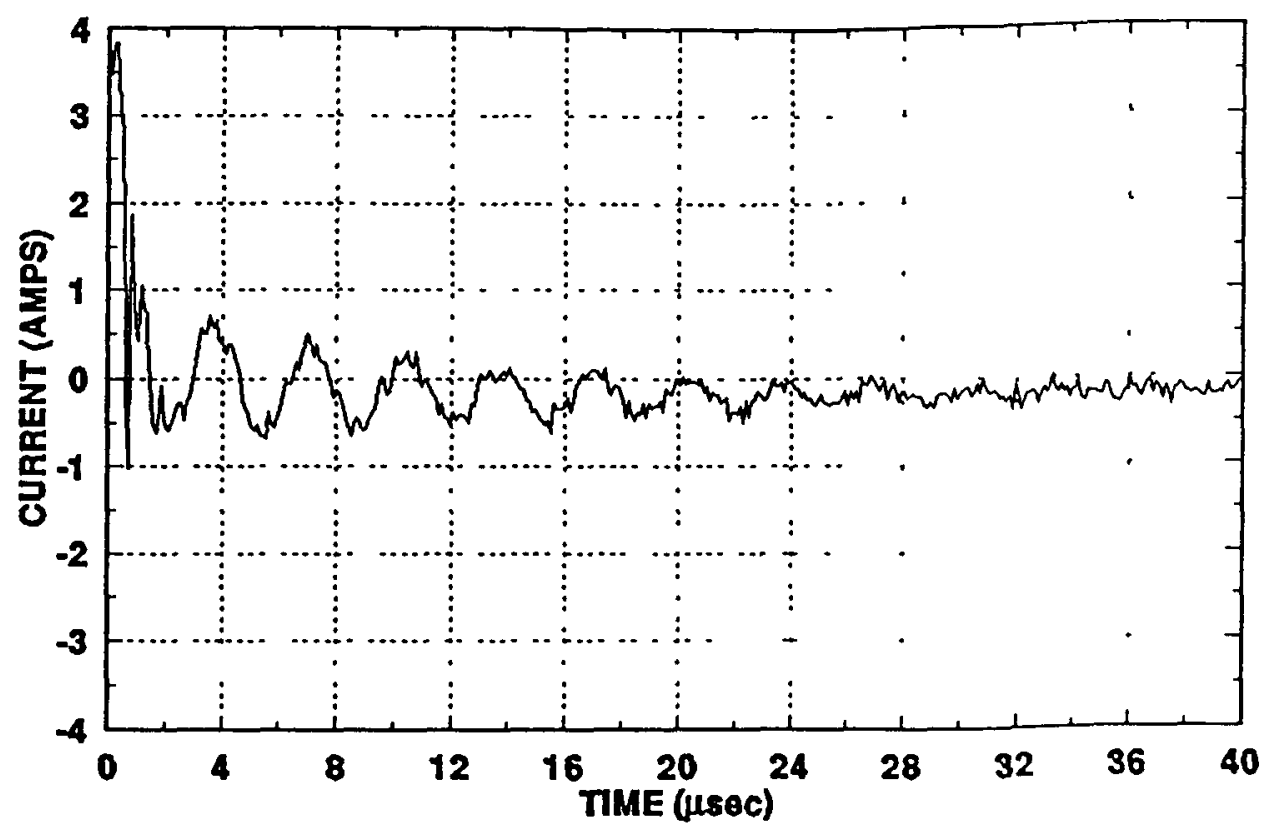

Figure B-4. Upper CVT Noise with Fiber Bypassing Sensor, Shot 1899 


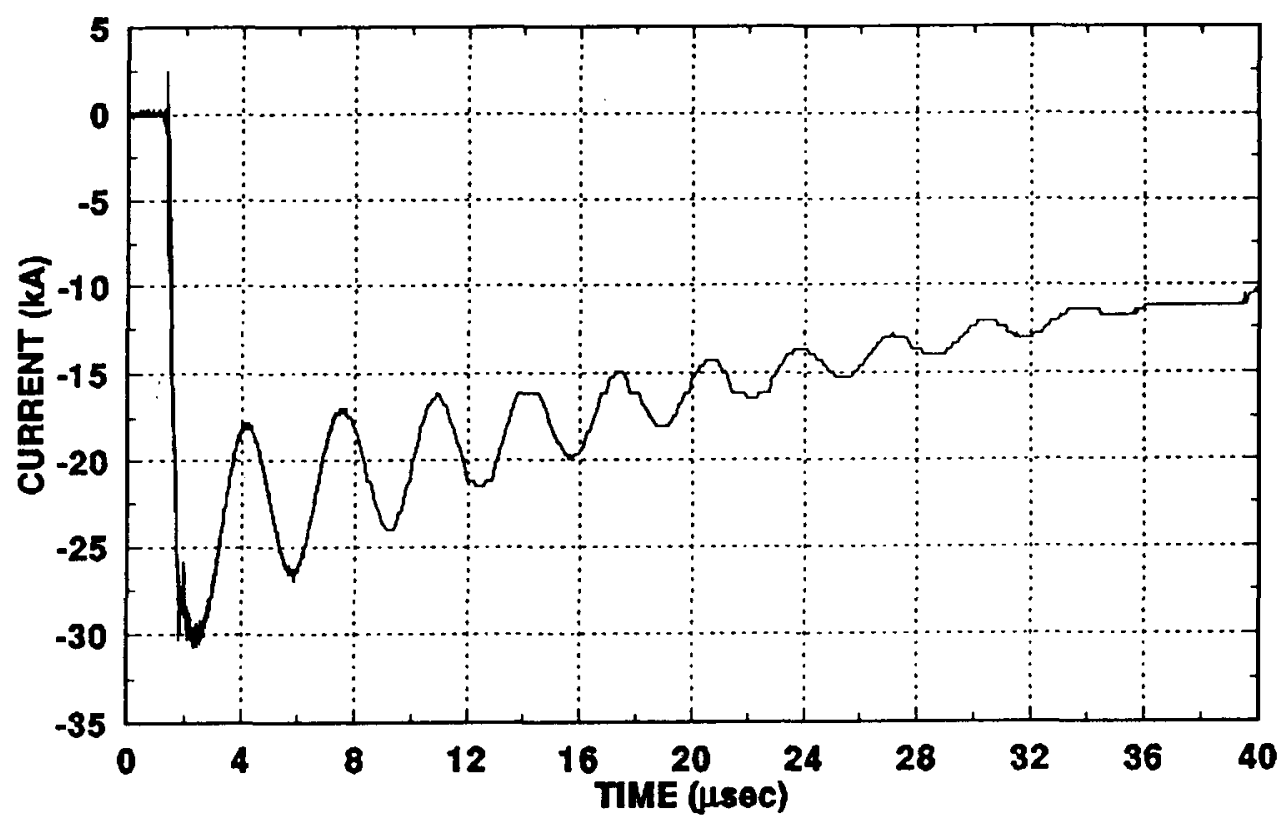

Figure B-5. Applied Test Current, Shot 1914

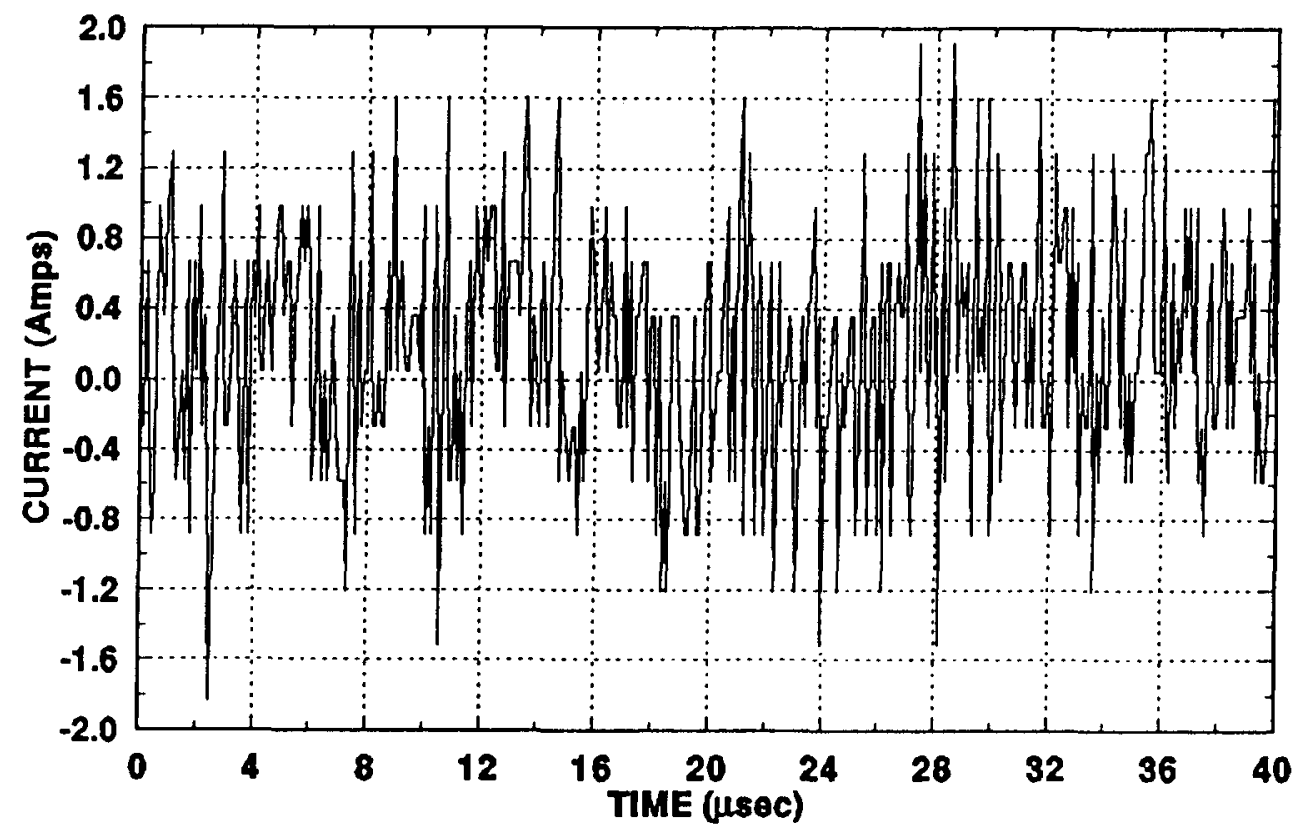

Figure B-6. Response of the Upper CVT with FOL Gain Set to Unity 


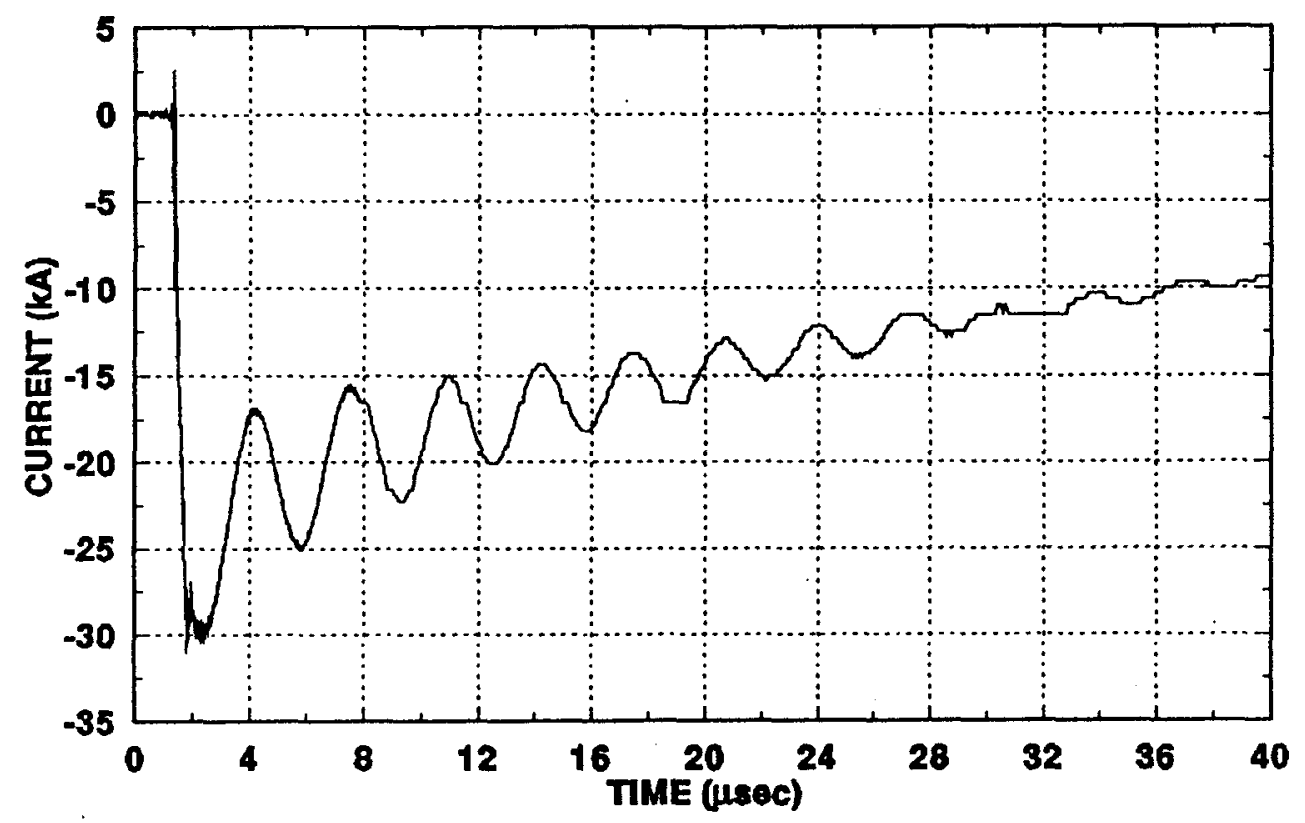

Figure B-7. Applied Test Current, Shot 1920

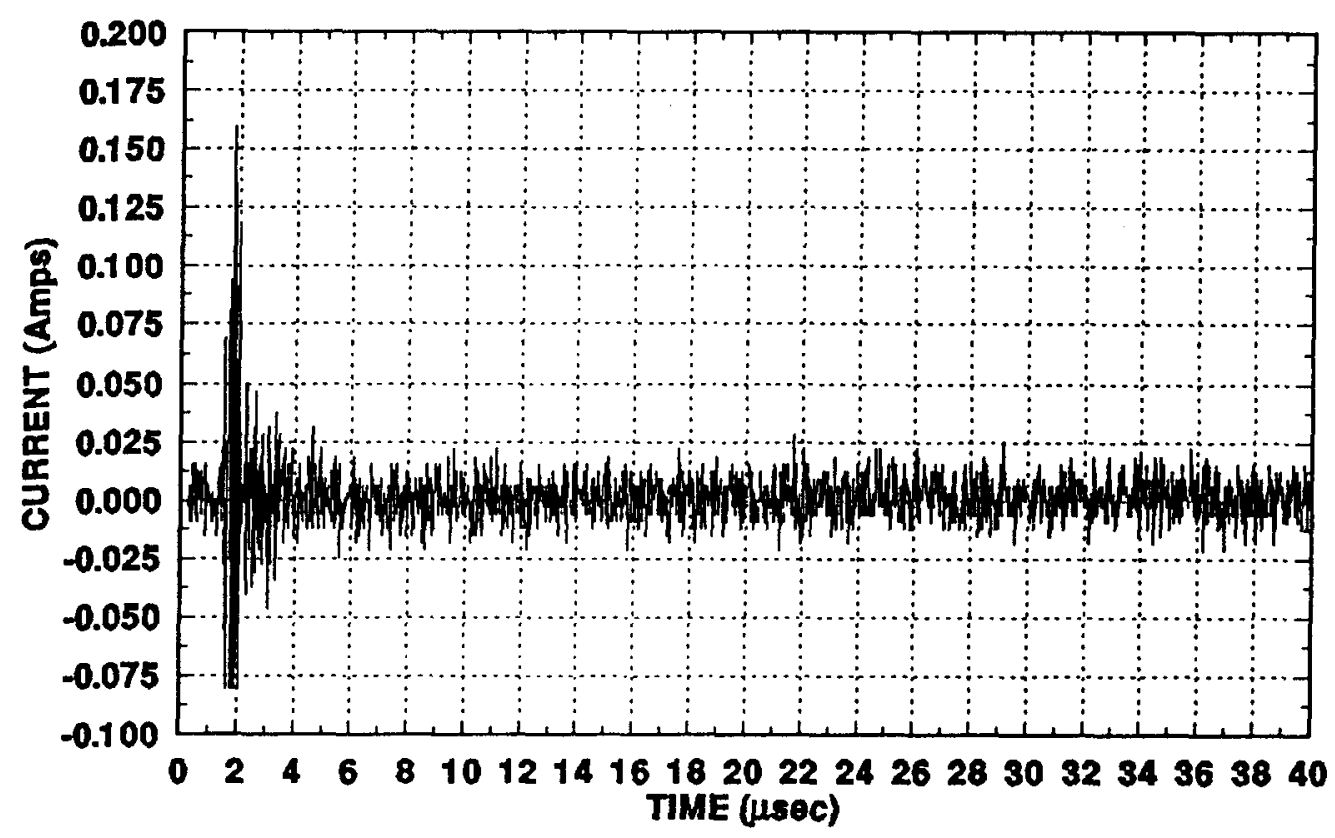

Figure B-8. Response of Lower CVT with FOL Gain of $\mathbf{x 1 0 0}$ 


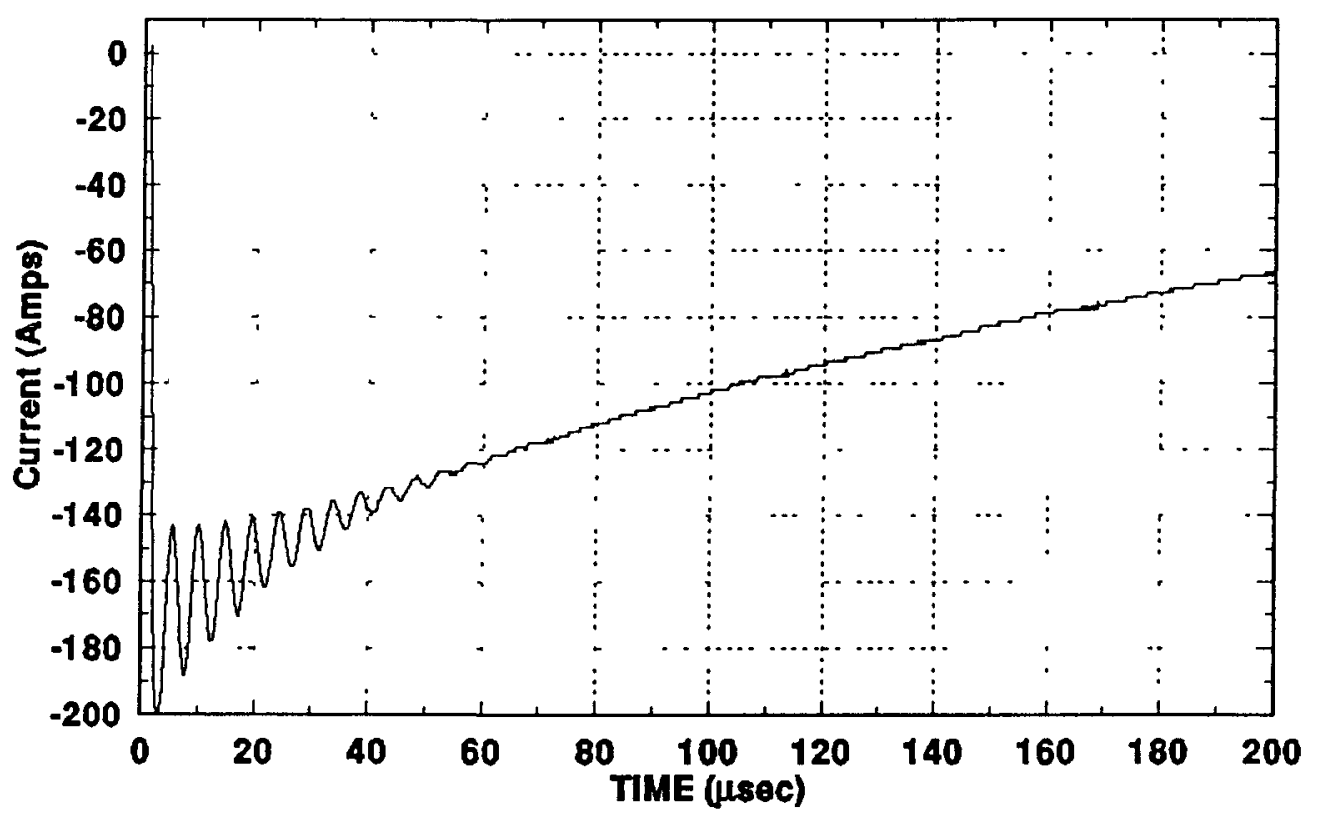

Figure B-9. Applied Test Current, Shot 1926

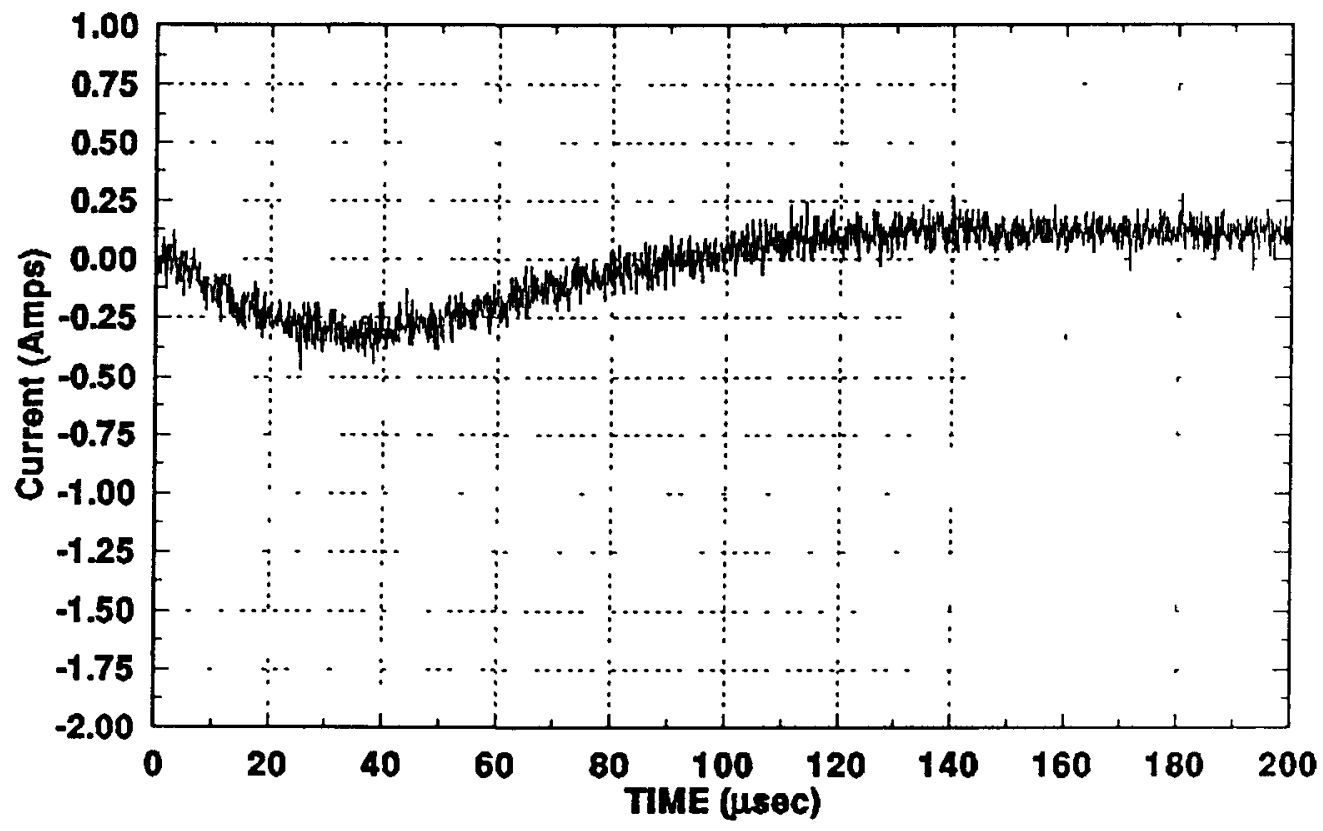

Figure B-10. Response of Upper CVT, Shot 1926 


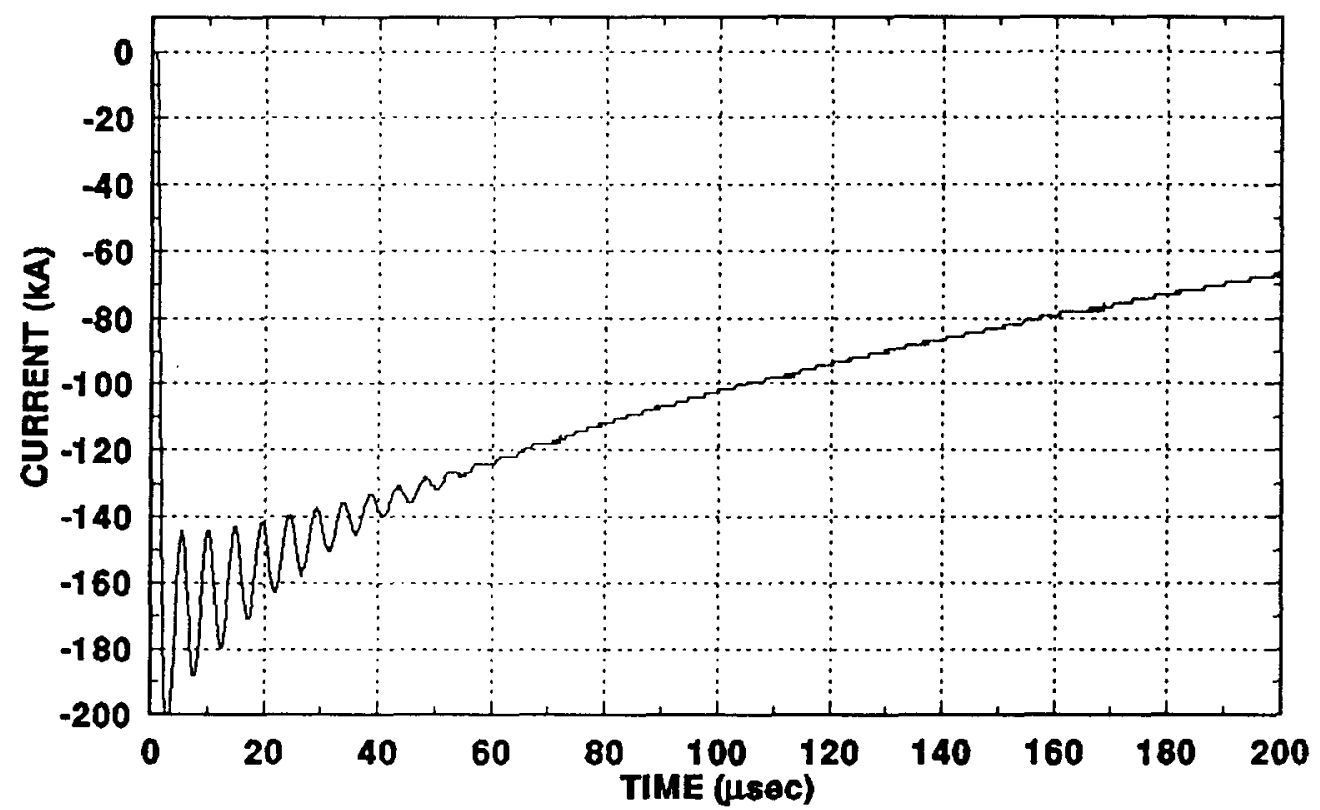

Figure B-11. Applied Test Current, Shot 1927

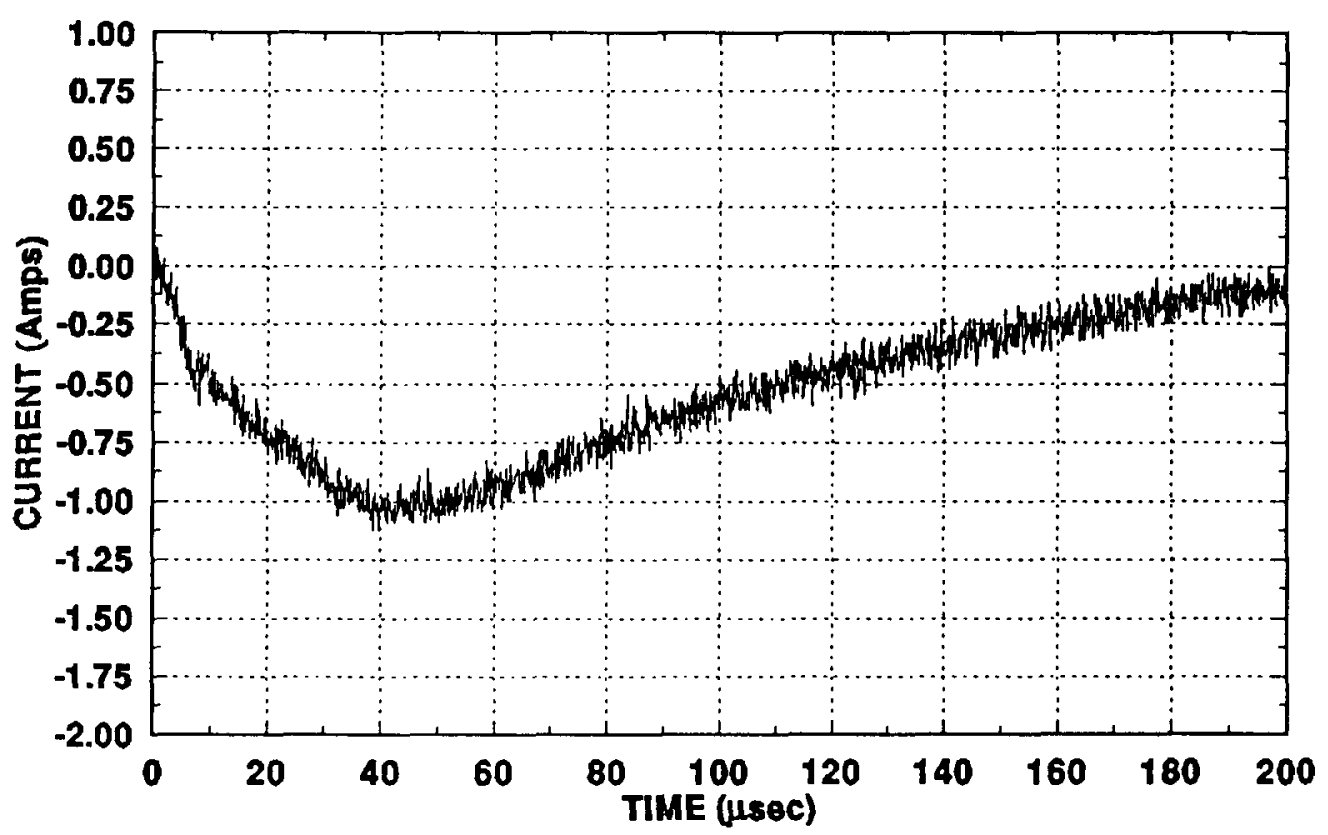

Figure B-12. Response of Upper CVT, Shot 1927 


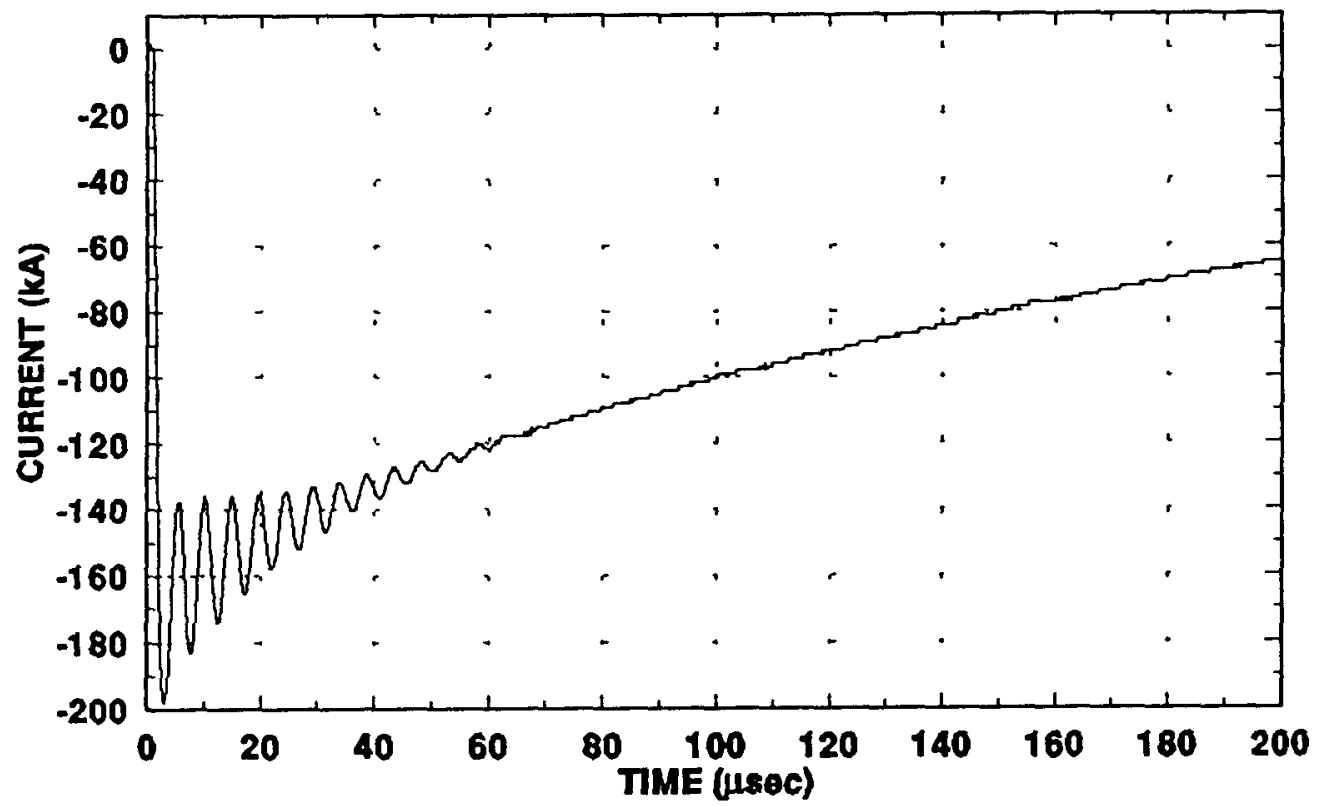

Figure B-13. Applied Test Current, Shot 1929

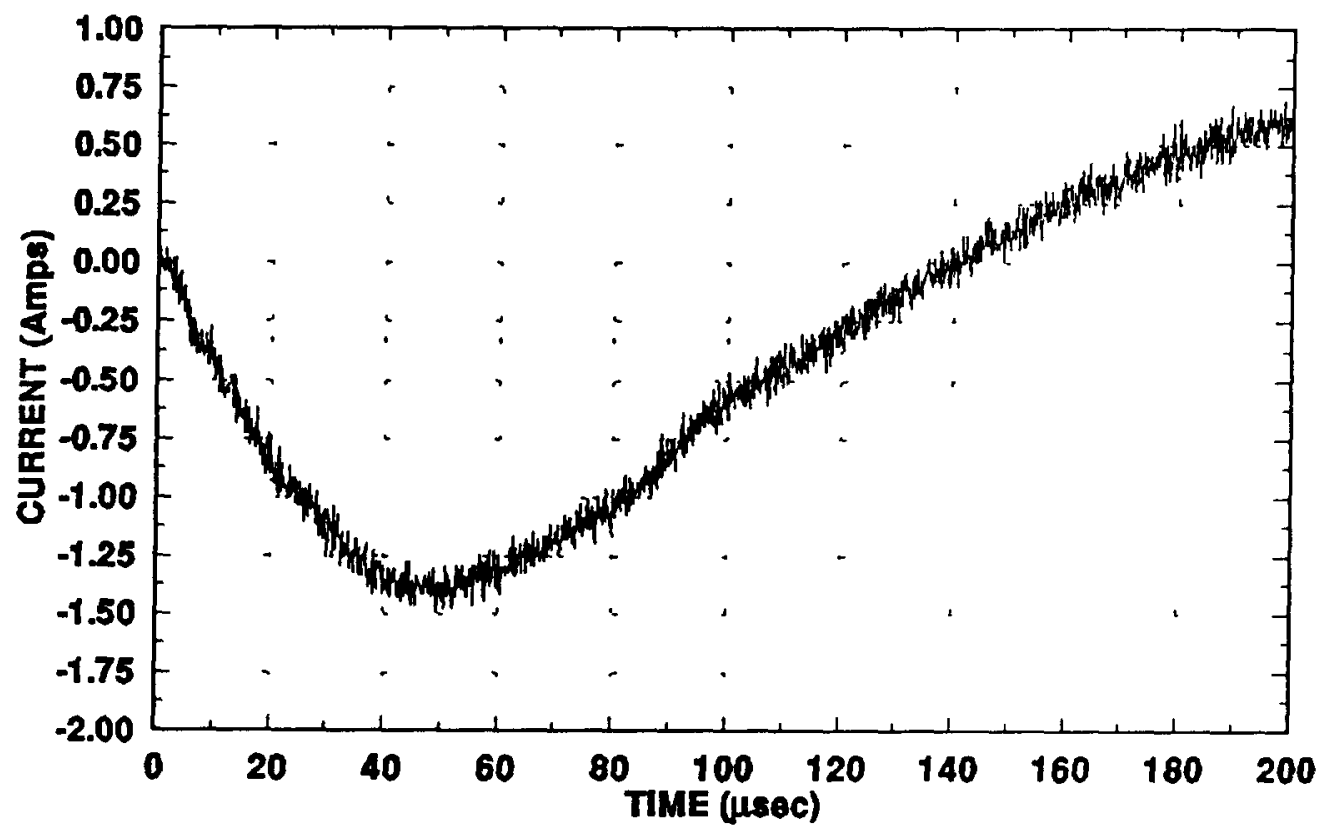

Figure B-14. CVT Noise, Shot 1929. Barrier Penetration Sealed with Copper Tape Across the Inside of the Plate 


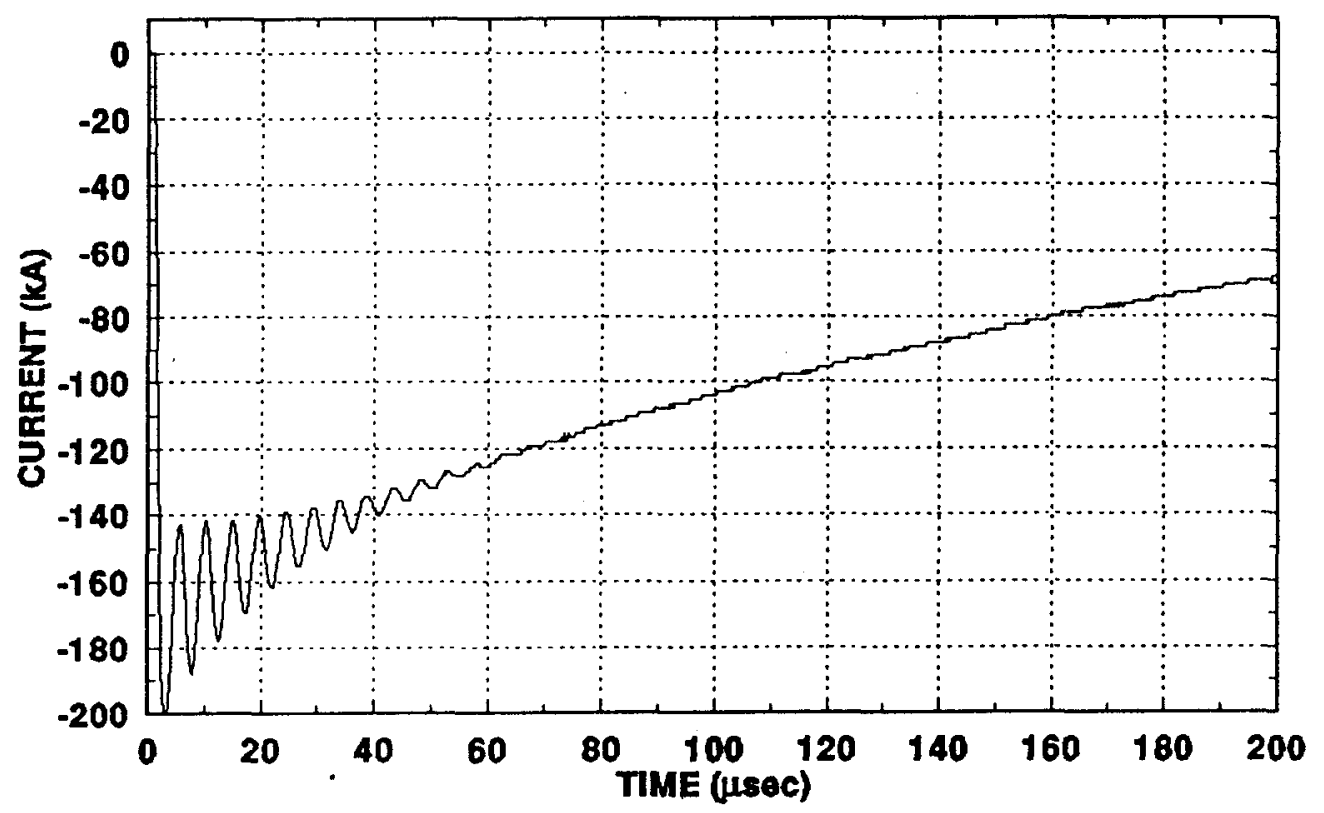

Figure B-15. Applied Test Current, Shot 1930

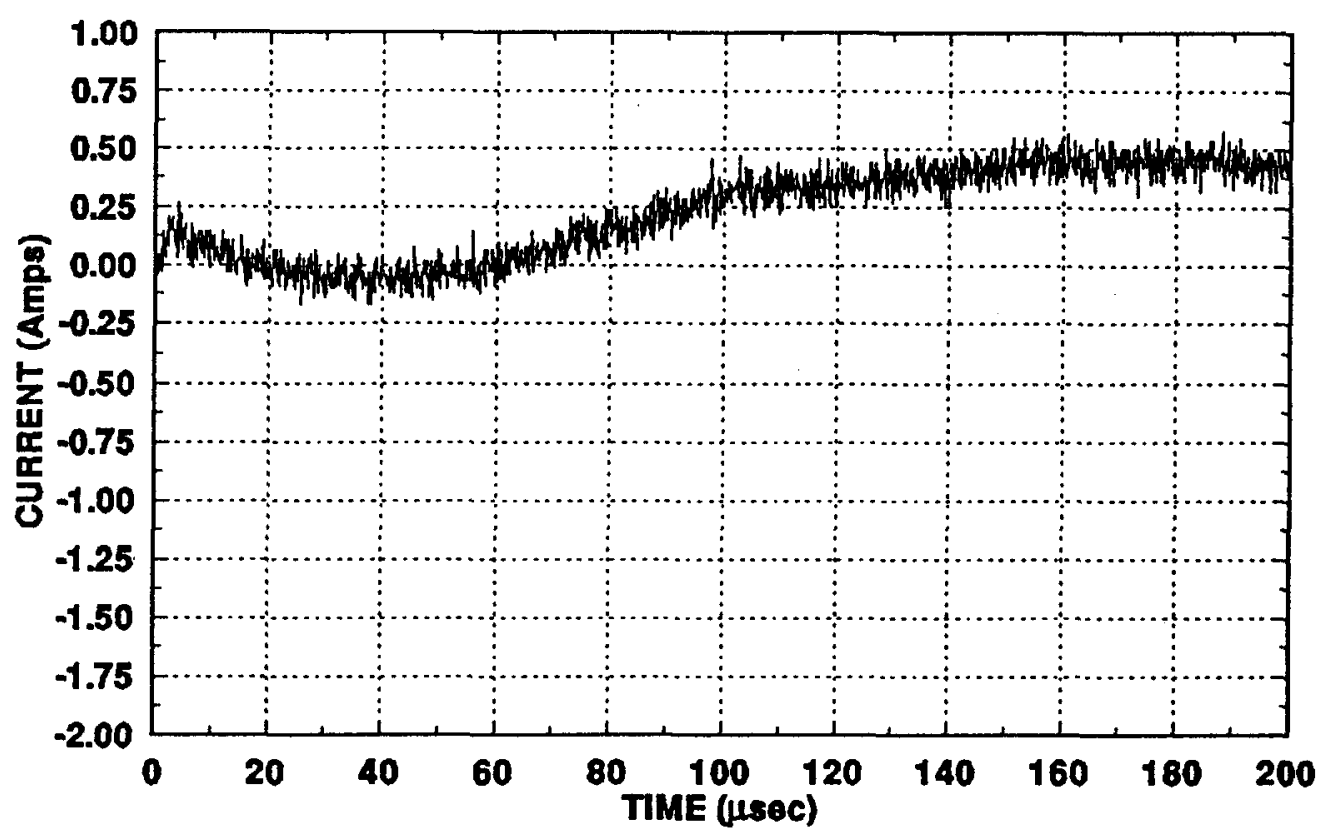

Figure B-16. CVT Noise, Shot 1930. Barrier Penetration Sealed with Copper Tape Across the Inside of the Plate 


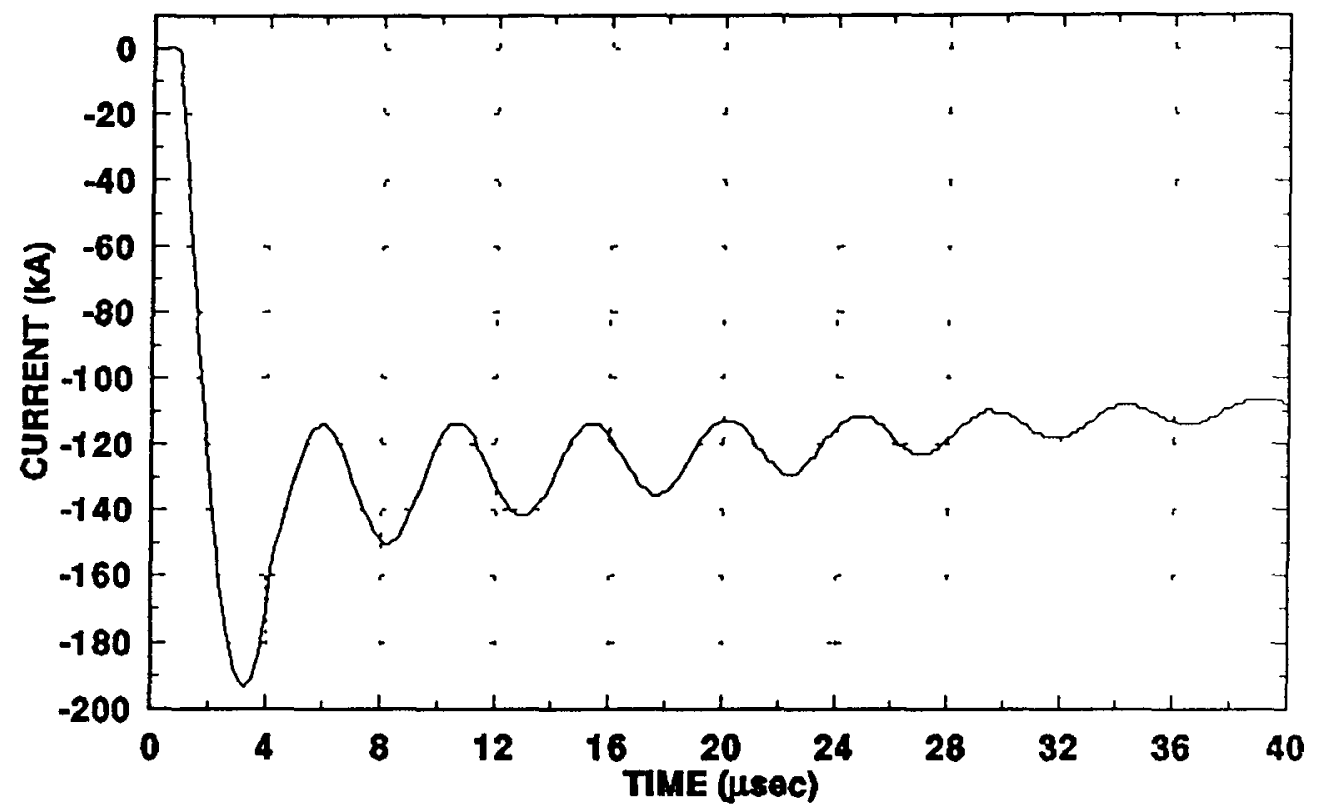

Figure B-17. Applied Test Current, Shot 2027

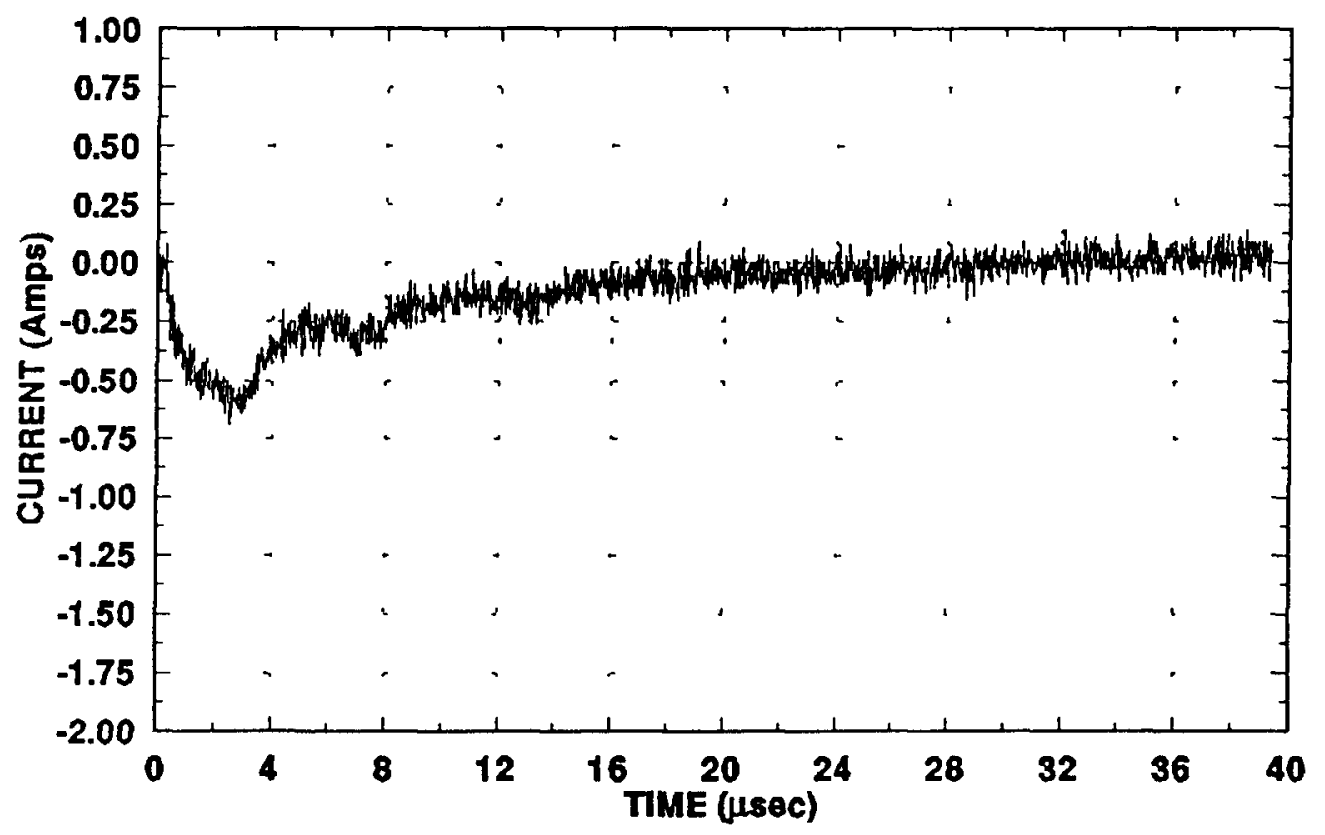

Figure B-18. Response of Upper CVT, Shot 2027. Repeat of 1926, 27. 


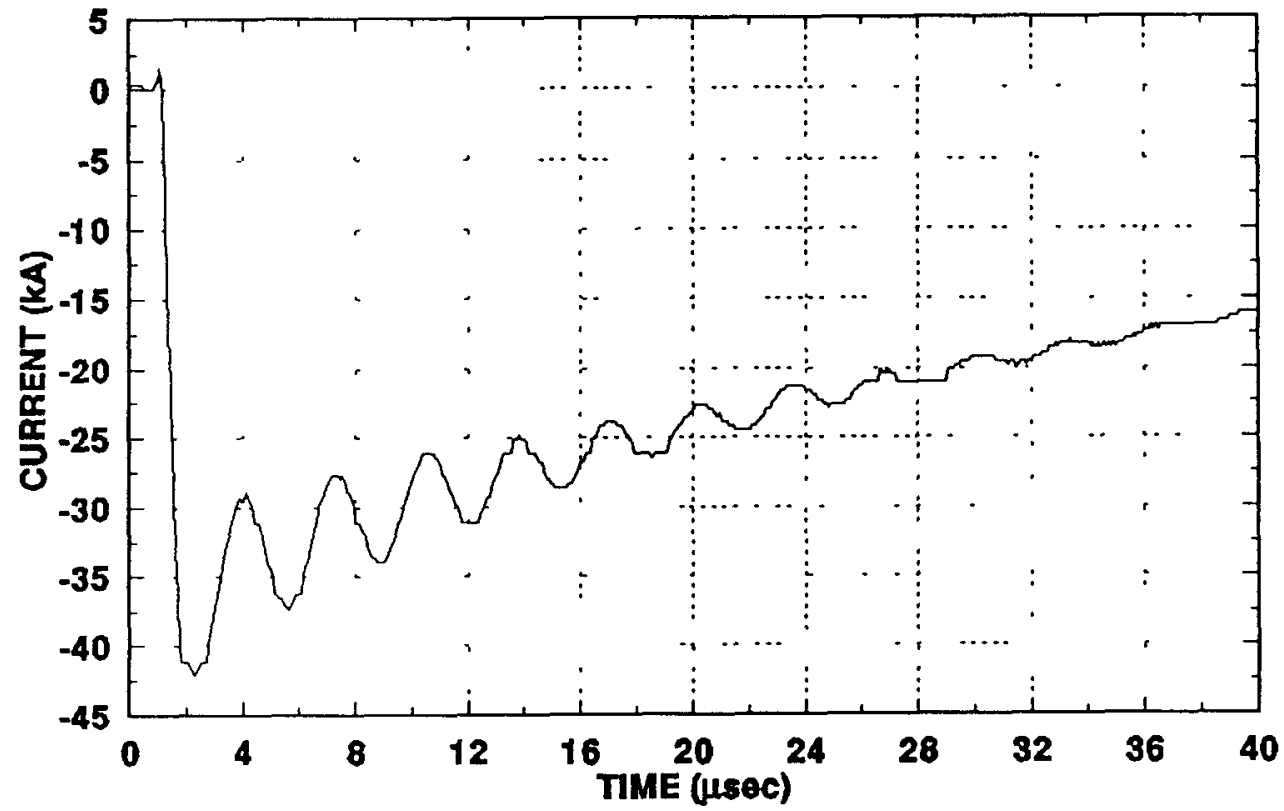

Figure B-19. Applied Test Current, Shot 2033, Stroke 1

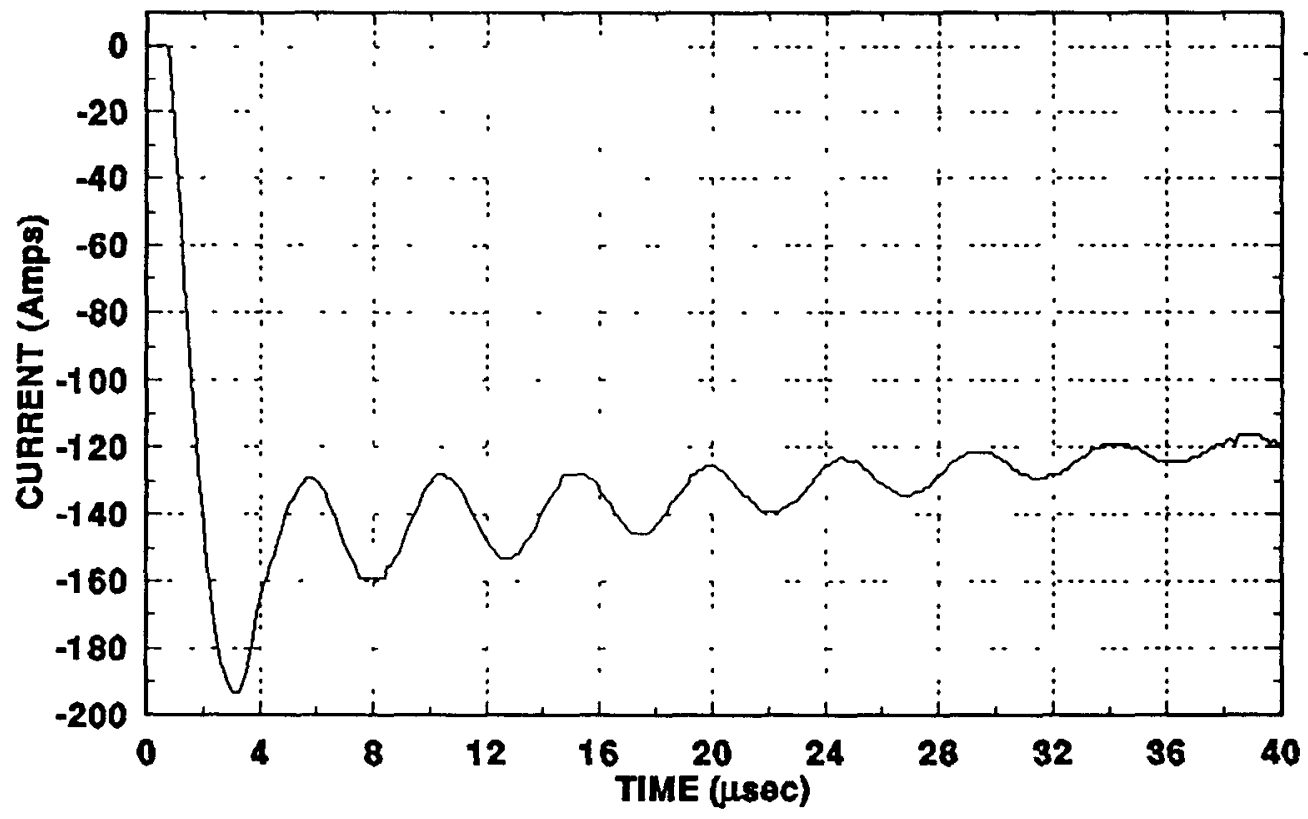

Figure B-20. Applied Test Current, Shot 2033, Stroke 2 


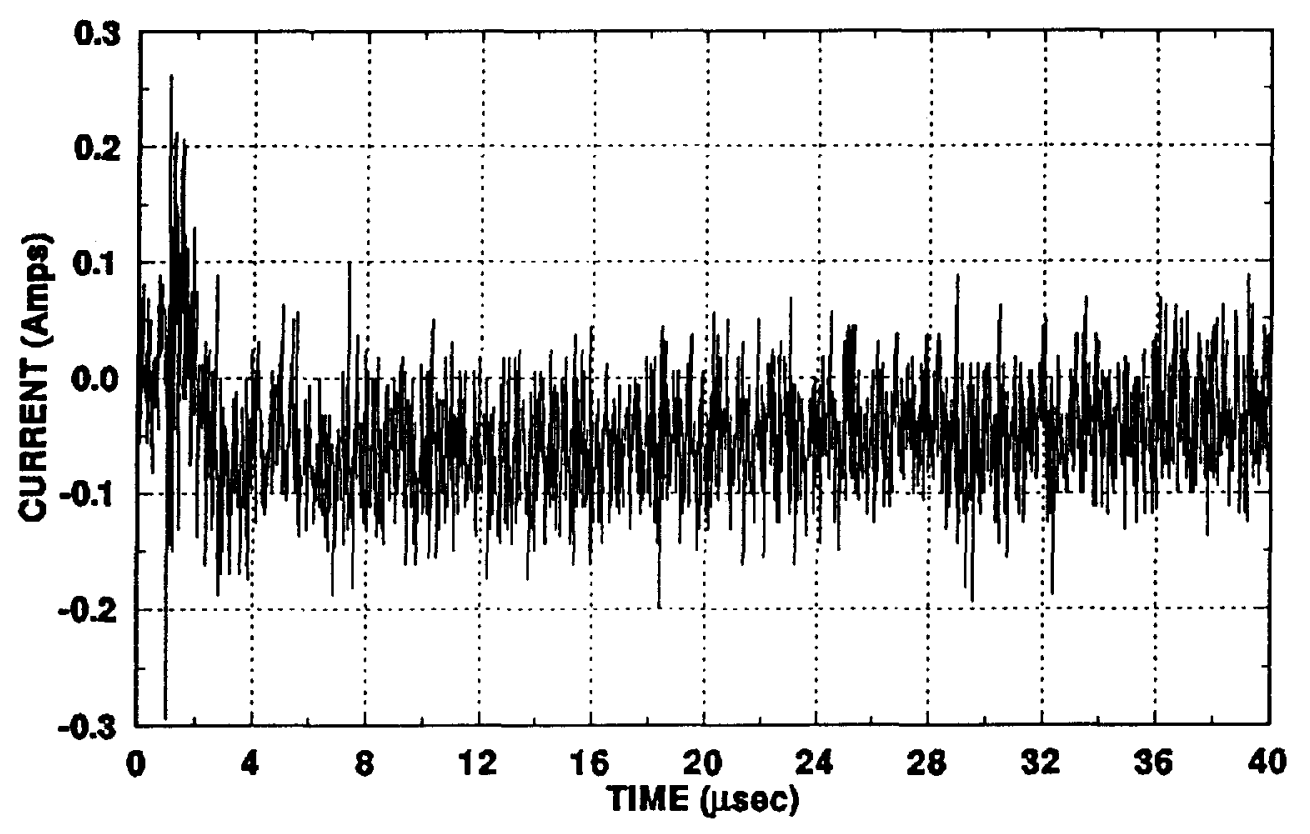

Figure B-21. Response of Upper CVT, Shot 2033, Stroke 1

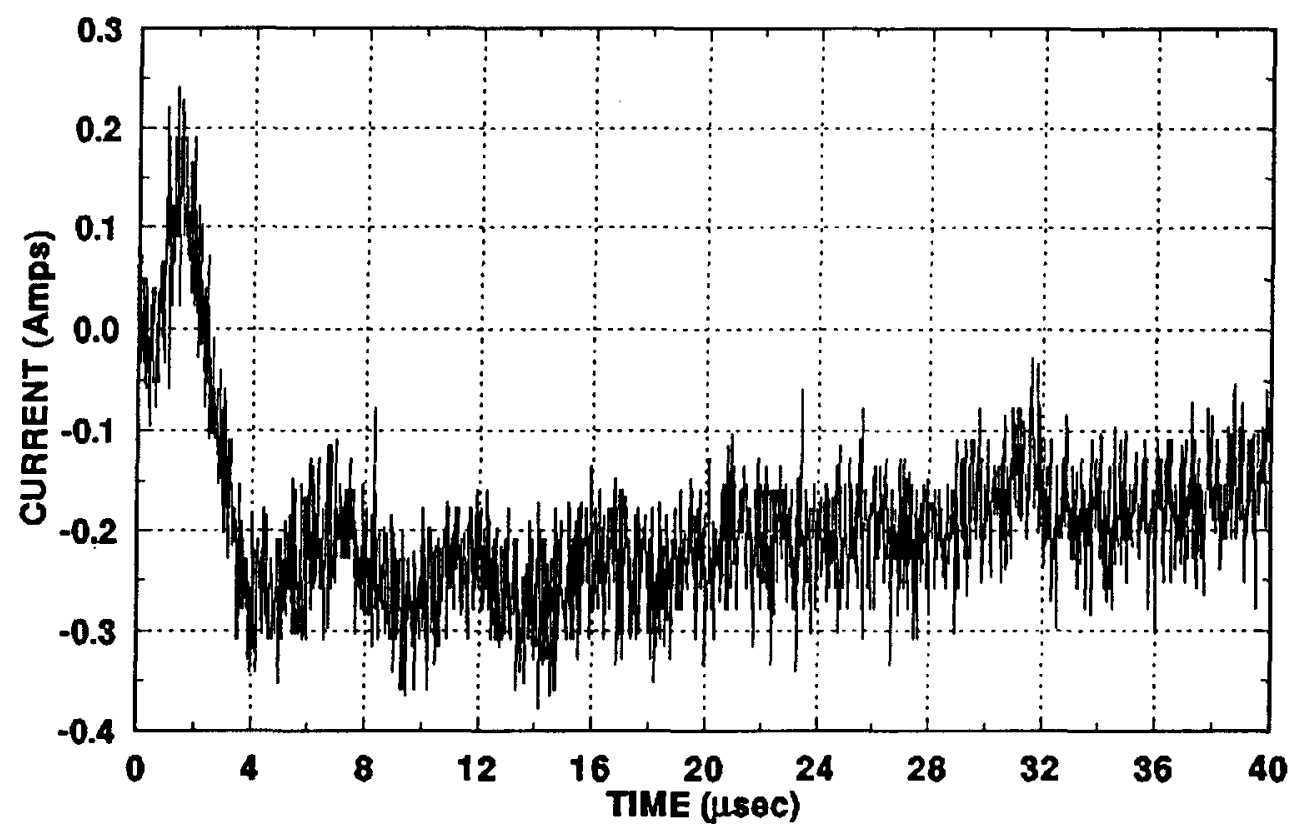

Figure B-22. Response of Upper CVT, Shot 2033, Stroke 2 


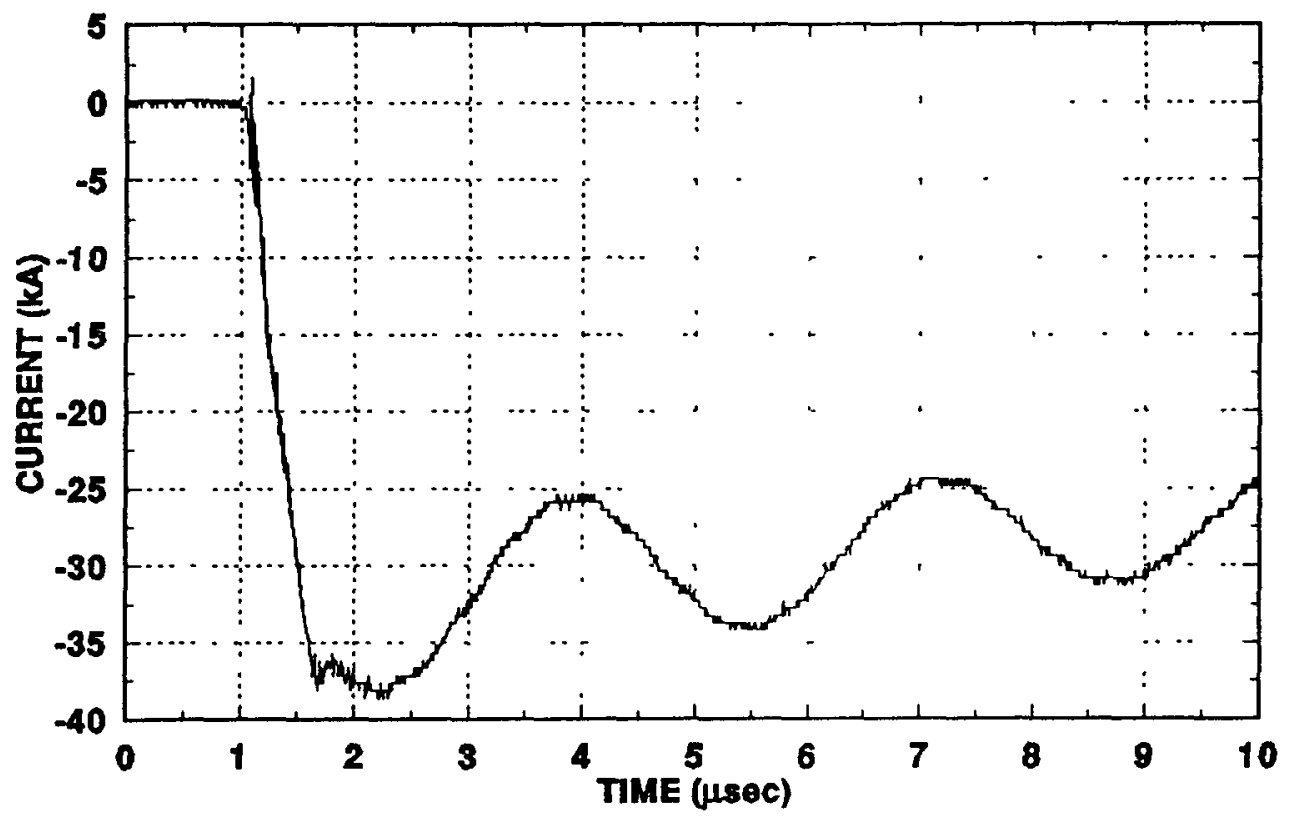

Figure B-23. Applied Test Current, Shot 2049, Stroke 1

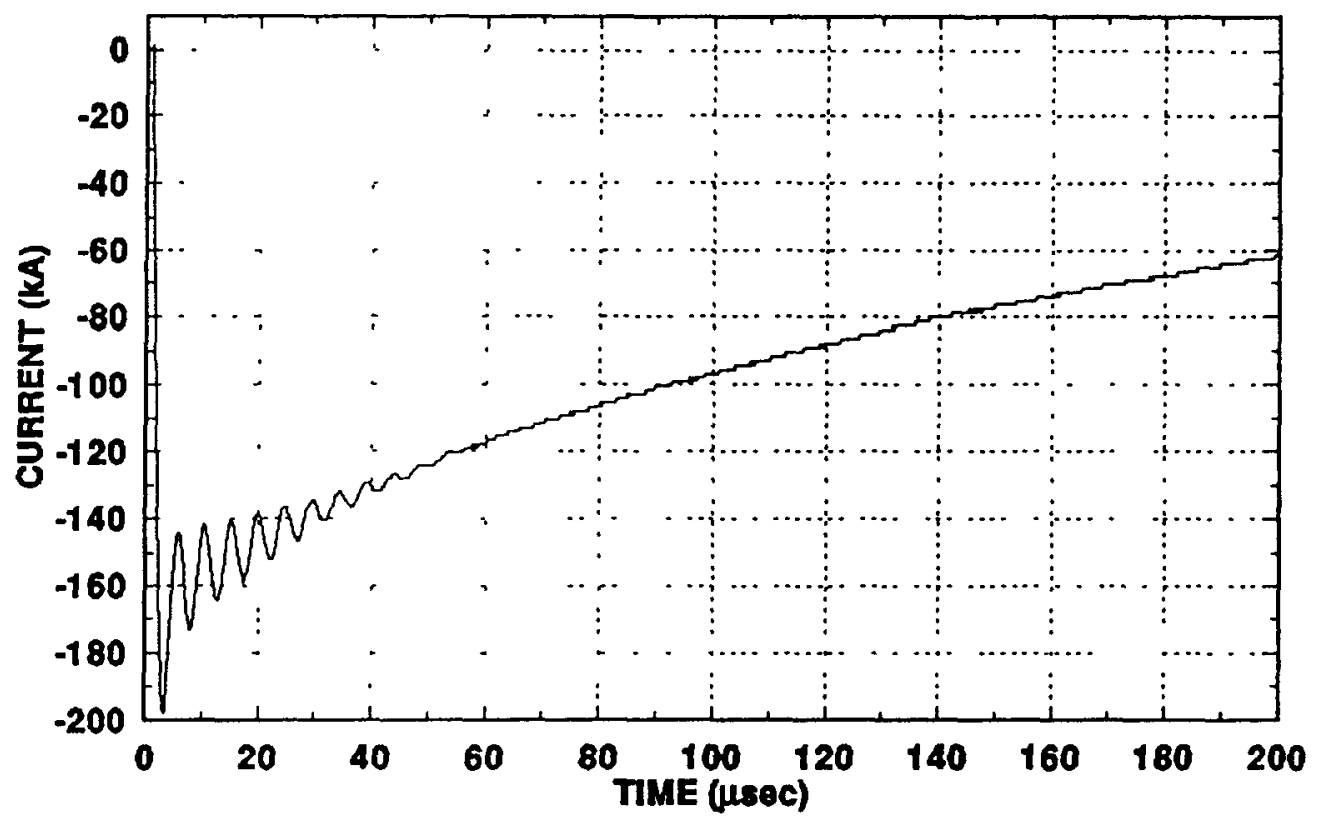

Figure B-24. Applied Test Current, Shot 2049, Stroke 2 


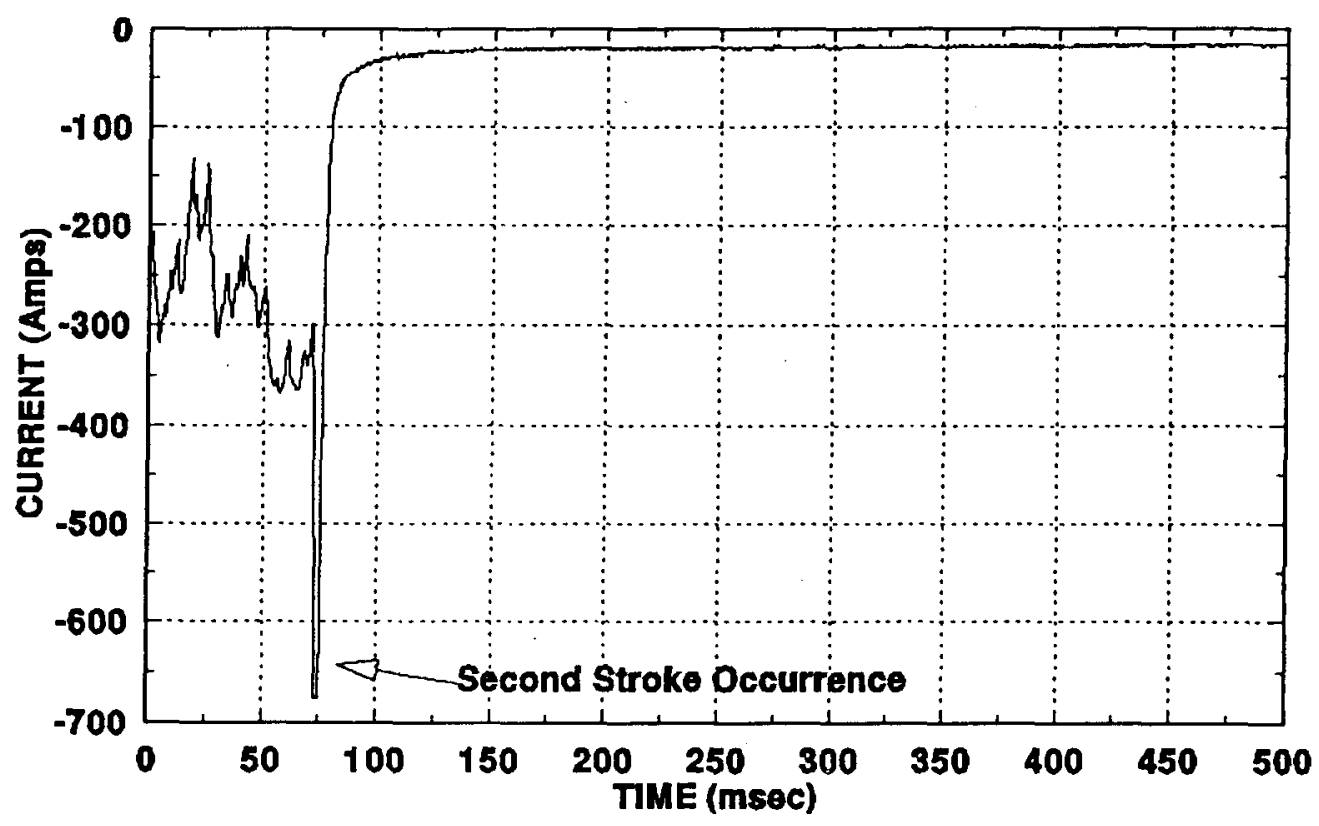

Figure B-25. Applied Continuing Current, Shot 2049

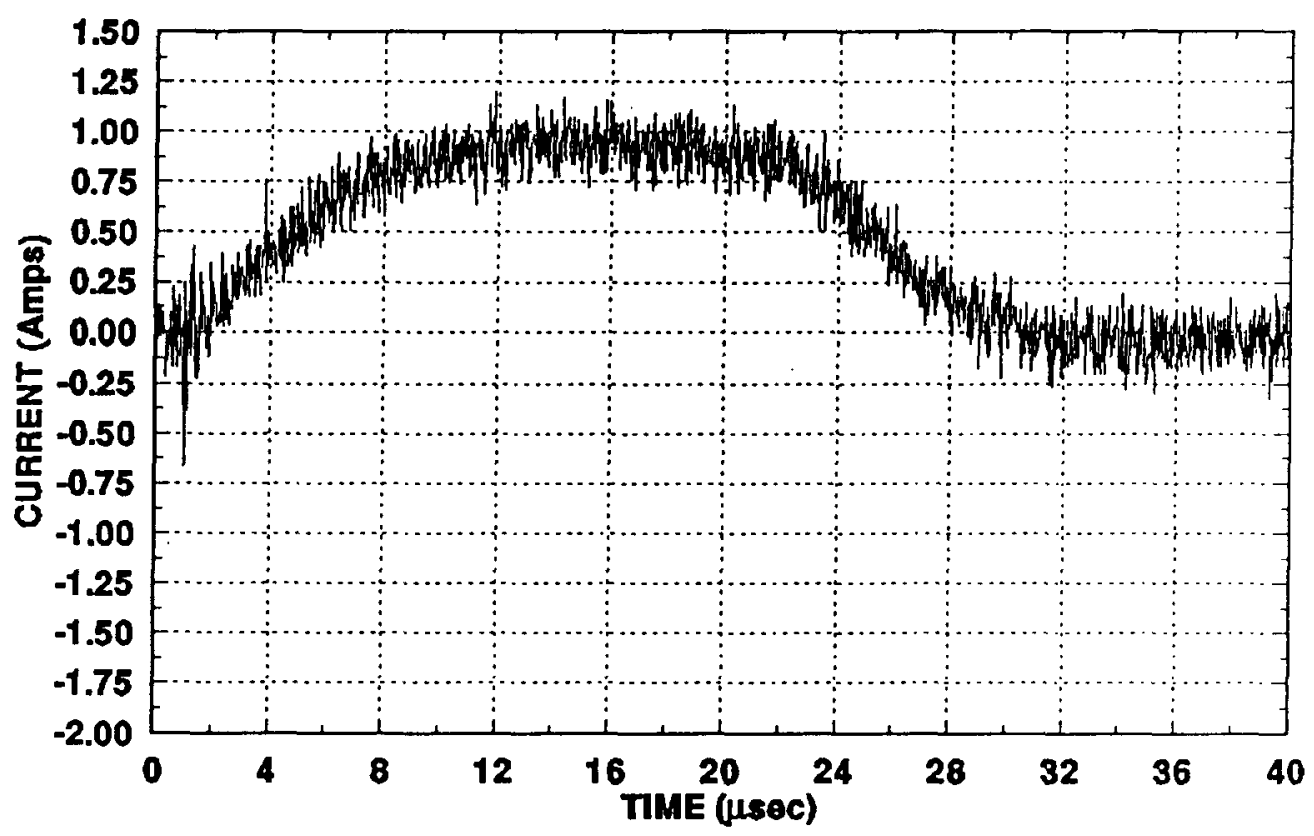

Figure B-26. Response of Upper CVT, Shot 2049, Stroke 1 


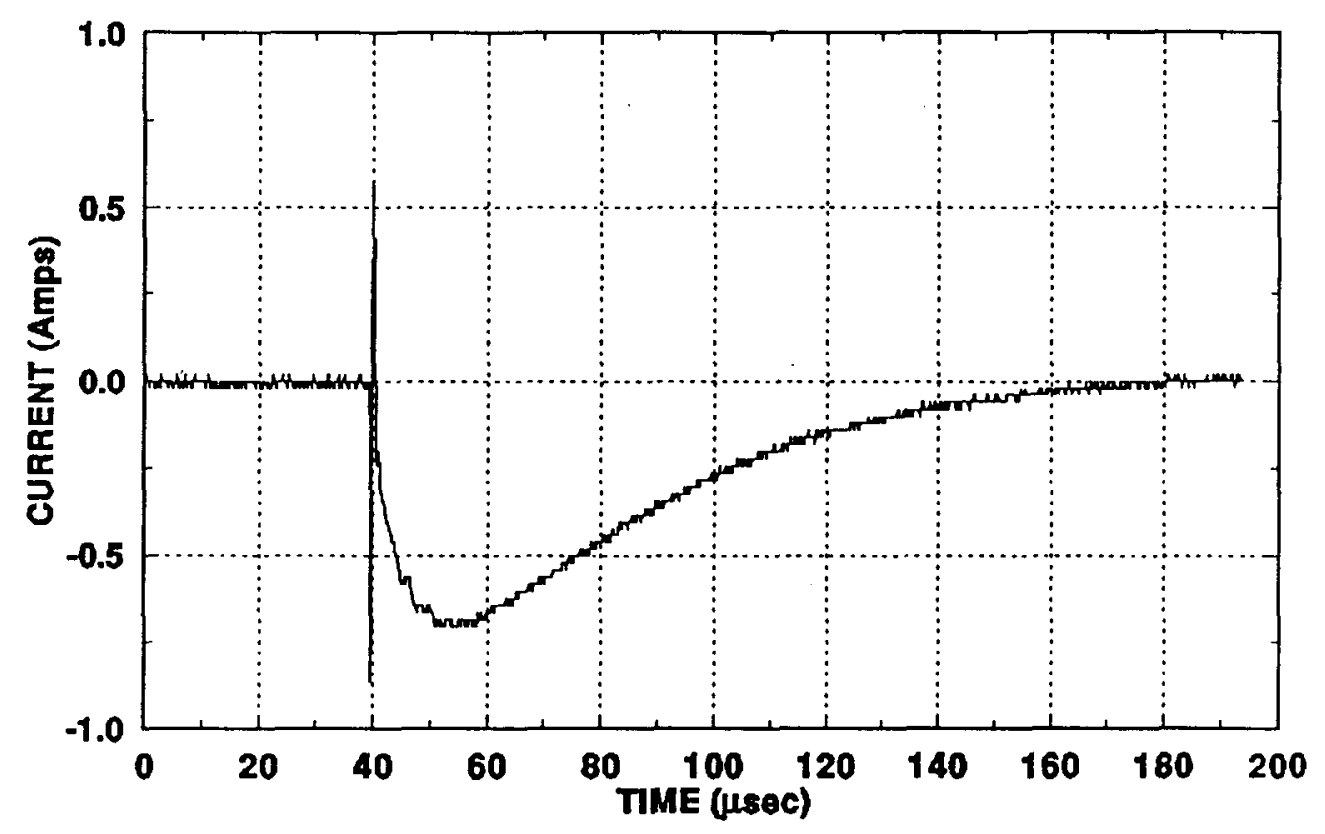

Figure B-27. Response of CVR, Shot 2049, Stroke 1

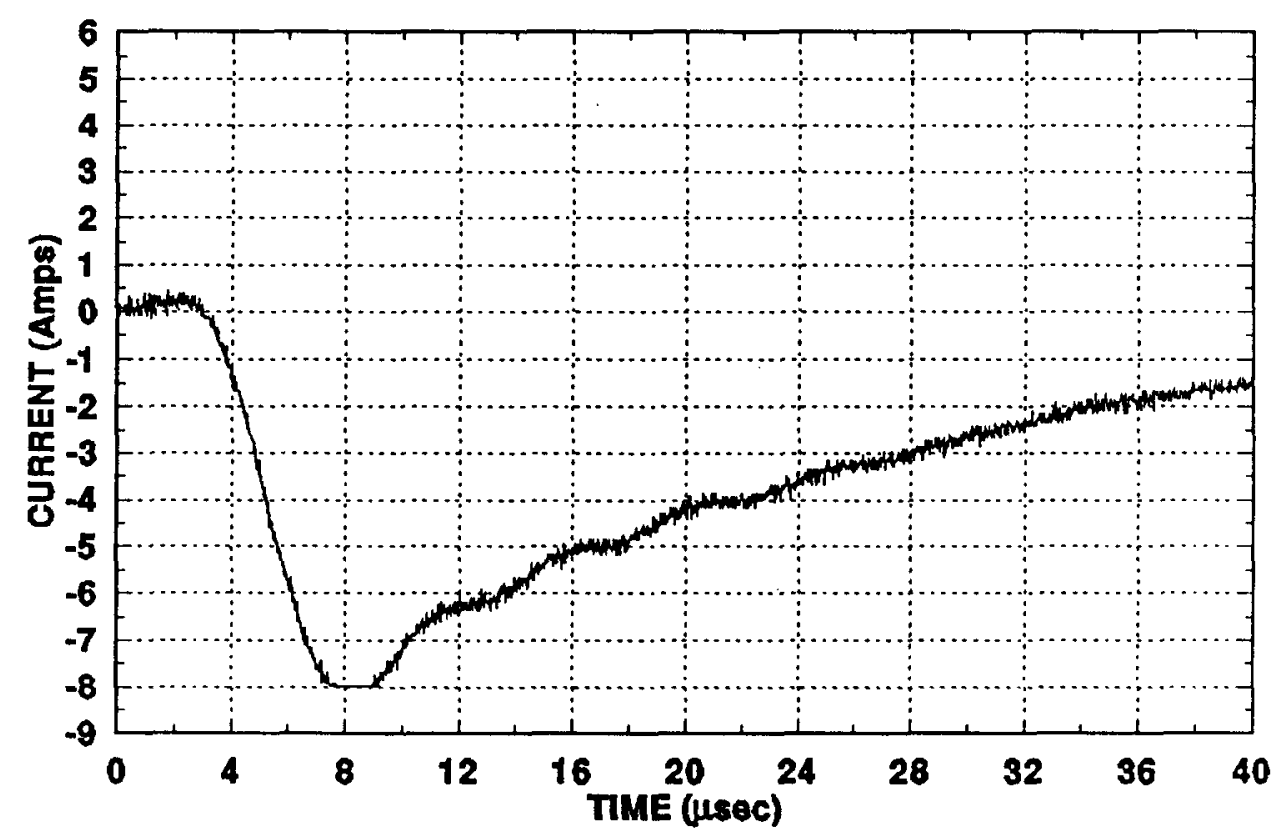

Figure B-28. Response of Upper CVT, Shot 2049, Stroke 2 


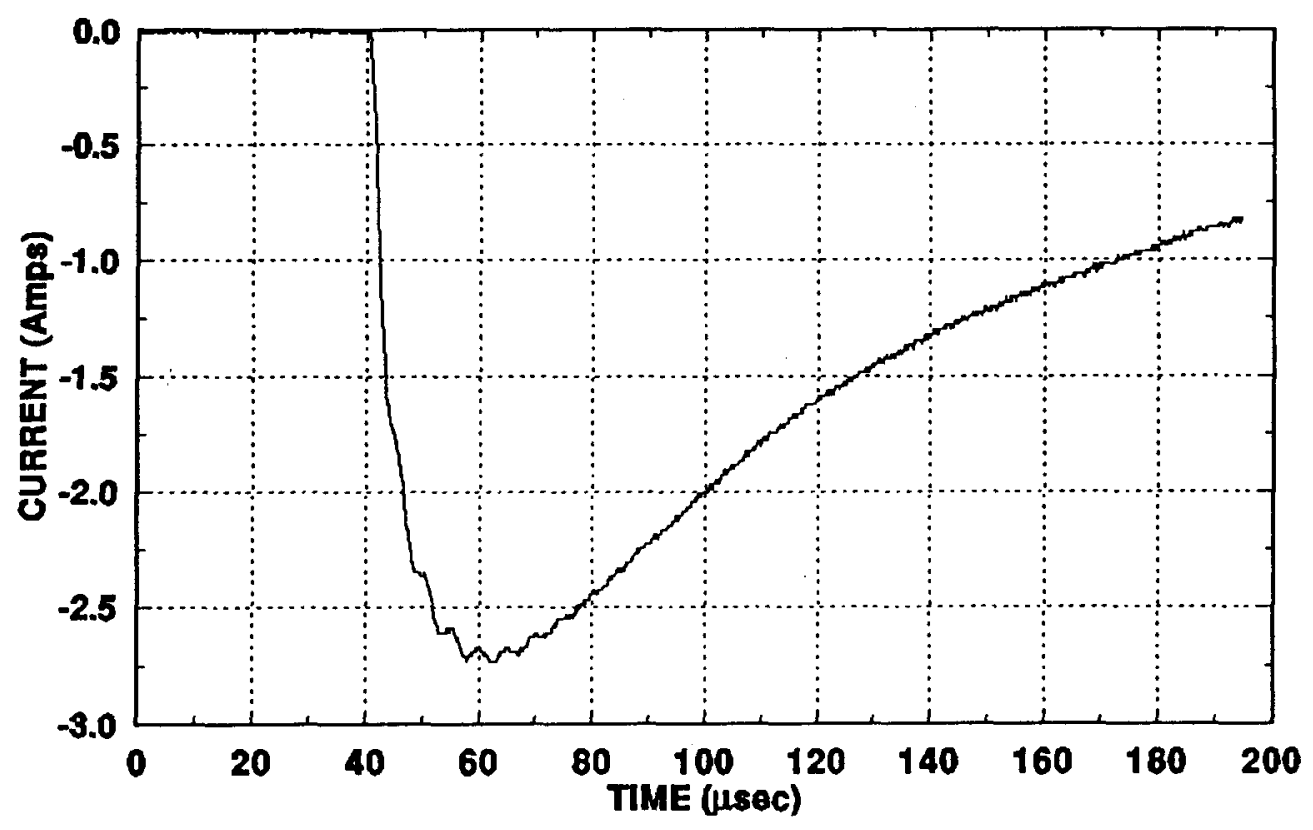

Figure B-29. Response of CVR, Shot 2049, Stroke 2

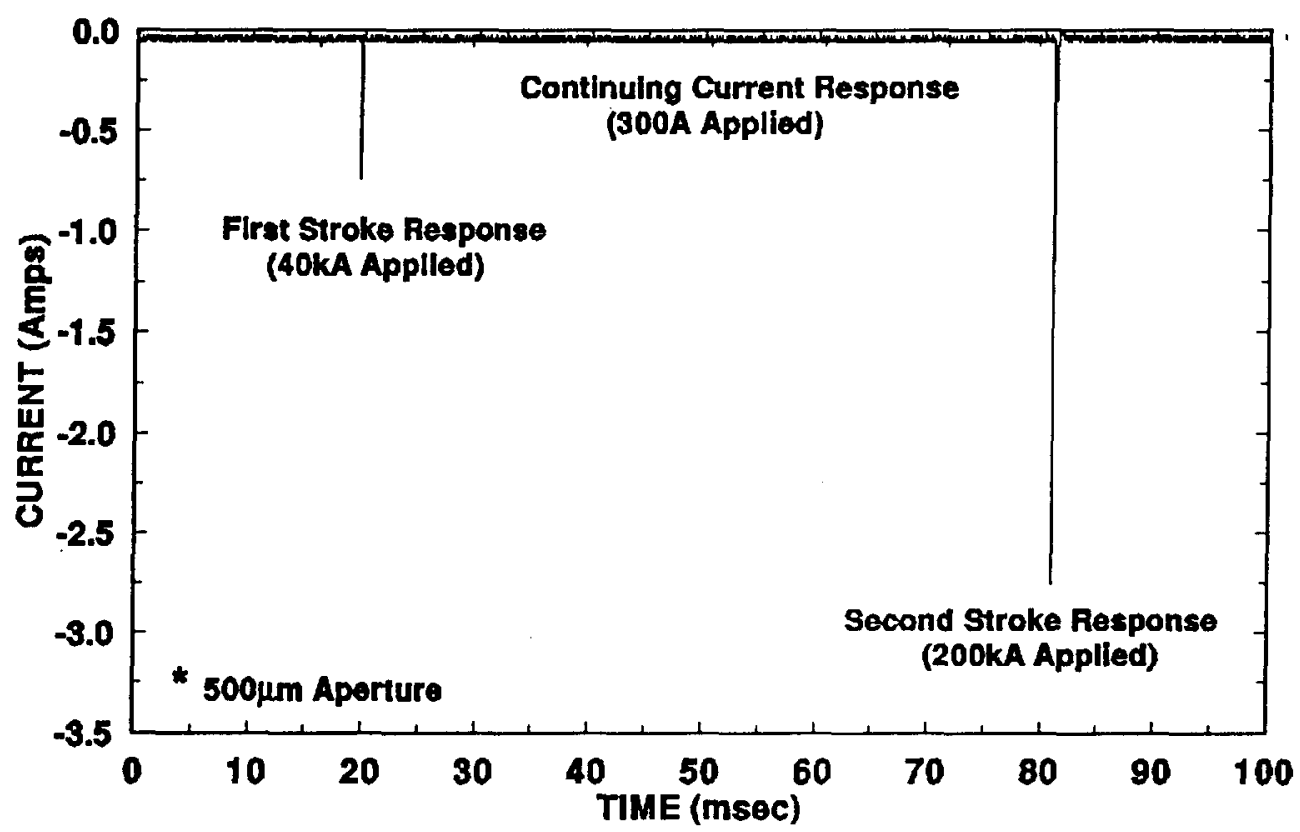

Figure B-30. Full Flash Response of CVR, Shot 2049, 4- $\mu$ s Sampling 


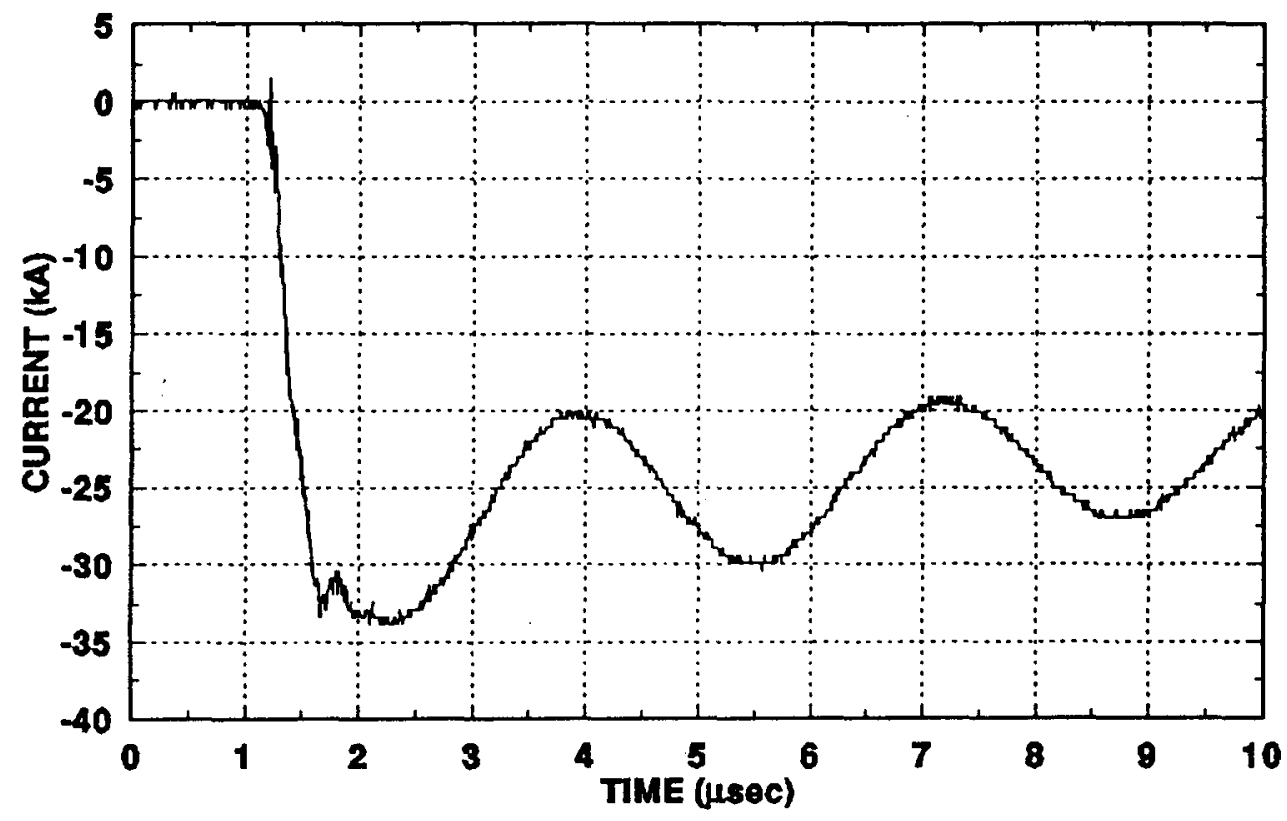

Figure B-31. Applied Test Current, Shot 2050, Stroke 1

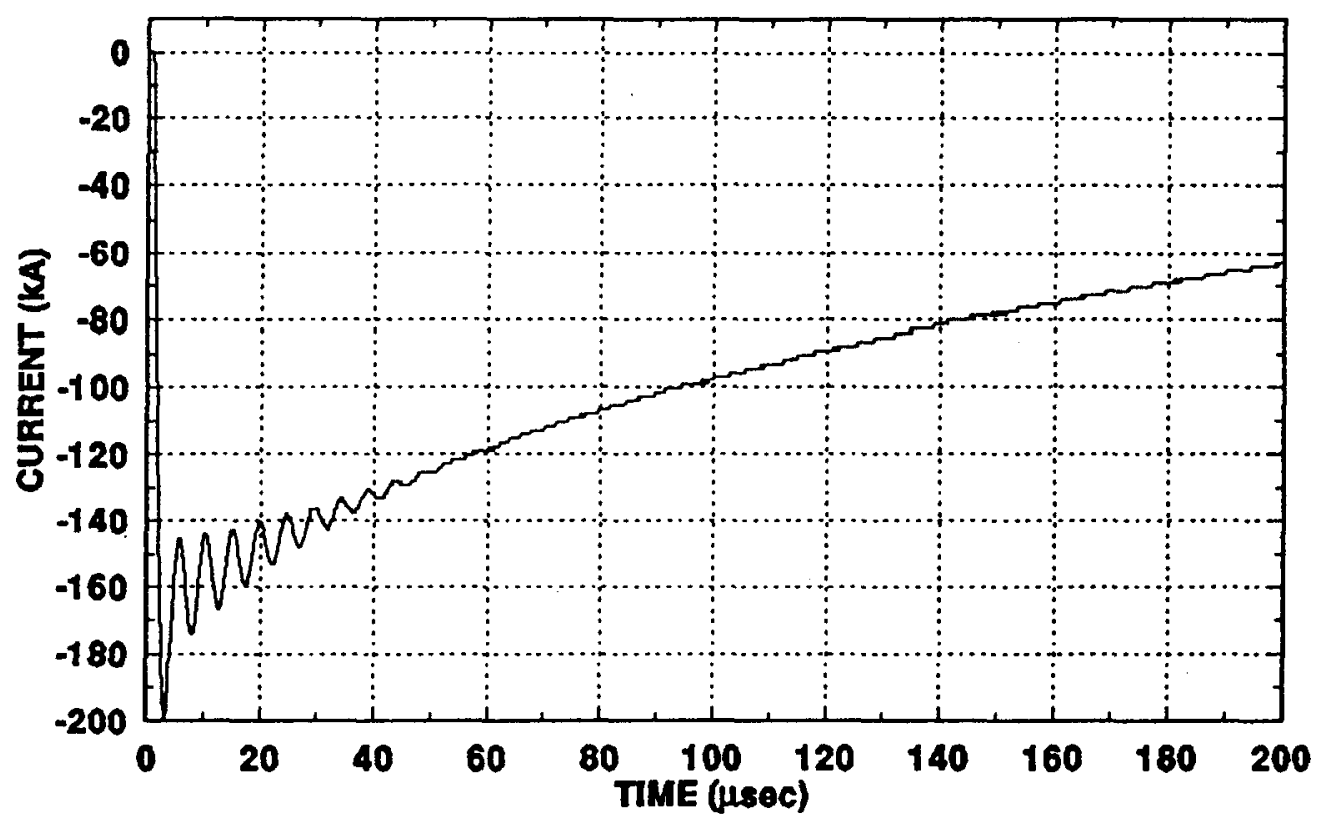

Figure B-32. Applied Test Current, Shot 2050, Stroke 2 


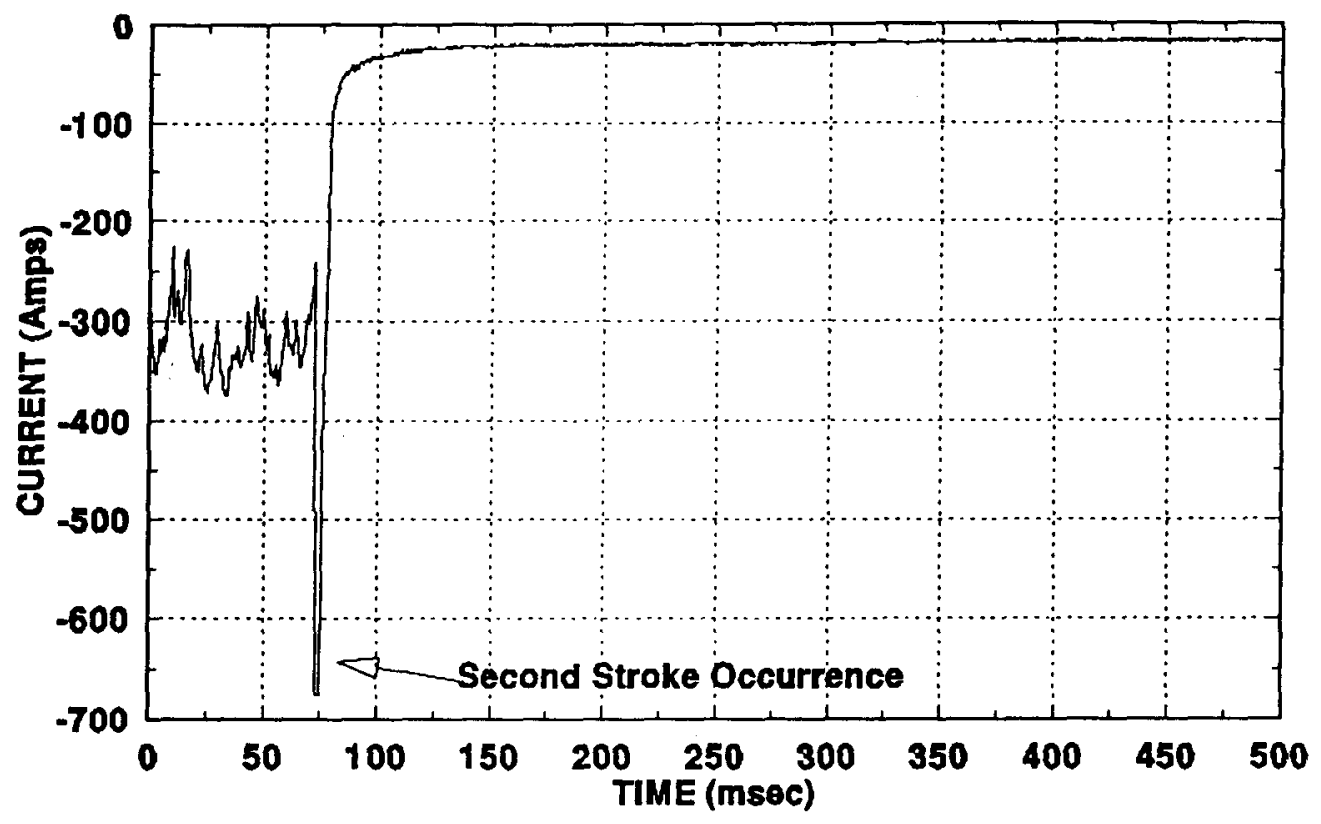

Figure B-33. Applied Continuing Current, Shot 2050

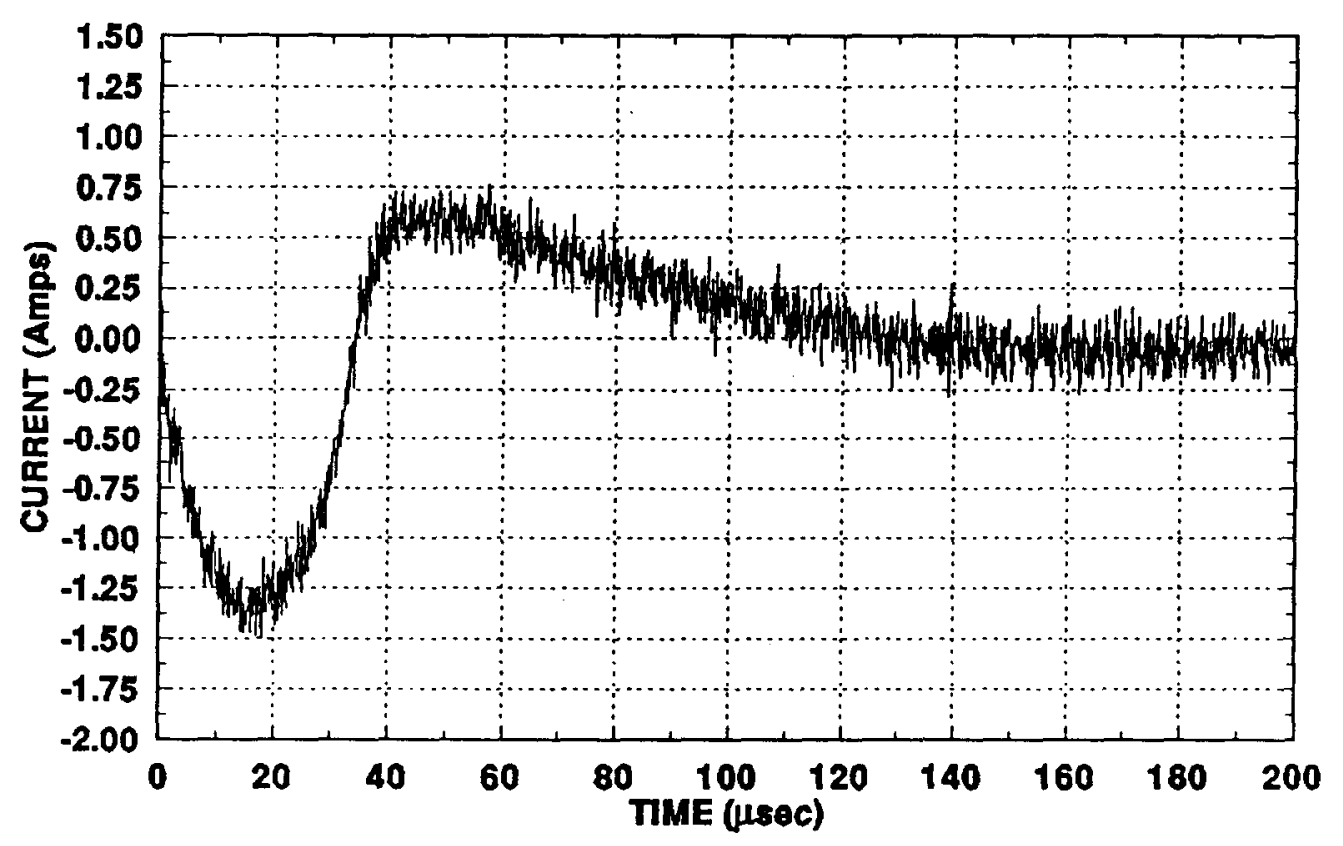

Figure B-34. CVT Noise, Shot 2050, Stroke 1. Penetration Plugged with Solder. 


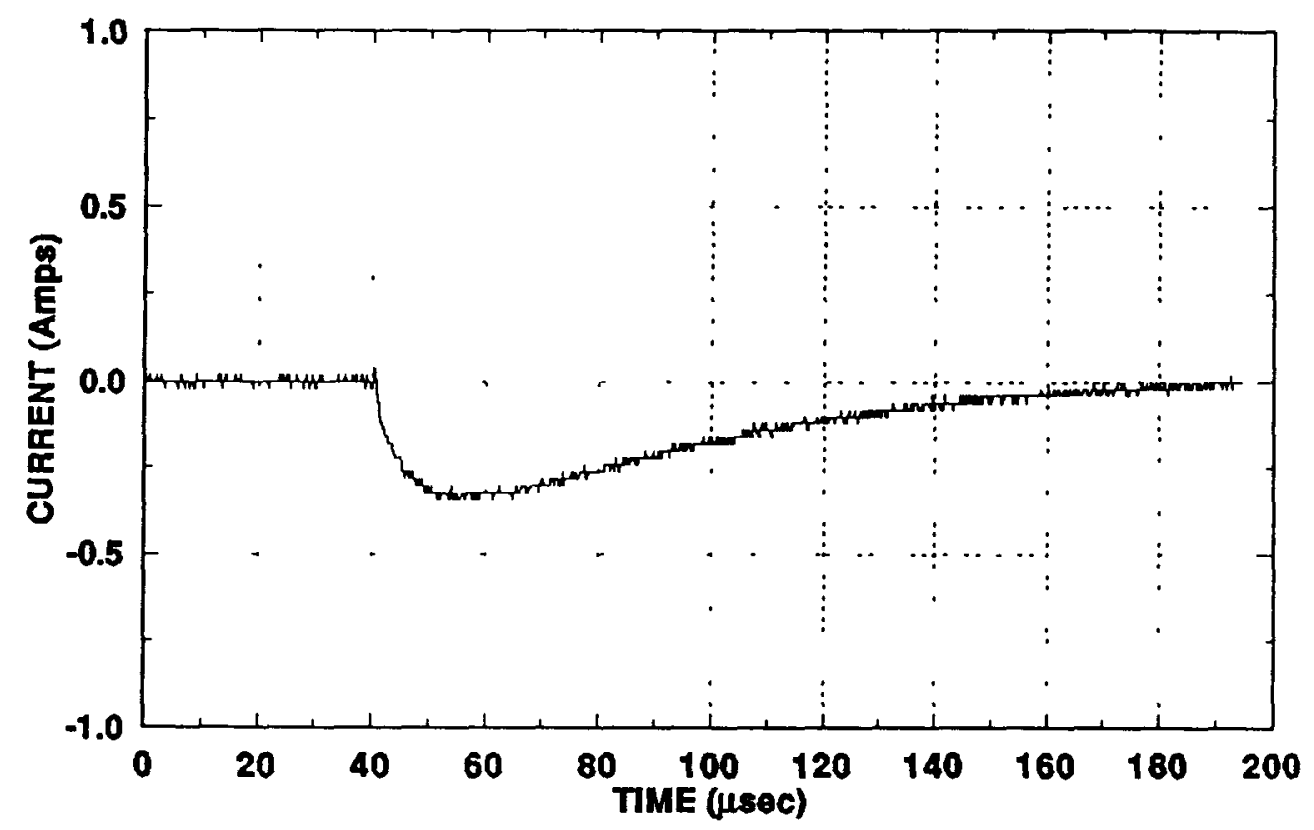

Figure B-35. CVR Noise, Shot 2050, Stroke 1. Penetration Plugged with Solder

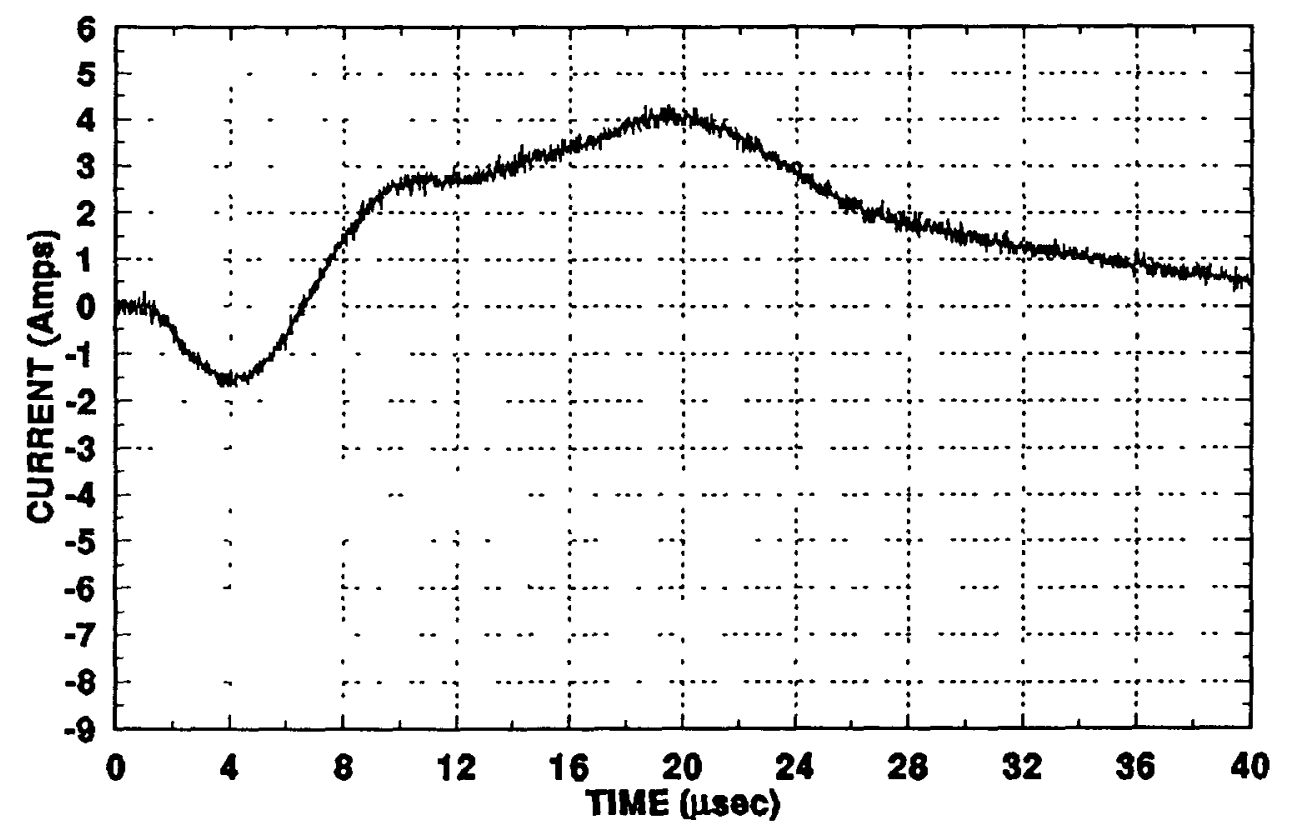

Figure B-36. CVT Noise, Shot 2050, Stroke 2. Penetration Plugged with Solder. 


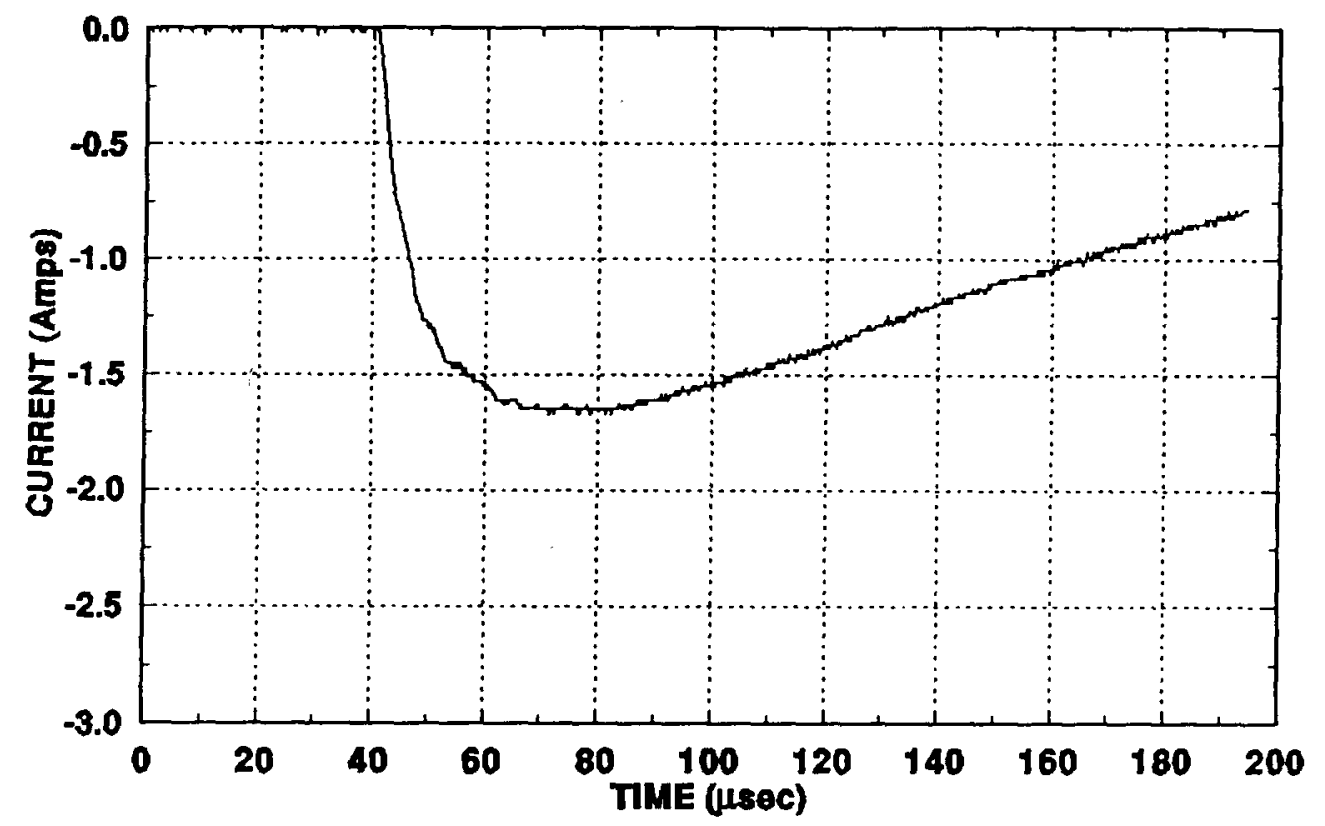

Figure B-37. CVR Noise, Shot 2050, Stroke 2

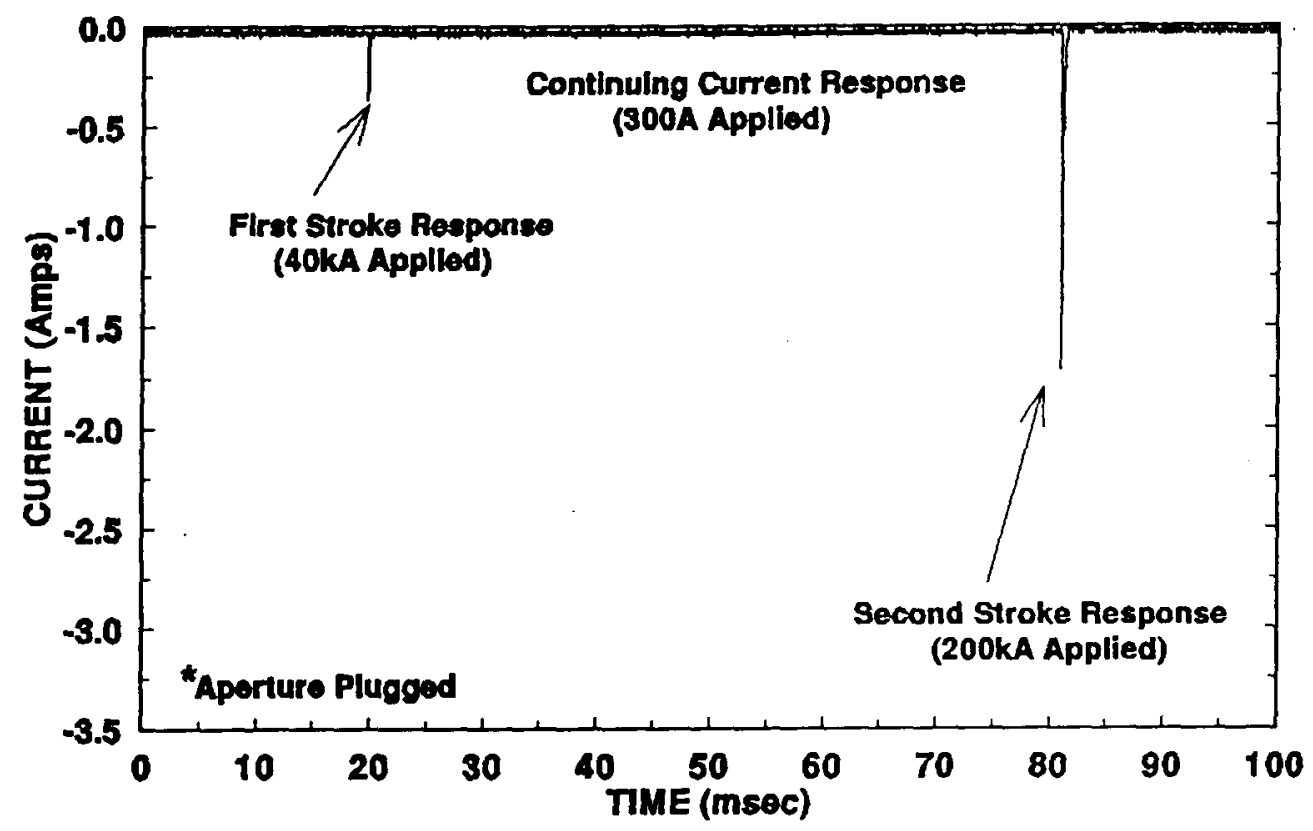

Figure B-38. Full Flash CVR Noise Record, Shot 2050, 4- $\mu$ s Sampling 
(NO DATA FOR STROKE 1)

Figure B-39. Applied Test Current, Shot 2051, Stroke 1

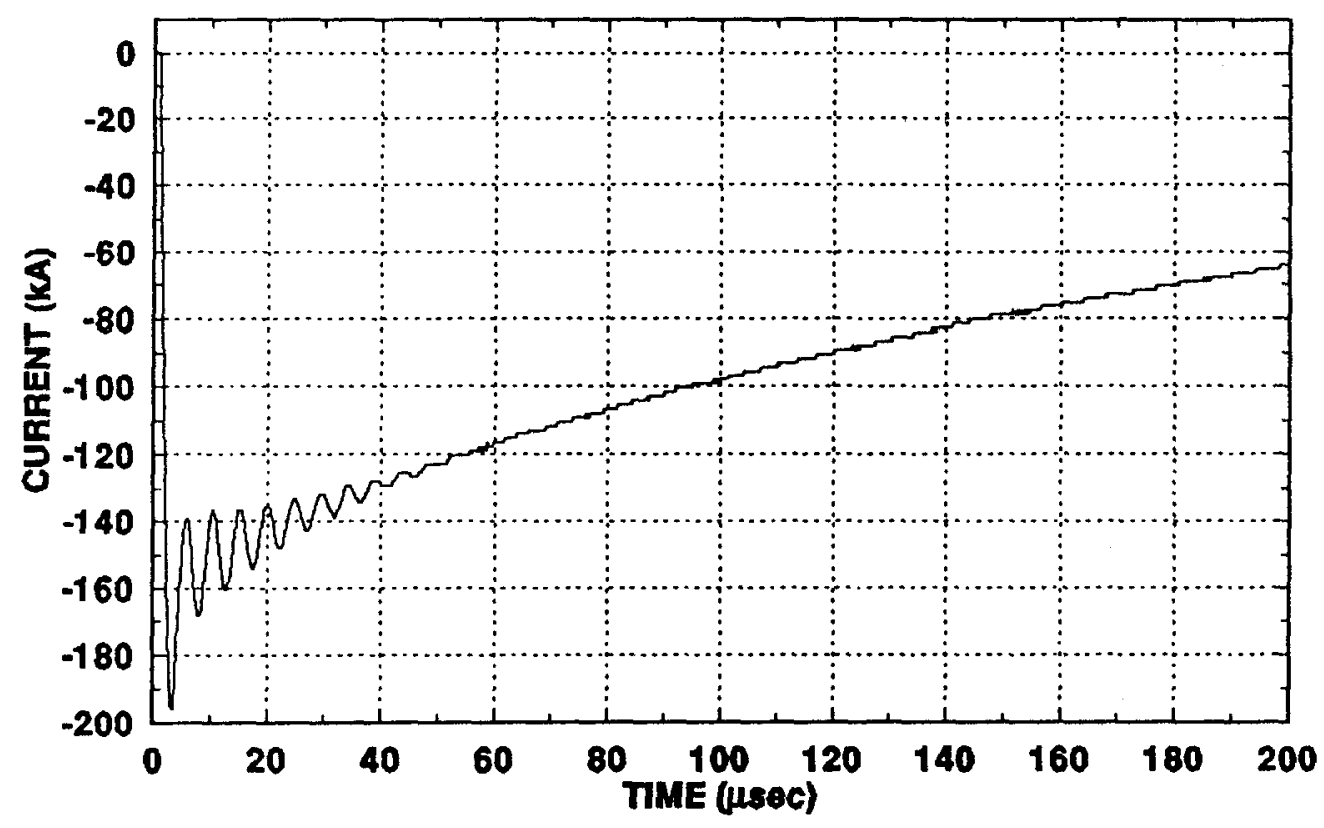

Figure B-40. Applied Current, Shot 2051, Stroke 2 


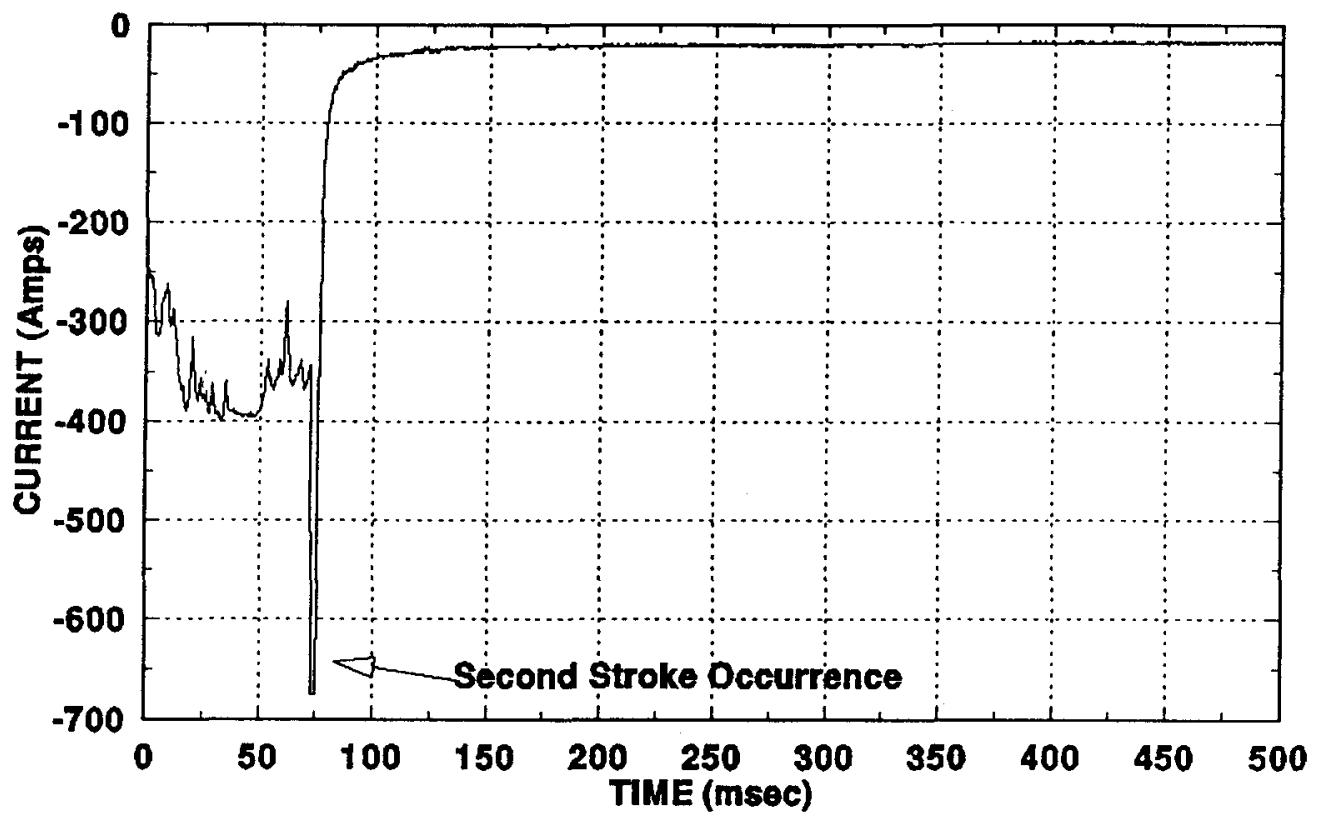

Figure B-41. Applied Continuing Current, Shot 2051

(NO DATA FOR STROKE 1)

Figure B-42. CVT Noise, Shot 2051, Stroke 1. Penetration Plugged with Solder. 
(NO DATA FOR STROKE 1)

Figure B-43. CVR Noise, Shot 2051, Stroke 1. Penetration Plugged with Solder.

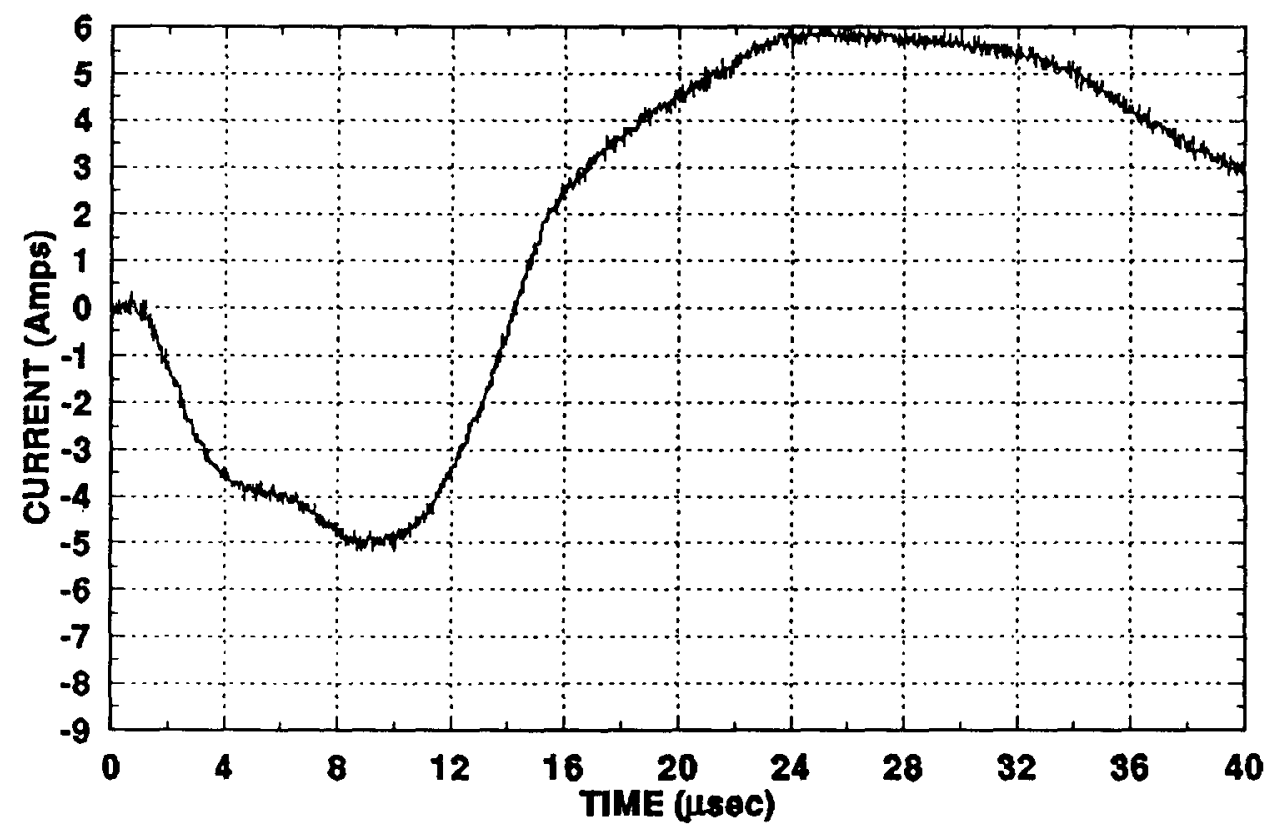

Figure B-44. CVT Noise, Shot 2051, Stroke 2. Penetration Plugged with Solder. 


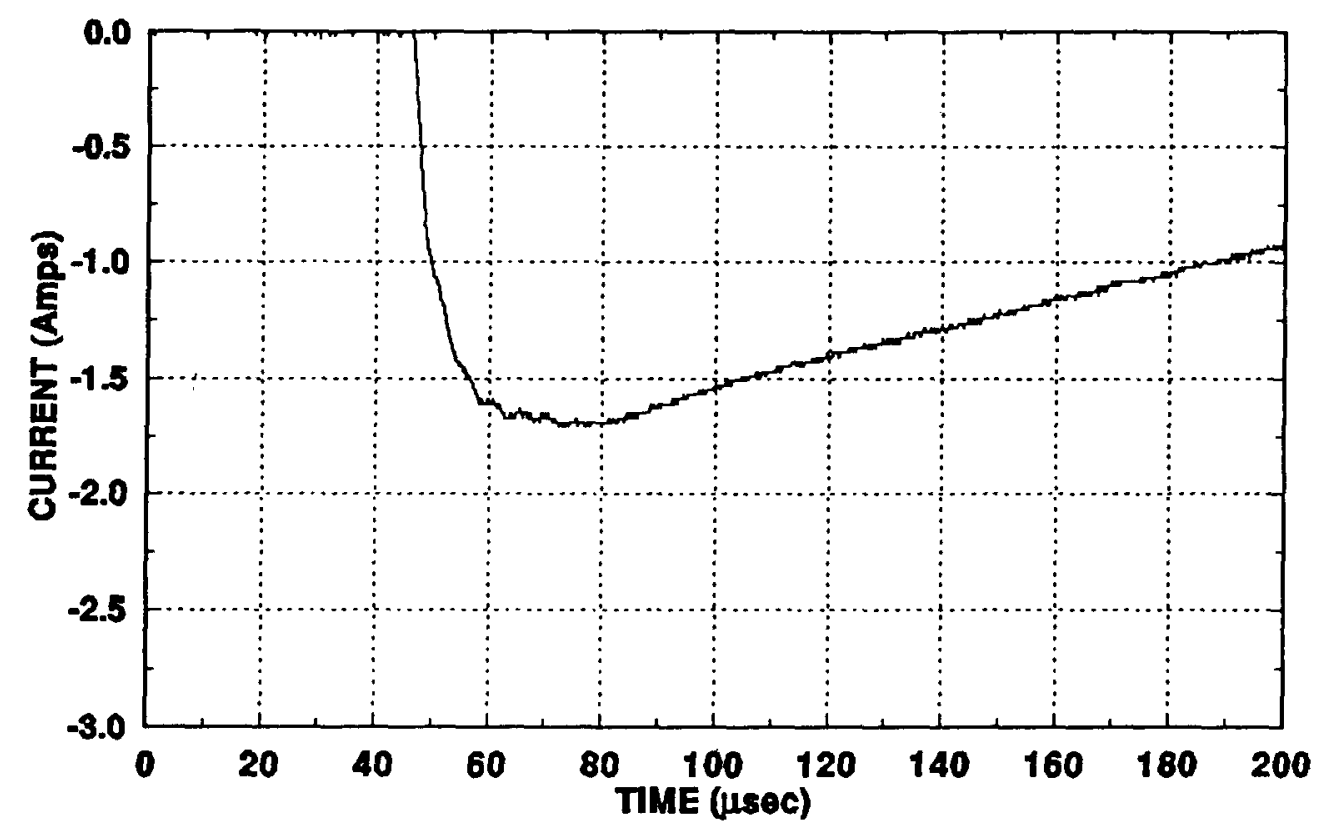

Figure B-45. CVR Noise, Shot 2051, Stroke 2

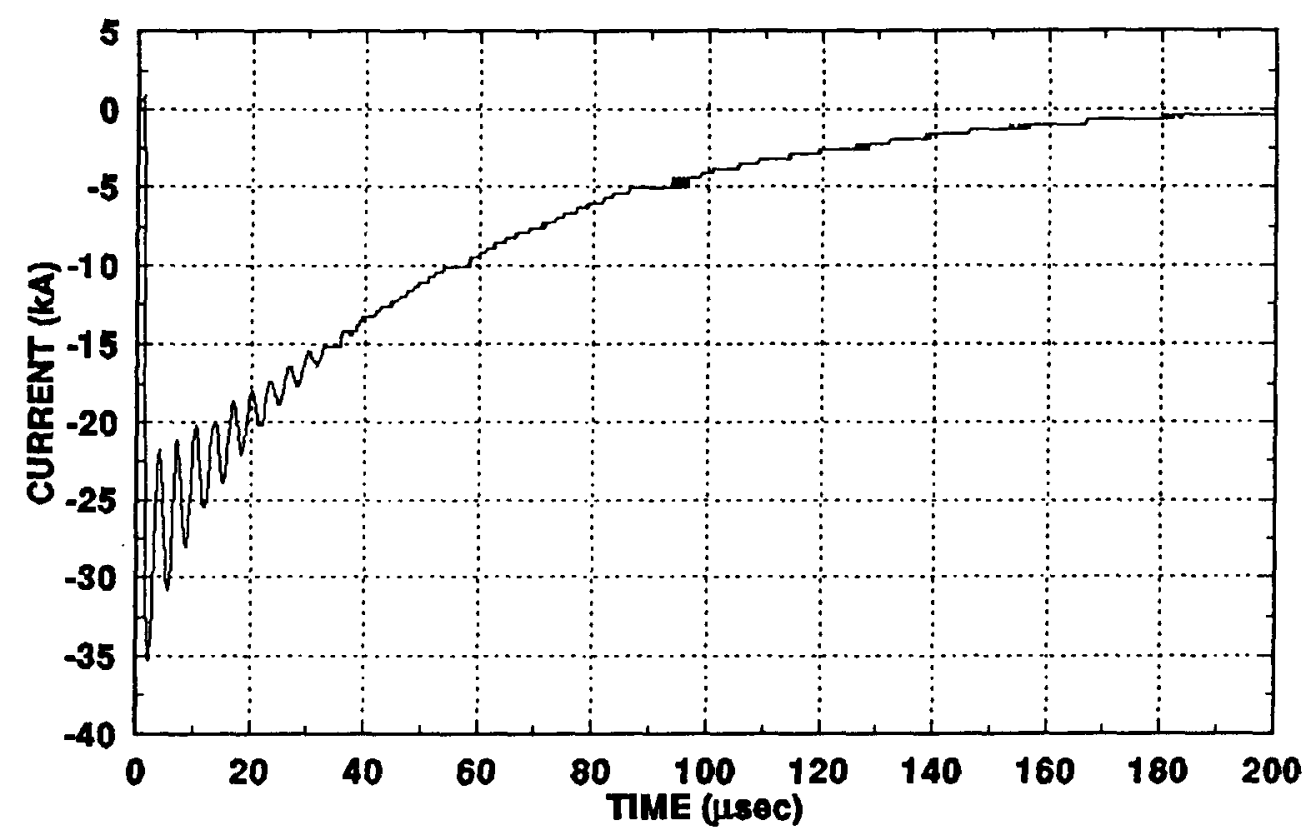

Figure B-46. Applied Test Current, Shot 2052, Stroke 1 


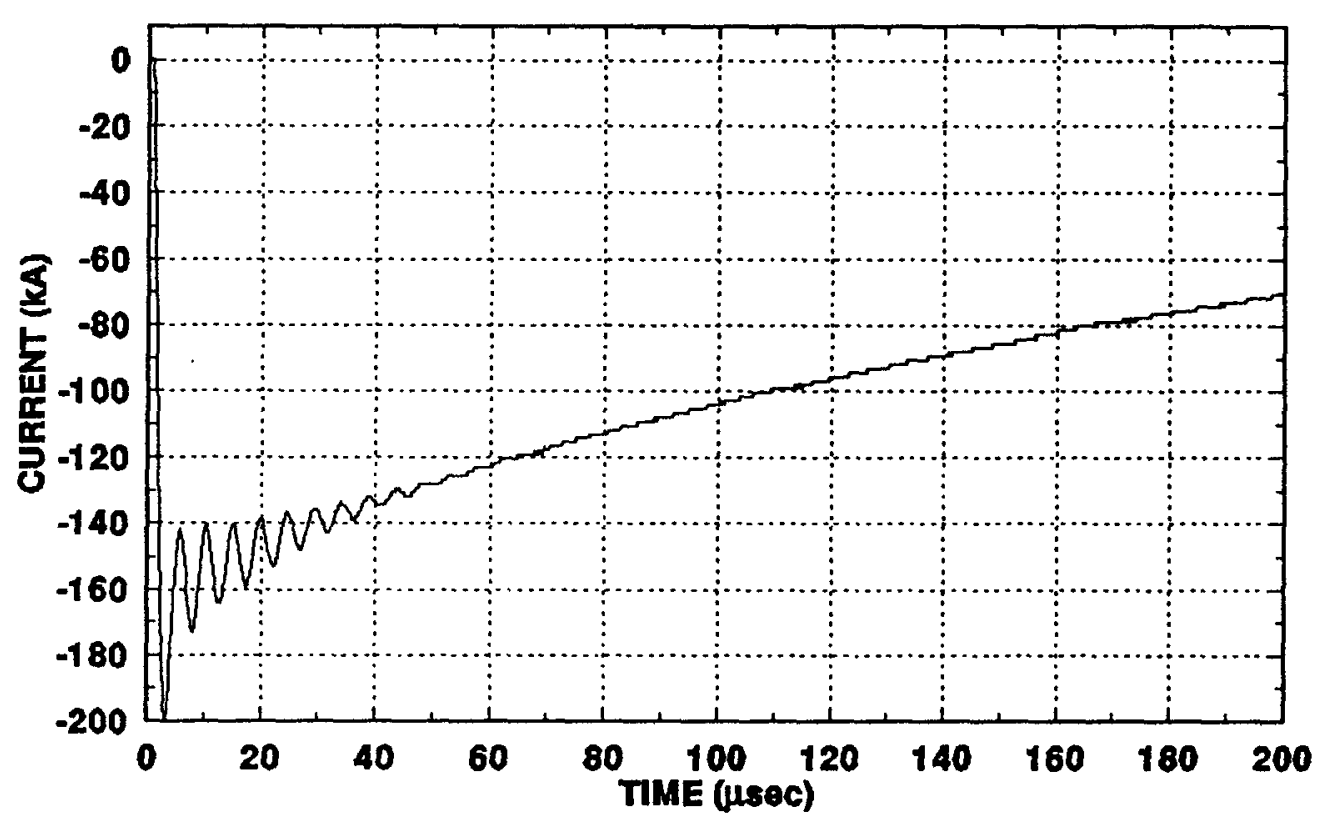

Figure B-47. Applied Current, Shot 2052, Stroke 2

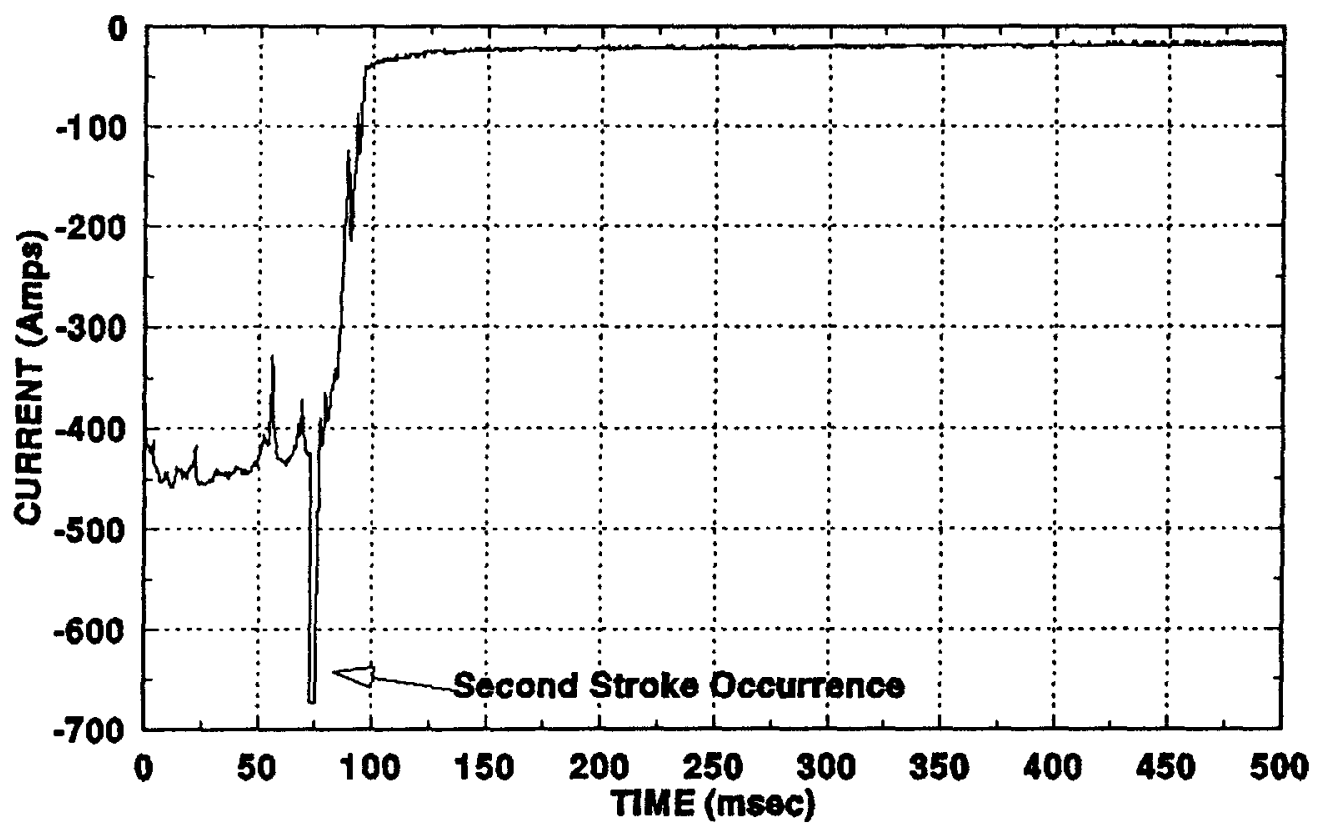

Figure B-48. Applied Continuing Current, Shot 2052 


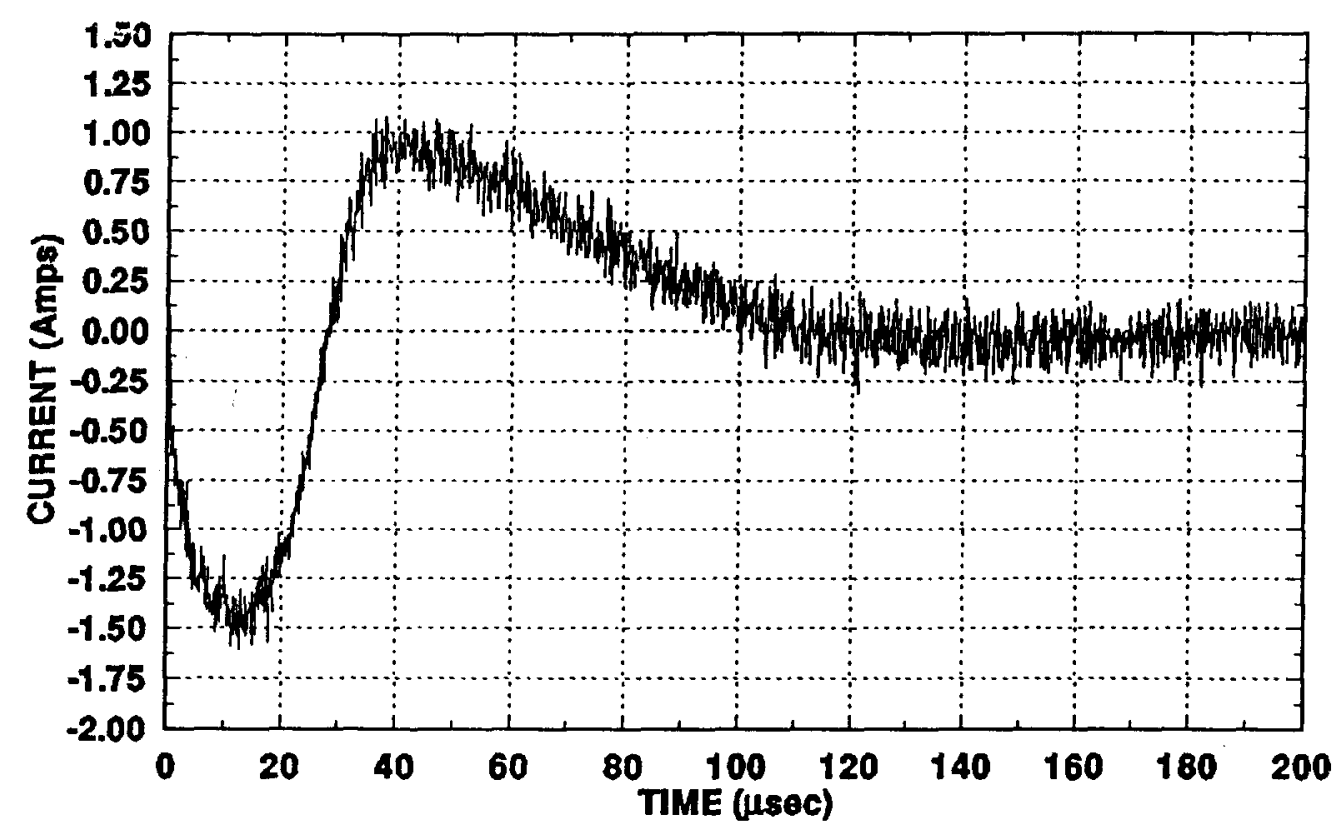

Figure B-49. CVT Noise, Shot 2052, Stroke 1. Penetration Plugged with Solder.

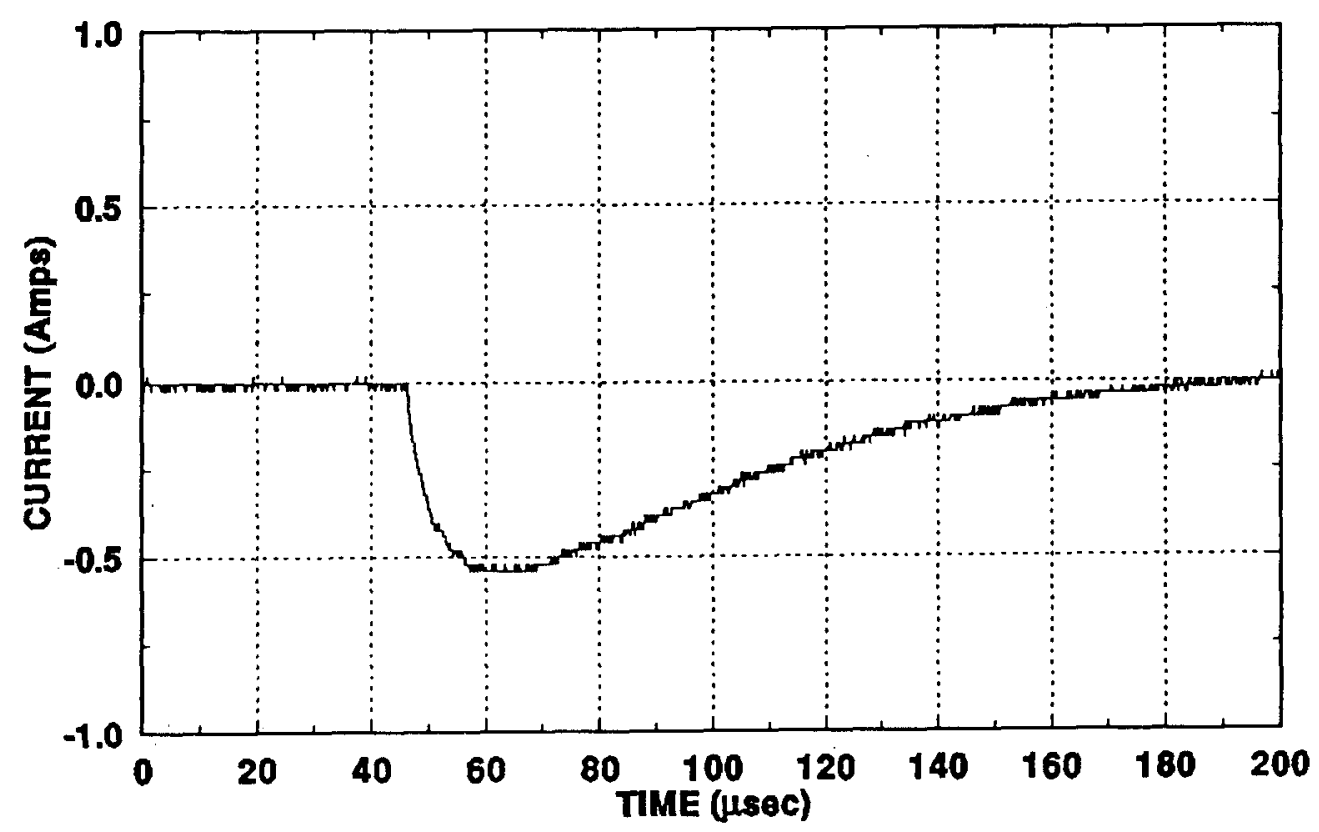

Figure B-50. CVR Noise, Shot 2052, Stroke 1. Penetration Plugged with Solder. 


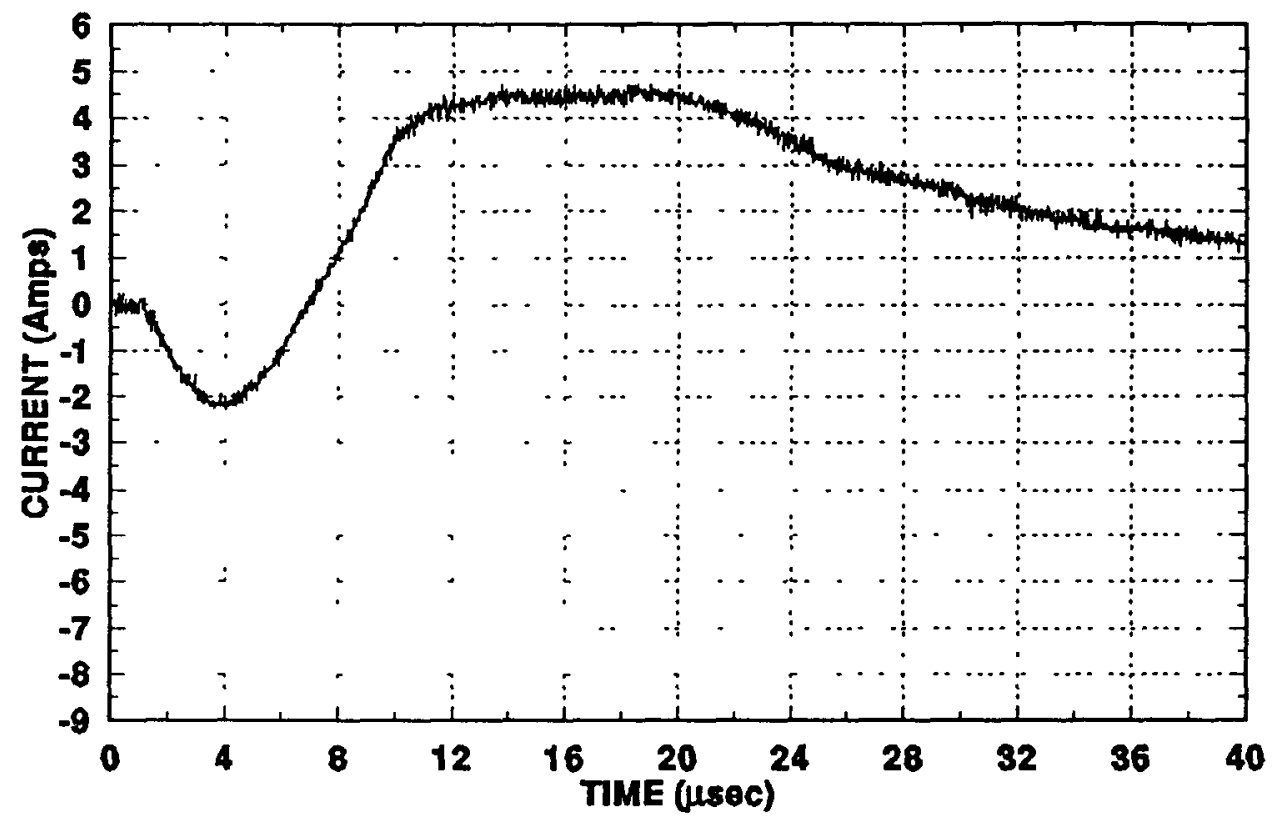

Figure B-51. CVT Noise, Shot 2052, Stroke 2. Penetration Plugged with Solder.

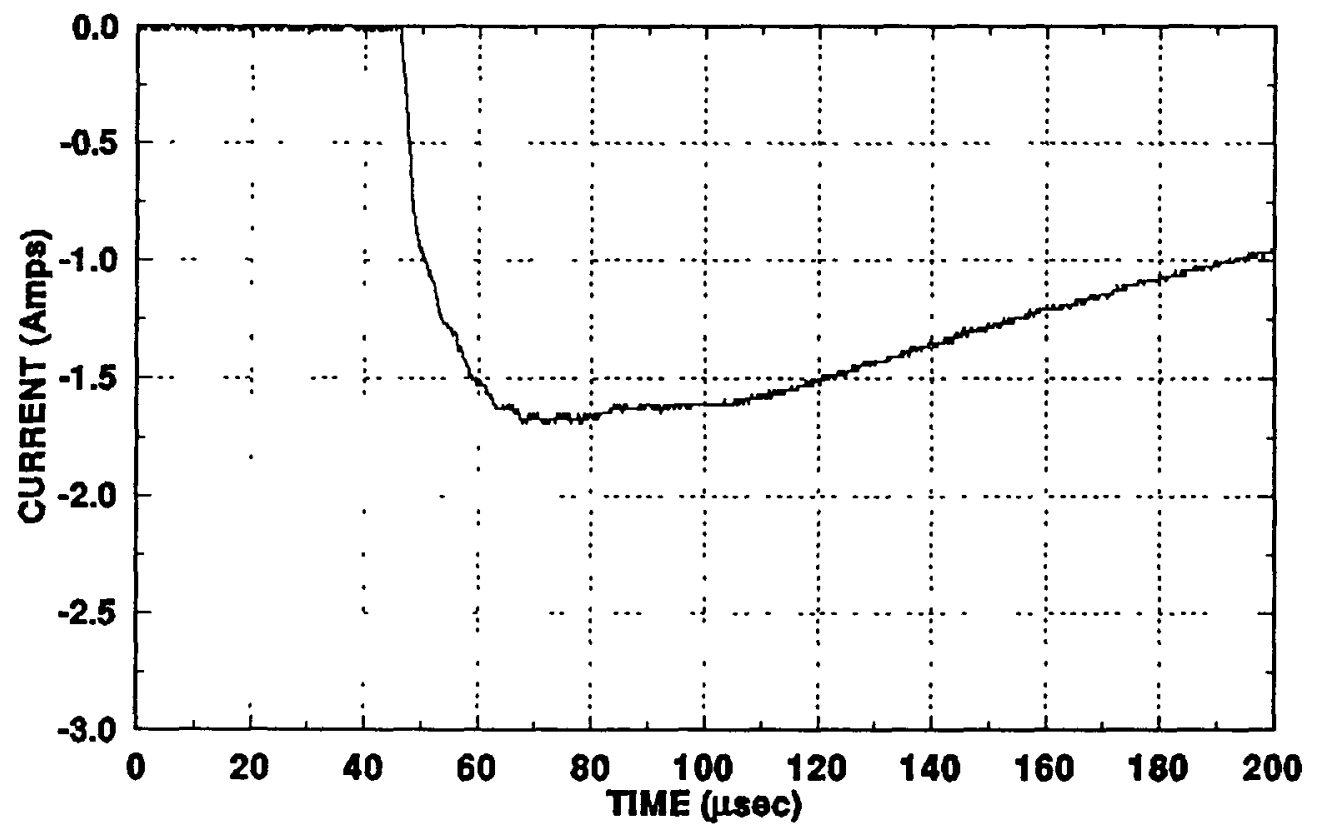

Figure B-52. CVR Noise, Shot 2052, Stroke 2 


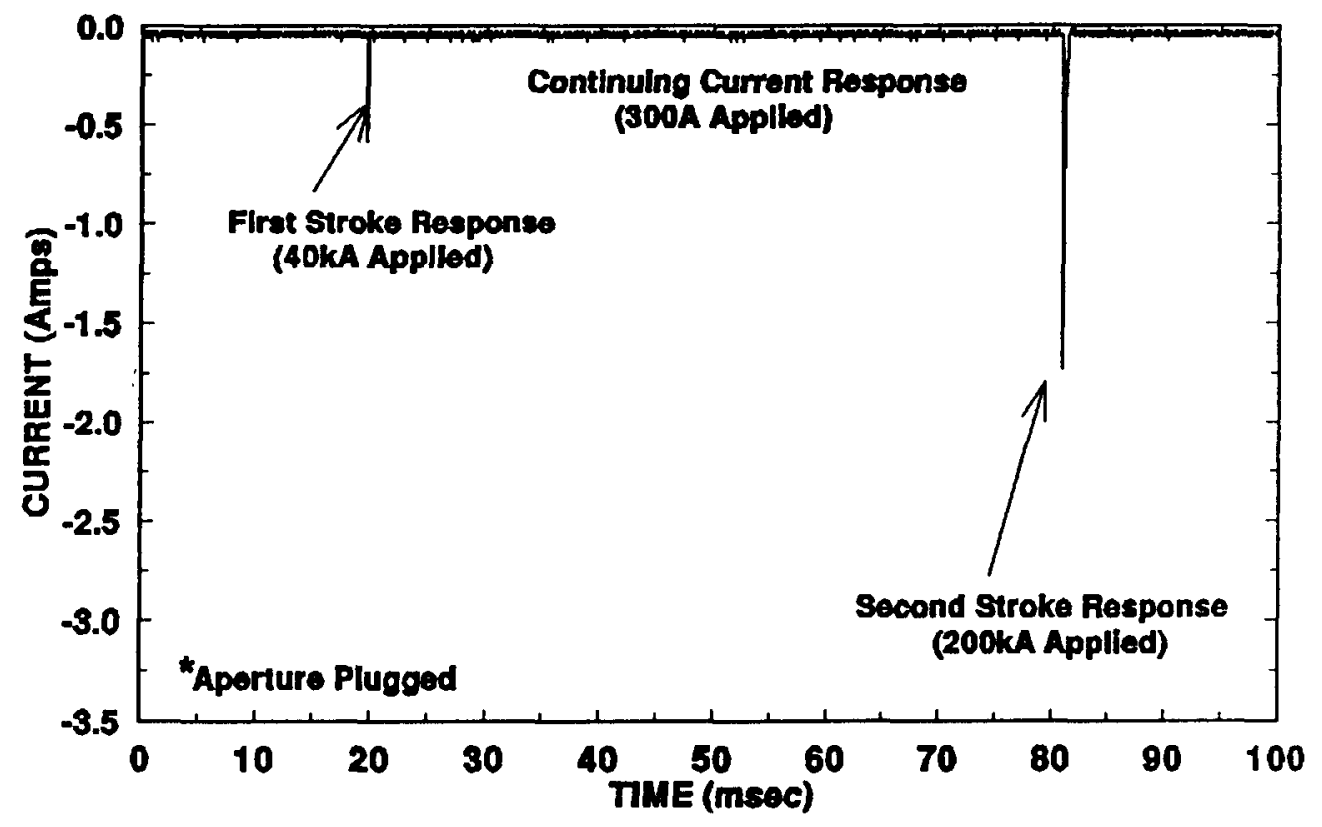

Figure B-53. Full Flash CVR Noise Record, Shot 2052, 4- $\mu$ s Sampling 


\section{DISTRIBUTION}

1 Martin Marietta

Specialty Components, Inc.

Attn: L. Hinkle, MS053

P. O. Box 2908

Largo, FL 34649

$3 \quad$ Allied Signal International

Kansas City. Division

Attn: A. G. Bennett, BP46

W. Kirk, BP46

J. Hendrix, E2B7

P. O. Box 1159

Kansas City, MO 64141

3 Los Alamos National Laboratory

Attn: D. L. Paisley, P950/M-7

J. Kennedy, M7

T. Turner, M7

P. O. Box 1663

Los Alamos, NM 87545

3 University of California

Lawrence Livermore National Laboratory

Attn: W. G. VanHolle, L-368

R. W. Solarz, L-487

G. Smith, L-006

P. O. Box 808

Livermore, CA 94550

3 EG\&G Mound

Attn: D. Schaeffer, COS-4

B. Neyer, COS-4

S. Mendenhall, COS-4

P. O. Box 3000

Miamisburg, OH 45343

$\begin{array}{lll}1 & 324 & \text { V. J. Johnson } \\ 1 & 324 & \text { D. Loescher } \\ 1 & 324 & \text { R. D. Pedersen } \\ 1 & 331 & \text { J. A. Cooper } \\ 1 & 1512 & \text { A. C. Ratzel } \\ 1 & 1512 & \text { W. M. Trott } \\ 1 & 2231 & \text { R. F. Carson } \\ 1 & 2231 & \text { E. P. Royer } \\ 1 & 2235 & \text { J. P. Anthes } \\ 1 & 2235 & \text { P. W. Dressendorfer }\end{array}$




\section{DISTRIBUTION (Continued)}

\begin{tabular}{rll}
1 & 2512 & J. G. Harlan \\
1 & 2512 & J. A. Merson \\
1 & 2513 & D. E. Mitchell \\
1 & 2513 & S. M. Harris \\
1 & 2514 & L. L. Bonzon \\
1 & 2514 & A. M. Renlund \\
1 & 2551 & L. A. Andrews \\
1 & 2562 & G. T. Randall \\
1 & 2563 & F. Bitsie \\
1 & 2574 & D. M. Berry \\
1 & 2574 & D. K. Leland \\
1 & 2574 & L. S. Weichman \\
1 & 2574 & C. F. Briner \\
1 & 2574 & J. F. Jones, Jr. \\
1 & 2642 & S. F. Kuehn \\
1 & 2642 & R. S. Urenda \\
1 & 2643 & K. G. McCaughey \\
1 & 2643 & G. L. Benavides \\
1 & 2753 & M. E. Morris \\
5 & 2753 & M. A. Dinello \\
10 & 2753 & R. J. Fisher \\
2 & 2753 & R. D. Jones \\
1 & 2756 & W. C. Sweatt \\
1 & 3180 & J. L. Watts \\
1 & 5128 & S. S. Kawka \\
1 & 5161 & M. G. Orrell \\
1 & 5161 & F. F. Dean \\
1 & 5161 & M. A. Rosenthal \\
1 & 5161 & K. L. Wrisley \\
1 & 5161 & J. J. Cuderman \\
1 & 5166 & R. C. Hartwig \\
1 & 5166 & E. A. James \\
10 & 5166 & K. D. Meeks \\
1 & 5166 & N. G. Rackley \\
1 & 5166 & R. E. Setchell \\
1 & 5167 & J. K. Shane \\
1 & 5167 & J. A. Andersen \\
1 & 5167 & K. Ortiz \\
1 & 9352 & J. D. Kotulski \\
1 & $8523-2$ & Central Technical Files \\
1 & 7141 & Technical Library \\
\hline & 7151 & Document Processing for DOE/OSTI \\
G. C. Claycomb \\
I155
\end{tabular}

